\title{
"Not Just About the Vegetables": \\ Community Supported Agriculture and \\ Discourses of the Local and Nature in the Ottawa Area
}

\author{
by \\ Melissa Miller, B.A. (Honours) \\ A thesis submitted to the \\ Faculty of Graduate Studies and Research \\ in partial fulfillment of the requirements for the degree of \\ Master of Arts \\ Department of Geography and Environmental Studies \\ Carleton University
}

(C) Melissa Miller, January 2008 


$\begin{array}{ll}\begin{array}{l}\text { Library and } \\ \text { Archives Canada }\end{array} & \begin{array}{l}\text { Bibliothèque et } \\ \text { Archives Canada }\end{array} \\ \begin{array}{l}\text { Published Heritage } \\ \text { Branch }\end{array} & \begin{array}{l}\text { Direction du } \\ \text { Patrimoine de l'édition }\end{array} \\ \begin{array}{l}\text { 395 Wellington Street } \\ \text { Ottawa ON K1A 0N4 }\end{array} & \begin{array}{l}\text { 395, rue Wellington } \\ \text { Ottawa ON K1A ON4 }\end{array} \\ \text { Canada } & \begin{array}{l}\text { Canada } \\ \end{array}\end{array}$

Yourfile Votre référence ISBN: 978-0-494-36812-1 Ourfile Notre référence ISBN: 978-0-494-36812-1

NOTICE:

The author has granted a nonexclusive license allowing Library and Archives Canada to reproduce, publish, archive, preserve, conserve, communicate to the public by telecommunication or on the Internet, loan, distribute and sell theses worldwide, for commercial or noncommercial purposes, in microform, paper, electronic and/or any other formats.

The author retains copyright ownership and moral rights in this thesis. Neither the thesis nor substantial extracts from it may be printed or otherwise reproduced without the author's permission.
AVIS:

L'auteur a accordé une licence non exclusive permettant à la Bibliothèque et Archives Canada de reproduire, publier, archiver, sauvegarder, conserver, transmettre au public par télécommunication ou par l'Internet, prêter, distribuer et vendre des thèses partout dans le monde, à des fins commerciales ou autres, sur support microforme, papier, électronique et/ou autres formats.

L'auteur conserve la propriété du droit d'auteur et des droits moraux qui protège cette thèse. $\mathrm{Ni}$ la thèse ni des extraits substantiels de celle-ci ne doivent être imprimés ou autrement reproduits sans son autorisation.
In compliance with the Canadian

Privacy Act some supporting forms may have been removed from this thesis.

While these forms may be included in the document page count, their removal does not represent any loss of content from the thesis.
Conformément à la loi canadienne sur la protection de la vie privée, quelques formulaires secondaires ont été enlevés de cette thèse.

Bien que ces formulaires aient inclus dans la pagination, il n'y aura aucun contenu manquant.

\section{Canadä}




\begin{abstract}
Community supported agriculture (CSA) is a young, but quickly growing, movement in Canada, that, like other alternative agrifood initiatives, is based on creating locally-based spaces for more associative and environmentally- and socially-just agrifood systems. Drawing on a case study of CSA in the Ottawa area, this research explores the ways in which the growers envision themselves in regards to the globalized conventional agrifood system. The thesis examines the movement's key discourses of (re)localizing the agrifood economy (through the creation of direct farmer-consumer relationships and the (re)embedding of communities in particular places) and that of building respect for nature (through the practice of organic and biodynamic agriculture and reconnecting people to the land and their food). These discourses challenge nature-society and local-global binaries and offer up new ways of framing these realms as interdependent and mutuallyconstitutive. In revealing the political processes behind these discourses and how they shape the practices and aspirations of the growers, this research also considers the CSA movement's effectiveness in realizing its broader goals.
\end{abstract}




\section{Acknowledgements}

I would like to thank the growers who graciously took time from their hectic schedules to invite me into their homes (and gardens) and participate in the interviews that form the backbone of this thesis. I would also like to thank Dr. Fiona Mackenzie for the thoughtful advice and helpful insights that she provided to me over the course of this research. Last, but not least, I would like to thank Gonzalo, not only for his seemingly limitless support and patience, but for his ability to get me to crack a smile even during the toughest times, and my parents, for acting as volunteer research assistants - attending and reporting on meetings of their local food groups and providing me with seemingly endless newspaper clippings, encouraging me in all my endeavors and influencing the ways in which I view rural and agricultural life in small town Ontario. 


\section{Table of Contents}

$\Lambda$ bstract

Acknowledgements

Table of Contents iv

List of Tables

List of Appendices vii

Chapter 1: Introduction $\quad 1$

Chapter 2: Theoretical Framework 6

The Origins of Political Ecology $\quad 7$

The Rise of Poststructuralism $\quad 8$

Discourse 11

Social Nature $\quad 13$

The Politics of Place and Scale: Deconstructing the Global and the Local 15

Chapter 3: Methodology, Research Methods and Introduction to the Case Study 19

Methodological Framework 19

$\begin{array}{ll}\text { Research Methods } & 23\end{array}$

In-depth Interviews

Participant Observation 27

Discourse Analysis $\quad 28$

Looking back on the research experience 28

Who Participated? The CSA Growers in the Ottawa Area 29

Chapter 4: The Historical and Philosophical Roots of the CSA Movement and

its Manifestation in the Ottawa Area $\quad 39$

The Rise of the Alternative Agrifood Movement 39

Situating CSA in the Alternative Agrifood Movement $\quad 42$

The History of CSA in North America 44

European and Japanese Roots 46

The Japanese Teikei System 47

The European Influence: Biodynamics 48

Models of CSA

Shared or Supported? 53

Chapter 5: From Seed to Plate - Growing a Local Agrifood System 57

Links and Sites: Different Conceptualizations of the 'Local'

Building Local Agrifood Economies

A Defensive Kind of Localism 66

Toward a Community Supported Agriculture $\quad 68$

$\begin{array}{ll}\text { Trust in your Farmer and your Food } & 72\end{array}$

Who benefits from Local Food Systems? Issues of Power and Privilege 77

A More Inclusive and Reflexive Vision of the Local 82

Chapter 6: Discourses of Nature in CSA $\quad 85$

An Agriculture in Harmony with Nature 86

Caretakers of the Earth 95

Reconnecting People with Nature $\quad 100$ 
Providing People with 'Real' Food 103

Mobilizing Discourses of 'Nature' 105

Chapter 7: Conclusion $\quad 108$

Bibliography $\quad 115$ 


\section{List of Tables}

Table 2.1: Characteristics of Ottawa Area CSAs 


\section{List of Appendices}

Appendix 1: Table of Socio-Economic Backgrounds of Participating Growers

Appendix 2: Map of the Ottawa Area

128 


\section{Chapter 1: Introduction}

In recent years an alternative geography of food has emerged as attention has increasingly been directed towards the problems associated with industrialized agrifood systems (Morgan et al. 2006; Watts et al. 2005; Winter 2003). Rccent food scares surrounding Bovine Spongiform Encephalopathy (BSE), genetically modified organisms, avian flu and bacterial contamination such as E. coli and salmonella outbreaks have resulted in a loss of public confidence in the globalized food supply and an increase in the number of consumers questioning where their food comes from and how it is produced and distributed (Bell and Valentine 1997; Frcidberg 2004). This growing consumer anxiety over food safety and nutrition combined with a deepening concern for the perceived negative environmental and social consequences of industrialized agriculture have contributed to a growing number of consumers demanding "quality" products - quality being associated with local and natural foods (Murdoch et al. 2000: 108). This has led to an increase in alternative agrifood initiatives that cncourage environmentally, socially and economically just models of food production, distribution and consumption (Allen et al. 2003). In some places, especially North America and Europe, food systems arc consequently becoming (re)embedded in local ecologies and cultures, creating an alternative geography of food that is based on food chains rooted in specific places and natures (Morgan et al. 2006).

The community supported agriculture ${ }^{1}$ (CSA) movement plays an active role in shifting the geography of food. CSA is a young, but quickly growing, movement in

\footnotetext{
${ }^{\prime} \mathrm{CSA}$ is often referred to as community shared agriculture in Canada. I discuss the politics around the naming of the movement in Chapter 5.
} 
Canada that, like other alternative agrifood initiatives, is based on encouraging direct relationships between producers and consumers. In many ways the movement has a dual personality in the sense that it acts as both a decentralized marketing strategy and a catalyst for social awareness and an associative economy (Cone and Kakaliouras 1995; DeLind and Ferguson 1999). While the CSA movement has strong philosophical foundations, there is a diversity of models being used in North America. Regardless of the structure of a CSA, the basic premise is that the members share the risk with the producer by purchasing a share of the harvest for a set price at the beginning of the season. This mutual commitment guarantees a market for the producer - thus reducing financial risk and potential food losses - and provides the member with a weekly delivery or pick-up of fresh and usually organic vegetables and herbs. Occasionally, other products such as fruits, flowers, eggs, honey and meats are also offered. By directly linking urban consumers with rural producers, CSA aims to reconnect people with the social, economic and natural processes of food production and revitalize rural economies.

Despite the recent academic interest in organic agriculture and local food systems research, empirical studies of CSA are sparse, have been mainly focused in the United States and examine for the most part aspects relating to membership (Kolodinsky and Pelch 1997; DeLind and Ferguson 1999) or the technical aspects and philosophy behind the production side of the model (Fieldhouse 1996; Lass et al. 2003; Worden 2004). Regardless of the rising interest in CSA on the part of both producers and consumers, the growth of the CSA movement in Canada has been largely overlooked by academics. ${ }^{2} \mathrm{My}$ hope is that this thesis will provide some insight into the CSA movement in Canada by

\footnotetext{
${ }^{2}$ The exception is a 1996 article by Paul Fieldhouse in which he discusses the conceptual background of the CSA model, its up-take in the Prairies and how it relates to community food security initiatives.
} 
reflecting on a case study of CSA growers in the Ottawa area. Using a theoretical framework informed by political ecology and social nature, I discuss the ways in which CSA growers in the Ottawa area are connected to the broader North American alternative agrifood movement and how they envision themselves in regards to the globalized conventional agrifood system in general. In particular, I explore how, by engaging with the discourses and practices of the CSA movement, the growers attempt to create spaces for locally-based resistance to the environmental, cultural and economic degradation that they associate with the globalized agrifood system.

The CSA movement provides an interesting case study for a closer examination of the political processes involved in the social construction of the 'local' and 'nature.' By looking at the growers' motivations for joining the CSA movement and the complex meanings that they give to binaries such as 'local/global', 'natural/social' and 'organic/conventional', this thesis unveils the multiple ways in which people working in CSA view the world and how they see their role in challenging and reshaping the conventional agrifood system. According to Patricia Allen (2004: 9), this sort of analysis "represents an essential step for better understanding the sites of and possibilities for change in the agrifood system."

This thesis is based on empirical research conducted between January and March of 2007. I draw on the narratives of 14 CSA growers in the Ottawa area in order to examine the discourses and meanings that shape their agricultural practices and their understanding of the CSA movement and its place in the globalized agrifood system. I focus on the strongest discourses shaping the movement: that of the (re)localization of agrifood economies through the creation of direct consumer-producer relationships and the 
(re)embedding of communities in particular places; and that of building the human respect for nature through the practice of organic and biodynamic agriculture and connecting people to the land and their food. In turn, I explore how these discourses work both for and against the movement's broader goals of providing growers and eaters with more control over where and how their food is produced and creating socially-and ecologicallyjust communities that are connected to specific place- and nature-based agrifood economies.

I have divided the remainder of this thesis into six chapters. In the following chapter I outline the theoretical framework of this research, discussing how key concepts from the fields of political ecology and social nature can assist in an in-depth analysis of the politics and discourses of alternative agrifood initiatives such as CSA. In Chapter 3, I establish my methodological approach to the research and the research methods that I employ. I also present the case study and introduce the growers who participated in the research. In Chapter 4, I outline the historical and philosophical underpinnings of CSA, describe the various models of CSA and introduce current issues and debates shaping the movement today. Turning to Chapter 5, I explore how CSA growers in the Ottawa area envision their role in building a local agrifood economy and how they see CSA as playing a significant part in creating a space where both growers and eaters of food can resist the effects of the globalized conventional agrifood system. In Chapter 6, I examine how the CSA growers consider themselves caretakers of nature and see it as their duty to educate themselves and their members about the ecological and social aspects of food production and consumption. I conclude this thesis in Chapter 7 , with a summary of my main arguments and a discussion of how this work, by engaging with political ecology and social 
nature, can contribute to the discipline of human geography and the field of agrifood studies. I also consider the future prospects of the CSA movement, with a focus on the Ottawa area, by reflecting on the main challenges that the growers face in terms of achieving their environmental, social and economic goals and how the multiple ways in which they have constructed discourses of the local and nature can work to further or hinder the movement, depending on the context. 


\section{Chapter 2: Theoretical Framework}

Using a theoretical framework informed by political ecology, I seek to investigate the connections between CSAs in the Ottawa area, the broader alternative agrifood movement, and the globalized conventional agrifood system as a whole. In particular, I will explore how through the discourses and practices of the CSA movement, the growers attempt to construct a foundation for locally-based resistance to the environmental, cultural and economic degradation that they associate with the conventional agrifood system. Agriculture is one of the oldest and most deeply-rooted examples of the relationship between society and nature, with food being a perfect example of a hybrid socio-natural commodity. Farmers, through their stewardship of the land, plants and animals, develop a special relationship with nature. This is especially the case for small-scale, organic and biodynamic market gardeners, such as the CSA growers in this study, whose livelihoods are premised on the production of 'natural' food that is grown in a manner that is respectful of ecological processes and thus relies on an intimate understanding of localized environmental conditions.

Over the past two decades, political ecology has emerged as a field within the discipline of geography that provides critical approaches to understanding the relationship between human societies and nature. Political ecologists are concerned with examining the historical, social, political and economic contexts that shape agricultural and environmental practices and how class, race and ethnicity affect uneven access to and control over resources (Moekli and Braun 2001; Peet and Watts 1996, 2004). Political ecology provides a good epistemological framework for analysis of alternative agricultural initiatives such as 
CSA, as it enables the researcher to understand the causes and solutions to problems in the agrifood system as being both natural and social (Allen 2004: 17). The framework provides useful tools for exploring the discourses, practices and motivations of CSA growers, as their day to day lives involve intimate interactions with nature and are based on the sustainable management of natural resources. In this chapter I will briefly outline the field of political ecology and explore how its conceptual framework and related theories regarding discourse, social nature and the politics of place, help to understand the practices and motivations of CSA growers in the Ottawa area and how they place themsclves in the globalized agrifood economy.

\section{The Origins of Political Ecology}

The origins of political ecology can be traced back to the 1970s, with multidisciplinary roots in political economy, cybernetics, ecological anthropology, cultural ecology and natural disaster research. The field emerged during a time when environmental issues were becoming highly politicized and there was a theoretical need to integrate local cnvironmental practices with the global political economy (Watts and Peet 2004; Paulson, Gezon and Watts 2003). Scholarly work in these fields tended to focus on subsistence communities in the developing world, with detailed analyses of human-environment relationships in very specific locales (Paulson, Gezon and Watts 2003). Two geographical texts - The political economy of soil erosion (1985) by Piers Blaikie and Land degradation and society (1987) by Piers Blaikie and Harold Brookfield - are considered the intellectual and theoretical foundations for political ecology. Blaikie and Brookfield (1987: 17) explain how the framework "...combines the concerns of ecology and a broadly defined 
political economy. Together this encompasses the constantly shifting dialectic between society and land-based resources, and also within classes and groups within society itself."

In the 1980s, the rising presence of Marxist theory within political economy greatly influenced political ecologists to ask questions concerning the relationship between nature and society, the social production of nature, and how land and resource use are deeply connected to issues of social and economic justice. The resulting structural political ecology represented a shift away from the neo-Malthusian tendencies of human and cultural ecologists to blame population growth, inappropriate technology and the unsustainable land use practices of poor people as the causes of environmental crises. Political ecologists began to look instead to the multi-scalar historical, economic and political structures influencing environmental problems (Peet and Watts 1996).

\section{The Rise of Poststructuralism}

Interest in political ecology expanded during the 1990s and a new generation of academics began to question why the focus of study for early political ecologists was a rural, usually male, apolitical "land manager" from the developing world (Paulson, Gezon and Watts 2003: 208). While topics that were popular during the structuralist years of political ecology, such as poverty and ecological degradation, remained the focus of interest, the approach to studying these topics became much more varied and complex. The influence of critical social theories such as poststructuralism, postcolonialism and gender and discourse theory was evident. New concerns with knowledge-power, institutions and regimes of truth, and cultural difference inspired the rethinking of political ecology (Peet and Watts 1996: 2). 
Using these new conceptual tools, a new generation of political ecologists sought to explain "the means by which control and access of resources or property rights are defined, negotiated and contested within the political arenas of the household, the workplace and the state" (Watts and Peet 2004: 12). Poststructuralism moved political ecology beyond its structuralist (Marxist) foundations - namely the tendency to focus on the material aspects of resource struggles - to an examination of the symbolic meanings, or discourses, shaping the struggles (Peet and Watts 1996). The field of political ecology opened up by "giving greater salience to the ethnic identities, gender roles and relations, institutions, governance apparatuses, political involvements, and other social factors that condition the knowledge, decisions, and actions of diverse land managers" (Paulson, Gezon and Watts 2003: 208).

In recent years, various scholars have worked to emphasize the 'political' in political ecology. Feminist political ecology emerged as a way of integrating the politics of gender and resistance (Rocheleau, Thomas-Slayter and Wangari 1996). Feminist political ecologists focus on gender as "a critical variable in shaping resource access and control, interacting with class, caste, race, culture, and ethnicity to shape processes of ecological change, the struggle of men and women to sustain ecologically viable livelihoods, and the prospects of any community for "sustainable development"' (Rocheleau, Thomas-Slayter and Wangari 1996: 4). Others have developed critiques of the knowledge and power that underlie environmental sciences, discourses and practices (Braun and Castree 1998; Escobar 1996). In reaction to the increasing attention to politics, Pete Vayda and Brad Walters (1999) argue that there has been a trend towards 'politics without ecology' within political ecology, and that political ecologists are avoiding the ecological, or the power of nature, in their focus on the political. This view is disputed by scholars such as Peter 
Walker (2005) and Michael Watts and Richard Peet (2004), who argue that ecology has always played an important role in political ecology analyses and who warn that nature cannot be treated as a simple concept.

Other recent efforts have encouraged political ecologists to broaden their scope beyond 'Third World' and rural landscapes. The majority of the political ecology literature has been focused on the global South - what Raymond Bryant and Sinead Bailey (1997) refer to as a "Third World political ecology" (i.e. Mackenzie 1998; Neumann 1998; Schroeder 1996). James McCarthy (2001) believes that the conceptual tools used in political ecology can be equally used in the context of the industrialized 'First World'. Issues such as access to and control over resources, marginality, the importance of local histories, globalization and the politics of scale, and the legacies of colonialism are also highly relevant in developed world settings (ibid. 2001).

Of late, political ecologists have also begun to explore the intersections of society and nature in an urban context (Keil 2003; Swyngedouw 1995), moving beyond the view that "cities are purely social spaces, and that cultural, economic and political processes exist, by some strange magic, entirely separate from the countless non-human entities and organisms that are enrolled in, and help shape urban life" (Braun 2005: 635). This effectively challenges the binaries of the 'urban' and the 'rural'. In this thesis, through the examination of CSA in the Ottawa area, I hope to contribute to these recent explorations of first world and urban political ecology, while considering the varied axes of social difference and diversity of meanings and motivations that come into play over issues surrounding humans' use of natural resources and interaction with natural processes. 


\section{Discourse}

As discussed above, poststructuralist political ecology is characterized by its nonessentialist way of understanding identities and categories such as gender, race, and nature as social constructs. The relationship between knowledge, power, discourse and nature is of great concern to poststructuralist political ecologists. The incorporation of discourse analysis into political ecology is generally regarded as a positive development. Discourse is defined as "a specific series of representations, practices and performances through which meanings are produced, connected into networks and legitimized" (Johnston et al. 2000: 180). Discourses are heterogeneous, embedded, situated and performative (ibid.: 180). In poststructuralist thought, the matcrial and the symbolic are always intertwined, as there is no way of understanding the material apart from how it is portrayed in discourse (Bryant 2001). According to Peet and Watts (1996: 38): "One of the great merits of the turn to discourse, broadly understood, within political ecology, is the demands it makes for nuanced, richly textured empirical work (a sort of political-ecological thick description) which matches the nuanced beliefs and practices of the world." In this thesis, I use these concepts to explore the discourses of the CSA movement as a whole and CSA growers as individuals and how the ideals of the movement are translated into practice. I use the term discourse in reference to how CSA is framed, defined and articulated by producers and the CSA literature in general.

Discourse analysis is a valuable tool in the study of social movements, such as the CSA movement. Arturo Escobar (1992) believes that social movements are equally struggles over meaning as struggles over material resources. Similarly, Peet and Watts (1996: 37) explain how social movements that are organized around common concerns can 
be practical struggles over livelihood and survival, but also work to contest the 'truths' and discourses that shape and influence people's experiences within a particular system. According to Patricia Allen (2004: 2), more and more people are taking charge of their food systems because they "are not content to let food production, distribution, and quality be defined and determined by faceless others." She claims that, consciously or not, they are part of a new alternative agrifood movement that is growing in North America. The actions and activities associated with this movement are the result of both an increased knowledge about the conventional agrifood system and a growing belief that the system can be changed (ibid.: 1). Agriculture and food are powerful discursive symbols and an analysis of these "rapidly developing alternative discourses and practices lags behind their proliferation in communities and institutions" (ibid.: 4).

The power of social movements lies in their ability to challenge dominant discourses by educating the public. Because of their heterogeneous and partial naturc, there are always multiple competing discourses operating at any given time. Discourses are continually being contested and negotiated, providing important space for resistance (Rose 2001). The discursive construction of reality is "a crucial realm of power for social movements that do not control major economic resources or the formal political process" (Allen 2004: 6). In his 2001 study, McCarthy justifies his use of political ecology in the context of the 'first world' Wise Use movement in the United States because the movement exhibits many of the same features that characterize social movements based on use of and access to land and resources in the global South. Cultural identity, local knowledge as an alternative to expert science, reinventions of community and tradition, a resolute defense of the local, and action outside of and in opposition to state arenas are common central 
features of social movements globally (ibid.: 1283). I hope to add to this body of political ecology literature, by similarly exploring the discourscs, namely the construction of nature and the local, of the 'first world' CSA movement.

\section{Social Nature}

The discursive construction of nature plays a powerful role in the CSA movement. The ecological and social values of a more 'natural', organic, or biodynamic agriculture play a large part in defining the importance of CSA. In this thesis I will examine how the participants' understanding of nature and what kind of nature they believe is desirable influences their practices and experiences as CSA growers in the Ottawa area and shapes the movement as a whole.

The recent emergence of the social nature approach within the field of political ecology is founded on the idca that nature is a social construct (Castree 2001; Escobar 1996, 1999). Arturo Escobar $(1996,1999)$ stresses that this conceptualization of nature does not mean that it does not exist materially, but that it is constructed by the meanings that we as humans assign to it. This understanding of nature calls for a discursive analysis that problematizes how we understand human-environment relations - especially the conceptualization of nature and society as distinct and separate realms. Noel Castree (2001: 3) argues that nature is "defincd, delimited, and even physically reconstituted by different societies, often in order to serve specific, and usually dominant, social interests. In other words, the social and the natural are seen to intertwine in ways that make their separation - in either thought or practice - impossible." Social nature theorists allow us to see that there is no singular and objective knowledge of nature and that knowledges of nature are highly political and powerful. 
The idea of nature being socially constructed is not new. The geographer Neil Smith (1984), drawing on Henri Lefebvre's work on the social construction of space, is often credited for early discussions of how capitalism has shaped the social construction of nature. Smith delves into the Marxist notions of 'first nature' (nature unaltered by humans) and 'second nature' (nature transformed by humans). He argues that capitalism has transformed first nature into second nature and the view that an external, pristine nature still exists separate from society is naïve and bourgeois (ibid.: 64).

More recently, Castree (2001) helps us to distinguish social nature from the two other prominent geographical approaches to understanding society-nature interactions: the 'ecocentric' approach and the 'people and environment' approach. While the latter is characterized by a managerial approach to nature where humans exert dominance over an external nature, the former criticizes contemporary systems of production and consumption and calls for humans to reconnect and live harmoniously with nature. Both approaches maintain the separation between society and nature, a separation that social nature works to deconstruct.

According to Castree and Braun (1998: 4) global nature is increasingly being commodified. From ecotourism to genetically modified foods, nature is being manipulated in new and very powerful ways. Sarah Whatmore's work on the genetically modified soybean (2002) brings forward the idea that human interference has created hybrid natures - natures that are neither fully natural nor social. William Cronon (1995) furthers the body of literature on the social aspects of nature in his work on wilderness. He argues that wilderness cannot be considered an essential nature that is pristine and devoid of human intervention because it is in itself a human construction. The defense of wilderness, or 
pristine nature, is the driving cause of the environmental movement; however, Cronon and others (e.g. Braun 2002), show us that the creation of wilderness spaces often requires both the physical and discursive removal of human traces, at times with grave social justice implications (i.e. displacement of indigenous peoples). Escobar (1999) stresses that we need to articulate an antiessentialist theory of nature that allows for different natures such as the 'organic' landscapes, the capitalist landscapes and the 'technoscapes' of biotechnology (ibid.: 5). These regimes are complex and premised on the understanding that nature is experienced in different ways depending on social position, group membership and historical context (ibid.: 5). This thesis looks at how growers in the CSA movement discursively construct nature and how this affects their practices and ability to achieve their goals relating to the creation of an alternative agrifood system.

\section{The Politics of Place and Scale: Deconstructing the Global and the Local}

Human geographers have greatly contributed to the literature surrounding the social construction of place, scale and the global and the local. In this section I will not attempt to summarize the large body of work donc in this field, but instead highlight the key concepts that are useful in an examination of how the politics of the local and the global come into play in the food system localization efforts of the CSA movement. What Melanie DuPuis and David Goodman (2005: 368) refer to as a "largely apolitical approach to place construction" in the agrifood literature can be reconciled through a reading of the "lively" debates on the politics of place and scale in human geography. They urge that agrifood research focusing on local food systems could benefit greatly from an enriched understanding of the importance of spatial and scalar political processes in the social 
construction of place, the contingent nature of sociospatial structures and scalar orderings, and a deeper analysis of the resulting 'winners' and 'losers' in these struggles (ibid.: 368).

Globalization discourses tend to situate the local in a place of subordination within the global economic order. In this sense the global is not merely a geographical scale that subsumes the local; it is a symbol of universality and homogeneity. Such discourses come from the standpoint that "the global is a force, the local is a field of play, the global is penetrating, the local penetrated and transformed" and construct globalization as an inevitable process that the local cannot resist (Gibson-Graham 1994: 27). There is now a general agreement in the social sciences that "imaginations of global-local ties are fictions: they are actively manufactured and have a constitutive role to play in how we see ourselves and others (and thus how we act in the world)" (Castree 2004: 139). Scholars such as J.K. Gibson-Graham (2003) emphasize the need to recognize that the discourses of the global and the local rely on particular social constructions and that there is nothing inherent about globalization and that the fate of the local is not set in stone. They explain that the recognition that the global and the local are social constructions creates space for the consideration of alternative constructions that allow the local to be a site of power, resistance and change (ibid. 2003).

The global and the local tend to be defined by what the other is not and thereby participate intimately in each others existence. Eric Swyngedouw (1997) posits that the local and global are deeply intertwined and mutually constituted; actions or changes at one scale affect the other. He refers to this process as "glocalization". As he explains:

Scale is neither an ontologically given and a priori definable geographical territory nor a politically neutral discursive strategy in the construction of narratives. Scale, both in its metaphorical use and material construction, is highly fluid and dynamic, and both processes and effects can easily move 
from scale to scale and affect people in different ways, depending on the scale at which the process operates...Scale is, consequently, not socially or politically neutral, but embodies and expresses power relationships ...concepts such as the "local" or the "global" are often merely speculative, discursive - but eminently powerful - vehicles that are used to order political, social, and economic processes in particular spatialized kinds of ways (ibid. 1997: 140).

DuPuis and Goodman (2005) support the view that the globalized industrial agrifood system has succeeded through the creation of a systemic 'placelessness,' and that place has a definite role in building alternative agrifood systems. They caution, however, that the championing of an "emancipatory food agenda that relies primarily on the naming and following of a particular set of norms or imaginaries about place" (ibid.: 360) can have exclusionary effects. As I will discuss in more detail in Chapter 5, while some scholars have provided empirically based evidence that 'relocalization' can encourage the creation of healthy, ecologically sound communities and local democratic processes and act as a tool of resistance against the globalized food economy (e.g. DeLind 2002; Hendrickson and Heffernan 2002; Kloppenburg et al. 1996), other observers draw on the work of David Harvey (1996) and agree that the local is not always an innocent term and it can provide the ideological foundations for reactionary politics and nativism (e.g. Allen et al. 2003; Allen 2004; DuPuis et al. 2006; Hinrichs 2003). Similar to the threats of an unreflexive and essentialized vision of nature discussed above, the local can also be romanticized and lead to unintended social justice consequences.

Clare Hinrichs (2003: 37) explains how the binary thinking that localization is the antidote to globalization is problematic because it can lead to a 'defensive localism' which imposes rigid spatial boundaries in defining the local 'good' and is built around assumptions about the homogeneity and common interests of local places that need 
defending. She suggests that the boundarics between the local and the global should be viewed as borders, rather than barricades: "As borderlands, such boundaries constitute the rich edges between contiguous places permitted and expected to be different. In this way, diversity receptive localization recognizes variation and difference both within and outside of the spatial local" (ibid.: 37). This advice is at odds with the majority of initiatives aimed at food system localization, because they often focus on highlighting essential features of places or regions. In this thesis, I draw on these concepts to try to answer the questions of how the concept of the local is used and defined in the discourses of CSA growers and what effects these definitions may have on the CSA movement's goals of social justice and equity. 


\section{Chapter 3: Methodology, Research Methods and Introduction to the Case Study}

This research, under the rubric of political ecology, is informed by the research methodologies of critical feminist theorists and relies on the use of qualitative methods. In this chapter, I describe my research methodology and methods and critically reflect on my own position in the research. I conclude the chapter with an introduction to the CSA growers who participated in the research and a description of their CSA operations. My hope is that by using this particular methodological framework, I will be able to contribute in-depth, empirical research that will give us further insight into the social, cultural and political contexts shaping the individual experiences of the growers in this study and how the CSA movement in the Ottawa area operates and adapts to change.

\section{Methodological Framework}

Political ecology avoids fixed, deterministic approaches to analyzing problems and stresses multi-scalar research by looking at the diversity of nature and society relations at the Iocal level while taking into account the larger historical, political and socioeconomic forces that shape and situate local problems (Allen 2004: 141). Critical feminist thcory adds another level of awareness to political ecology research efforts by problematizing claims to objectivity and the idea of a universal 'Truth'. A heightened consciousness of power dynamics, the politics of representation and the situatedness of knowledge allow for an increased attention to reflexivity in both research methods and the writing process (Flax 1992; Rose 1997). 
Qualitative methodologies have become increasingly important for the practice of poststructural human geography. As Claire Dwyer and Melanie Limb (2001: 6) phrase it, researchers working within this methodological framework "do not start with the assumption that there is a pre-existing world that can be known, or measured, but instead see the social world as something that is dynamic and changing, always being constructed through the intersection of cultural, economic, social and political processes." Qualitative methodologies are useful tools for researchers who wish to go beyond the statistical descriptions and generalizations of quantitative research and understand lived experiences through the exploration of the meaning of people's everyday social worlds and realities (Dwyer and Limb 2001: 6). In-depth qualitative research in general, and case studies in particular, act as windows into "constitutive processes, and a means for reconfiguring understandings and practices" (Hart 2004: 97). As Noel Castree explains, case study research in human geography serves an important function in that it shows the world to be "persistently diverse", but also that this diversity "arises out of multiscaled relations such that it does not emerge sui generis" (2005: 541; original emphasis). Case studies fit nicely with a poststructuralist political ecology framework by allowing the researcher to see social institutions and processes as lived, resisted, manipulated and transformed by the differentiated lives of the actors involved.

By choosing a qualitative methodological framework, specifically in-depth interviews, my intention is to capture the differences among the CSA producers, adding their diverse human experiences to my analysis and steering clear of generalizations. I have tried to explore any contradictions and reveal differences that arose during the interviews. In avoiding the creation of an essentialized research subject, or a subject who is more 
homogeneous, coherent, timeless, self-eontained and different from other populations than they might actually be (Abu-Lughod 1993), I work towards examining rather than silcncing this diversity.

In order to reflect on my own position within in this research, I would like to clarify my understanding that my own knowledge is partial and situated. My interest in the topic of CSA stems from a deep-rooted interest in the alternative agrifood movement in general. I grew up on a mixed family farm not far from Ottawa and this has greatly shaped my experiences with and perceptions of the Canadian agrifood system. For many years I have been involved in community food security and local food systems initiatives both at home and abroad and I am currently a member of one of the CSAs in this study. I would be dishonest in saying that I am not sympathetic to or do not align myself with many of the objectives of the alternative agrifood movement. In this sense, I think this research can be identified as a form of activist scholarship in that $I$ am committed to raising awareness about CSA as an alternative to the conventional agrifood system. I believe whole-heartedly that this kind of research is important because those working within the movement often do not have the time to study the larger context of their work. This type of analytical process "can reveal possibilities for and obstacles to success that may be obscured by day-to-day work" (Allen 2004: 8) As Audrey Kobayashi (2001: 56) explains, "Such scholarship makes no claim to neutrality or non-intervention. It is by definition normative and undertaken with the hope that the research will result in changed conditions for the subjects." That being said, I think it is important to keep in mind that rather than representing or speaking for a specific group of people "the idea is to help uncover discourses of resistance, put them into wider circulation, create networks of ideas" (Peet 
and Watts 1996: 34); and not to speak on behalf of the producers as a subaltem group, but to "speak of their struggles and speak with them" (Barron 2000: 94; original emphasis).

In-depth interviews provide a good way for the researcher to acknowledge the situated knowledges of the research participants. Such an understanding posits that "all knowledge is produced in specific circumstances and that those circumstances shape it in some way" (Rose 1997: 305). Interviews are "methodologically appealing because they allow a wide range of experiences to be documented, voices to be heard, representations to be made and interpretations to be extracted"' (Smith 2001:29).

Power and performativity are two aspects of interviews that merit further discussion. The relationship between the researcher and the researched is flexible; their positions and identities can be changed and (re)negotiated throughout the research process. From this I take that as a researcher, I cannot pretend to be all-knowing and all-seeing, but instead need to situate myself and my interpretations of the qualitative data by reflexively examining my positionality (Rose 1997: 305). In interviews, the balance of power between the researcher and researched is often unstable. Even though the researcher is the one asking the questions and has the ultimate control over the interpretation and dissemination of the data, the participants can exercisc control by refusing to answer questions, lying and withholding information. The issue of performativity also comes into play. As Pamela Cotterill (1992) explains, talking to a stranger in an interview is an unnatural setting where their role is unclear; they will often manage their own conduct. She refers to this as the 'best face' phenomenon, "where respondents' concern to accommodate the researcher by making the 'right' responses conceals privately held views they believe are unacceptable to others" (ibid.: 595). The interview itself should therefore be seen as a constructed 
performance between the researcher and the researched. When analyzing interviews it is important for the researcher to remember that in the end, "interviews only generate information about what the participants say they do rather than their actual practices" (Valentine 2001: 44). On that note, I will now discuss my research methods.

\section{Research Methods}

In order to examine the discourses and meanings that shape the practices of CSA growers in the Ottawa area, I draw on a series of in-depth, semi-structured interviews with a selection of the growers in the region and a critical reading of the popular and academic literature shaping the CSA movement in North America.

\section{In-depth Interviews}

For the purposes of this research project, I conducted a series of in-depth, semistructured interviews with 14 CSA growers in the Ottawa area. The potential participants were identified through local food directories produced by Just Food, a local food justice NGO and the Ottawa chapter of the Canadian Organic Growers. The participants were informed about the research project by email, or in person, and asked if they would be interested in participating in the research. The interviews represent growers from 8 of the 10 CSAs currently operating with members in the Ottawa region. The absence of the two remaining CSAs can be explained by the fact that one started up after I had already completed the interviews and conflicting schedules impeded an interview with a grower

from the other. I have also included a CSA operating near Wakefield, Quebec (about 50 $\mathrm{km}$ north of Ottawa), as the growers are acquaintances of mine and had expressed interest 
in participating in the study. These growers have strong ties to the CSA movement in the Ottawa area, even though their membership is not from the City of Ottawa.

The interviews took place between January and March of 2007. The interviews were carried out in person at the participants' homes, with two exceptions, where a meeting in a cafe was more convenient for the growers. The participants were all provided with a detailed description of the research project as well as an informed consent form which they read and signed before the interview began. I made sure that the growers were aware that they could stop the interview at any time, choose to not answer questions and withdraw their answers at any time. I also suggested that could feel free to read, and revise, if they felt necessary, any specific quotations that I use in this thesis; however no one took me up on that offer, most likely due to time constraints. The participants were offered full anonymity, however surprisingly, not one of the participants felt that this would be necessary. I have since decided that I will not attribute any of the quotations to specific participants.

Five of the CSAs are run by male and female partners and in every case but one I interviewed both operators. ${ }^{3}$ Two CSAs are run by women and the other two are managed as part of non-profit organizations, so I chose to interview the key people who were involved in the creation of the CSAs and who were at one time the CSA's primary growers or gardeners. In total, I interviewed nine women and five men. The prevalence of women in this model of agriculture will be investigated more thoroughly throughout this thesis.

Through the interviews, it was my intention that the CSA growers would be able to speak for themselves about their views and experiences. I chose semi-structured, in-depth

\footnotetext{
${ }^{3}$ One CSA is currently being passed from the mother to her son and daughter-in-law. In this case 1 interviewed all three growers - the mother alone and the couple together.
} 
interviews because I needed to be able to cover a variety of topics quickly and with ample opportunity to clarify issues and pursue new tangents as they arose, but I also wanted the participants to feel free to control the direction of the interview. I understood that as an interviewer I needed to be aware of how I was phrasing my questions, whether the questions I asked were appropriate and how the participant was reacting to both my questions and to me as a researcher. The interviews were overall very relaxed and conversational. While I used a broad list of questions as a guide, the interview usually started with me asking about the participants' personal backgrounds and interests in CSA before turning to their personal histories, experiences, practices and beliefs regarding CSA. I played little role in setting the course for the majority of the interviews other than asking the occasional questions to keep the conversation flowing and to ensure that the key topics that I was interested in were covered. I had particular interest in the personal stories of the growers because they allowed me to better understand how their experiences, interpretations, feelings and relationships have shaped their lives and the decisions that they make (Abu-Lughod 1993; Mbilinyi 1989). Engaging with the individual voices of the growers helped me to demonstrate differences in the ways in which individuals experience and give meaning to events and ideas.

One obstacle that I encountered was the process of interviewing couples. As mentioned above, I conducted five joint interviews with couples. This was at the participants' discretion and to their preference, due to the fact that I gave them the option of being interviewed together or separately. Exploring the realities of shared lives can be a complex process and the researcher must be sensitive to power relations between the couples. People who share a domestic space, "consciously and unconsciously negotiate 
activities and events. There is tension, compromise and equanimity in cohabiting space that partners usually articulate with difficulty" (Aitken 2001: 74). Overall, I did not find that one partner dominated the interviews, although there were a few times where I would direct questions to the other partner if I did not feel that they had expressed an opinion on a particular topic. Interviewing partners was a challenging, but also enjoyable, process, as it helped me to understand the day to day negotiations between couples who not only live together, but work together as well. Gaining insight on their shared experiences and at times differing motivations and conflicting views on topics relating to CSA and conventional and alternative agrifood systems was incredibly helpful to the development of my interpretation and analysis of the interviews.

My original list of questions was adjusted after the first interviews as thematic commonalities arose in the narratives and my research interests became more exact. For example, while I was initially interested in looking at the gender dynamics of CSA, specifically why women appear to have such a strong presence in the production side of the movement, I quickly realized that discourses of nature and the local play a much larger part in the growers' motivations for participating in the CSA movement, with issues of gender entangled throughout.

The interviews were digitally recorded and then transcribed. The longest interview was just over three hours long, while the majority were an hour and a half to two hours long. I felt very welcome in the participants' homes and our interviews were often interrupted by family life - children, meals and so on. In many ways I believe the interviews were beneficial for both me and the participants as we shared information about other CSAs operating in the region, thought-provoking literature and events and 
conferences of interest. While the winter timing of the interviews was ideal in terms of the growers being able to find the time to participate, it put a damper on my initial desire to experience the daily operations of the CSAs through participant observation. I did get the occasional snow-covered tour of the gardens, but most of my understanding of the spring and summer lives of the growers comes from shared photos, vegetables, eggs and friendly conversations over the past few months.

\section{Participant Observation}

Prior to starting the in-depth interviews with the growers, I was also able to participate in a day-long workshop entitled "The Path to Becoming a CSA Farmer." The workshop took place in Ottawa in January of 2007 and was organized by Just Food, a local food security NGO. The workshop was open to people who were operating or who were interested in starting up a CSA and included detailed sessions conducted by a handful of experienced CSA growers on topics such as land tenure, planting schedulcs, the procurement of seeds and tools, apprenticeship opportunities and finances. Participating in the workshop not only gave me the opportunity to meet local CSA growers, but also provided insight to the motivations, perspectives and concerns of people who are considering starting up a CSA and the sorts of formal and informal support networks that are in place for CSA growers in the Ottawa area. I was able to announce my research project at this workshop and the overwhelming positive response and support that $I$ received was highly motivating. 


\section{Discourse Analysis}

In this thesis, I explore the various discourses that are used to frame, define, and articulate CSA. Drawing on my interviews with $\mathrm{CS} \Lambda$ growers in the Ottawa area as wcll as CSA brochures, websites and newsletters and the popular CSA literature in general, I seek to analyze how the powerful discursive symbols of nature and the local are mobilized to justify the creation of an alternative to the conventional agrifood system. Discourse

analysis is concerned with how a particular discourse constructs blame, responsibility and accountability and whether it makes certain claims to 'truth' (Rose 2001). When analyzing discourse, it is vital to ask who is making the statement, for whom is it intended and in what context is it being constructed (ibid.). According to Allen (2004: 116), it is worth examining more closely the discourses embedded in alternative agrifood movements in order to "see where they may facilitate or obstruct the realization of their articulated goals." She maintains that with a close examination, it may become apparent that some of these discourses may be inadvertently reproducing aspects of the dominant agrifood system, thus limiting progress toward the movement's collective goals of agricultural sustainability and food security (ibid.).

\section{Looking back on the research experience}

Earlier in this chapter I briefly discussed the importance of reflexivity and the inherent power dynamics between the researcher and the research participants. In many ways, my involvement with and understanding of alternative agrifood initiatives opened many doors in my interactions with the CSA growers. Looking back, one technique that I often used to empathize with the gardeners was my openness to discuss my own experiences with agriculture. My farm background definitely aided me in the more 
'technical' discussions surrounding cultivation methods, machinery and livestock. The producers were often interested in my own opinions and frustrations and were kecn to learn more about my international experiences with alternative agrifood initiatives. Although this can be seen as a move to build trust between me and the person I was intcrviewing, it also made me more vulnerable, because by revealing things about my own life I was effectively adding myself to the research. This willingness to surrender control over the interview and to share information about myself, ultimately allowed me to be more reflexive of my position in the research (Falconer Al-Hindi and Kawabata 2002). I am still in touch with a few of the growers who participated in this research and have even become a member of one of the CSAs. I am happy to say that I have made a few new friends in the elaboration of this thesis! It is very important to me that this research be accessible to a broad range of people and it is my intention to make my research available not only to the participating growers but also to Just Food, who are doing on-going community-based research and project development relating to local agriculture and food security.

\section{Who Participated? The CSA Growers in the Ottawa Area}

I would now like to introduce the CSA growers who participated in this research and whose worldviews, aspirations, goals and frustrations form the basis of this thesis. The 14 CSA growers who participated in this research represent nine CSAs operating in the Ottawa region. The majority of the CSAs service members who reside in Ottawa and all but one of the CSAs are located within 60 kilometers of the city centre. In 2001, the new City of Ottawa was created with the amalgamation of the Region of Ottawa-Carleton and 11 local municipalities: Cumberland, Gloucester, Goulbourn, Kanata, Nepean, Osgoode, Ottawa, Rideau, Rockcliffe Park, Vanier, and West Carleton. As a result of the 
amalgamation, the population of the city is now 80 percent rural and has more farmland than any other city in Canada, with agriculture revenues totaling more than Toronto, Montreal, Vancouver, Edmonton and Calgary combined (City of Ottawa website). In rural Ottawa, almost 300,000 acres are farmed by over 1,300 agricultural operations. Dairy, beef, pork, poultry and cash-crop sectors characterize Ottawa's agriculture, however; smallholding production such as emu, horse farms and stable operations, vegetables, apiaries, berries, nurseries, greenhouse businesses, and many other niche operations are also present (City of Ottawa 2003).

The longest-running CSA has been in operation since 1997, but most have started up in the last three years. One participant was preparing for her first year of CSA production when I interviewed her. The growers garden $1 / 3$ to 2 acres of land for their CSAs and grow a variety of vegetables and herbs. A handful of the growers also raise a small number of livestock such as poultry, sheep and cattle on their farms. One uses heavy horses to cultivate her fields. Four of the CSAs operate on land that the growers own privately, four on leased or 'borrowed' (free usufruct) land and one is located on the grounds of an environmental learning/spiritual retreat centre. All of the CSAs are organic or biodynamic, however not all are certified. Three of the CSAs are certified organic - two of which are in transition to Demeter (biodynamic) and one is Demeter certified. In the 2007 season, there were approximately 400 CSA shares purchased in the Ottawa area, with the number of shares for the individual CSAs ranging from 15 to $100 .^{4}$ The philosophies behind the varying models of CSA that are manifested in the Ottawa area will be further discussed in the following chapter.

\footnotetext{
${ }^{4}$ Membership is more difficult to estimate, as shares are often split, sometimes between households, and the growers tend to be in contact only with the primary shareholder.
} 
Table 2.1 Characteristics of Ottawa area CSAs

\begin{tabular}{|c|c|c|c|c|c|c|c|}
\hline $\begin{array}{l}\text { Location } \\
\text { (distance } \\
\text { from Ottawa) }\end{array}$ & Acres & $\begin{array}{l}\text { Organic/ } \\
\text { Biodynamic }\end{array}$ & $\begin{array}{l}\text { Years in } \\
\text { Operation } \\
\text { as a CSA }\end{array}$ & $\begin{array}{l}\text { Land } \\
\text { Tenure }\end{array}$ & Shares* & $\begin{array}{l}\text { Pick-up } \\
\text { or } \\
\text { Delivery }\end{array}$ & $\begin{array}{l}\text { Market } \\
\text { Diversification }\end{array}$ \\
\hline $\begin{array}{l}\text { Almonte } \\
(48 \mathrm{~km})\end{array}$ & $21 / 4$ & $\begin{array}{l}\text { Certified } \\
\text { organic }\end{array}$ & 6 & $\begin{array}{l}\text { Free } \\
\text { usufruct }\end{array}$ & 75 & $\begin{array}{l}\text { Central } \\
\text { drop-offs } \\
\text { and farm } \\
\text { pick-up }\end{array}$ & $\begin{array}{l}\text { Ottawa } \\
\text { restaurant }\end{array}$ \\
\hline $\begin{array}{l}\text { Almonte } \\
(48 \mathrm{~km})\end{array}$ & 2 & $\begin{array}{l}\text { Non- } \\
\text { certified } \\
\text { organic }\end{array}$ & 3 & Own & 25 & $\begin{array}{l}\text { Farm } \\
\text { pick-up }\end{array}$ & $\begin{array}{l}\text { Farmers' } \\
\text { market }\end{array}$ \\
\hline $\begin{array}{l}\text { Arden } \\
(141 \mathrm{~km})\end{array}$ & 2 & $\begin{array}{l}\text { Certified } \\
\text { organic - in } \\
\text { transition to } \\
\text { biodynamic }\end{array}$ & 11 & Own & 100 & Delivery & $\begin{array}{l}\text { Farmers' } \\
\text { market, Ottawa } \\
\text { restaurant }\end{array}$ \\
\hline $\begin{array}{l}\text { Cumberland } \\
(42 \mathrm{~km})^{* *}\end{array}$ & $1 / 2$ & $\begin{array}{l}\text { Non- } \\
\text { certified } \\
\text { biodynamic }\end{array}$ & 2 & $\begin{array}{l}\text { Free } \\
\text { usufruct }\end{array}$ & 30 & $\begin{array}{l}\text { Delivery, } \\
\text { or market } \\
\text { pick-up }\end{array}$ & $\begin{array}{l}\text { Farmers' } \\
\text { market, Ottawa } \\
\text { restaurant }\end{array}$ \\
\hline $\begin{array}{l}\text { Clarence } \\
\text { Creek } \\
(56 \mathrm{~km})\end{array}$ & 2 & $\begin{array}{l}\text { Non- } \\
\text { certified } \\
\text { organic - in } \\
\text { transition to } \\
\text { biodynamic }\end{array}$ & 3 & Own & 30 & $\begin{array}{l}\text { Delivery } \\
\text { or farm } \\
\text { pick-up }\end{array}$ & $\begin{array}{l}\text { Farmers' } \\
\text { market }\end{array}$ \\
\hline $\begin{array}{l}\text { Nepean } \\
(27 \mathrm{~km})\end{array}$ & $1 / 3$ & $\begin{array}{l}\text { Certified } \\
\text { biodynamic }\end{array}$ & $3^{* * *}$ & $\begin{array}{l}\text { Leased } \\
* * * *\end{array}$ & 15 & $\begin{array}{l}\text { Farm } \\
\text { pick-up }\end{array}$ & No \\
\hline $\begin{array}{l}\text { Sarsfield } \\
(50 \mathrm{~km})\end{array}$ & $1 / 2$ & $\begin{array}{l}\text { Non- } \\
\text { certified } \\
\text { organic }\end{array}$ & $\begin{array}{l}\text { First season } \\
\text { in } 2007\end{array}$ & $\begin{array}{l}\text { Free } \\
\text { usufruct }\end{array}$ & 25 & $\begin{array}{l}\text { Delivery } \\
\text { or farm } \\
\text { pick-up }\end{array}$ & $\begin{array}{l}\text { Farmers' } \\
\text { market }\end{array}$ \\
\hline $\begin{array}{l}\text { Rockland } \\
(50 \mathrm{~km})\end{array}$ & $3 / 4$ & $\begin{array}{l}\text { Non- } \\
\text { certified } \\
\text { organic }\end{array}$ & 5 & $\begin{array}{l}\text { Own } \\
\text { (retreat } \\
\text { centre) }\end{array}$ & 18 & $\begin{array}{l}\text { Delivery } \\
\text { or farm } \\
\text { pick-up }\end{array}$ & $\begin{array}{l}\text { Farmers' } \\
\text { market }\end{array}$ \\
\hline $\begin{array}{l}\text { Alcove } \\
(53 \mathrm{~km})\end{array}$ & 2 & $\begin{array}{l}\text { Certified } \\
\text { organic - in } \\
\text { transition to } \\
\text { biodynamic } \\
\end{array}$ & 1 & Own & 50 & $\begin{array}{l}\text { Central } \\
\text { drop-off }\end{array}$ & $\begin{array}{l}\text { Farmers' } \\
\text { market }\end{array}$ \\
\hline
\end{tabular}

* Grower estimated number of shares for the 2007 season.

**This CSA moved to a new location $74 \mathrm{~km}$ outside of Ottawa for the 2007 season, also free usufruct.

***This CSA was in operation from 2003-2005, a new grower was found for the 2007 season.

****Located in the Ottawa Greenbelt on land leased from the National Capital Commission. This CSA operates as part of a non-profit organization that works with the local Waldorf School.

The majority of the growers in this study have a university or college background, however only two have educational backgrounds in horticultural or agricultural studies. Six have taken part in apprenticeships on CSAs or have received specific training in biodynamic or organic agriculture. None of the growers have a farm background and only a 
few reported growing up in rural areas. Many of the growers rely on off-farm income (either from them or their partners) for part or all of the year in addition to their earnings from the CSA and many also sell their produce at farmers markets or to local restaurants. The participants range from young couples in their $20 \mathrm{~s}$ and $30 \mathrm{~s}$ to retirees. However, overall the movement appears to be young in contrast to the aging population of conventional farmers ${ }^{5}$. At the workshop that I attended, the majority of the participants who were interested in starting up a CSA were in their twenties. For a detailed table of the socio-economic backgrounds of the participants see Appendix 1. In this thesis, 1 only identify the growers by their sex and whether they operate the CSA jointly or solely. That being said, the numbering scheme in Appendix 1 is not connected in any way to quotations that appear in this thesis.

The growing season in the Ottawa area is usually 16 to 18 weeks, from June until the end of September or early October. Farms with greenhouses are sometimes able to extend the season to 20 weeks. A full CSA share in the Ottawa area costs anywhere from $\$ 375$ to $\$ 650$, with delivery or drop-off in the city available at an additional price (usually around $\$ 50$ more). Many of the growers in this study are cautious about properly calculating the value of the produce included in the shares and usually price their vegetables according to wholesale organic prices, taking into consideration what other CSAs are charging for their shares. One grower commented on the importance of ensuring that the members are getting value for their money: "We want everyone to get at least $\$ 500$ worth. It was a bit tight last year. We want to improve the yield and increase the amount we're delivering for the same price" (Joint-operator, female). Another commented that if they charged the "real price" for food, nobody would buy it (Joint-operator, male). None

\footnotetext{
${ }^{5}$ According to the 2006 Census of Agriculture the average age of farm operators in Canada is 52.
} 
of the CSAs allow their members to pick and choose what types of vegetables are included in their shares; this however, can be difficult for consumers who are used to the choice and variety of doing their shopping at supermarkets. One grower explained:

One of the challenges of CSA is that everyone's diet and taste varies. You can't really accommodate that variation. You basically have to give them a standard package. But in some cases - we had a customer once who was allergic to something - they simply couldn't have it. You should at least try to accommodate them; otherwise they can't be a customer of yours.

(Joint-operator, female)

Another recounted how she believed that the surprise element is part of what makes CSA appealing to some customers, but soon came to realize that it might not be the case:

Part of the point of CSA is to introduce new vegetables to people and to get them to eat stuff they would never have picked up but they maybe could adore. That's part of the game - that you get a surprise. I thought people were into that, but we found out that people prefer the regulars, potatoes, tomatoes- the usual stuff. It's hard to articulate the diversity component to people, because you don't want to chase them away.

(Joint-operator, female)

Some CSAs do provide some choice in the offering of a variety of shares. In the Ottawa area, CSAs advertise a full share as being appropriate for a family of four, or two vegetarians. Three of the farms offer half shares, however some growers believe that they are not worth the trouble and that customers will always opt for the cheaper share. As one grower explained:

We're all full share and the reason why is because we do want to cater to our members, but we don't want to cater too much to our members. We feel that a full share is actually what people should be eating for vegetables. It's not too much...We find that people will always go down to the less expensive one. Not necessarily because that's the amount of food that they want but because that's the price they want to pay for their vegetables.

(Joint-operator, female)

A couple of the farms experimented with half shares, but decided that it was too much of an administrative hassle: 
The problem with half shares is that it looks like a little bit, so what we end up doing is giving more. So really people get more with a half share because the box looks so empty, especially at the beginning of the year, so you end up putting more in because you want to fill up the box, which isn't really helping our cause at all. We're giving away more than we can afford to give away. (Joint-operator, female)

These growers suggest that members split full shares if they feel that they will not be able to consume all of the vegetables. Some CSAs offer other types of shares as well. One is planning on offering a winter root vegetable and spring greens share on top of their regular season next year, three offer work or barter shares, one offers sliding scale or shares that are subsidized by the other nembers for low-income families (another grower is considering this for next season), and one donates a full share to the local food bank. The question of accessibility to this type of agriculture will be discussed further in Chapter 5 .

Many of the CSAs require that their members pick up their weekly basket at the farm or at drop-off points throughout the city. Having pick-ups at the farm or central dropoff points lessens the workload of the farmers, because they do not have to sort, weigh and evenly distribute the produce among the shareholders, who are asked to fill their own containers. A few of the CSAs also have a 'swap table' where members can exchange vegetables that they dislike or will not be able to eat. Others, for an additional price, offer delivery to the members' houses:

A lot of people say it's not really worthwhile and it's a lot of trouble, you know, one stop after another. It actually took several hours a week for the 12 shares. But on the other hand, when we had done the pilot project it was difficult because sometimes people would forget to pick up their baskets and you still had to be there for a eertain amount of time whether they showed up or not. I thought it was just easier for people when it's delivered to their home and easier for us in the sense that we know they're getting it because we're bringing it right to them. If they forget they'll still get it in a couple of hours. (Joint-operator, female) 
Other growers felt likewise, that delivery is not only convenient for the members, but also for them. It also reduces the carbon footprint of the food delivery by having one vehicle coming into the city instead of multiple vehicles driving out to the farm. However, some growers commented that home delivery can mean that you will never meet your members face to face, which goes against the community-building element of CSA. Yet another bemoaned the fact that convenience is even as issue in the CSA movement:

To me one of the problems, not just with agriculture but with all sorts of stuff in our world, is convenience. Sure they're paying the price we ask, but I feel like we're just another food convenience and I don't want to be. Not just growing, but being able to hand somebody high quality produce is not convenient. Someone is putting a lot of effort and energy into that. If you have a delivery on Wednesday morning it has to be harvested at least the day before - it doesn't matter if it is 110 degrees or freezing cold outside, it doesn't matter if there's a torrential downpour - farming has to happen. There's nothing about producing food that's convenient.

(Joint operator, male)

In this study, two CSAs have farm pick-up only, while the others have the option of farm pick up, with three offering home delivery and four offering delivery to central drop-off points across the city.

Recruitment and retention of membership are common challenges for CSA farmers. Many of the growers in this study rely on word of mouth and hand-made brochures to gain new members. A few advertise in community newspapers or have websites. None, however, complain about not being able to recruit new members, despite the fact that turnover rates are high for some of the CSAs. As one grower with a very high retention rates explains: "It was a lot of work the first year. It's an upfront cost - like solar poweryou have to buy the battery but then it will last forever. It's the same with my customers" (Sole-operator, female). Another grower, who is no longer operating a CSA, described how pleasing the membership can be, by and far, the most stressful aspect of CSA: 
I think what finally broke my heart was going through the third season, working my brains out and realizing this was the best season I've done so far - look at how much I'm producing and look at the quality of these vegetables. And someone called me up to say "I want you to know that me [sic] and my co-shareholder are not satisfied with the variety and volume of your vegetables'. (Ex sole-operator, female)

This grower lamented the fact that this particular member expected her money to be returned, despite the fact that her demand went against CSA values and the commitment that she made to the farm at the beginning of the season. ${ }^{6}$

As mentioned earlier in this section, there are two CSAs in the Ottawa area that are not farmer-run, but instead managed by non-profit organizations. One receives grant-based funding to hire gardeners to run the CSA; however the high turnover rate presents challenges as every year a new gardener has to learn the ins and outs of organic gardening and running a CSA; needless to say, the learning curve is steep. Three of the CSAs offer apprenticeships to people who are interested in learning about organic or biodynamic agriculture and CSA. The apprentices gain practical experience and training and free room and board, while the growers benefit from an extra set of hands during the season. In the CSA movement as a whole, apprenticeships are very common and one of the only ways of gaining the hands-on education vital to starting up a successful CSA.

Many CSA growers find alternative ways to diversify their market and sell surplus produce that has not been given to their membership. A few of the growers in this study decided to ease into CSA and start with selling their produce at local farmers' markets, roadside stands, or through no-commitment food box schemes for the first season. As one

\footnotetext{
${ }^{6}$ The consumer side of CSA has been covered in many empirical studies. For a more detailed analysis of consumer interest in CSA refer to Cooley and Lass (1998), Cone and Myhre (2000), Kolodinksy and Pelch (1997) and Thompson and Coskuner-Balli (2007).
} 
grower who was preparing for her first 'true' CSA season at the time of the interview explained:

The reason we just did market gardening was because we didn't know how our land would produce. We really didn 't want to promise food for an entire season without seeing what could be produced on our land. It was just too much of a risk... and too much of a risk to ask people to believe in us, having never even farmed that land. We felt too much pressure. It was such a good season for us last year so half way through we had vegetables coming out of our ears. We were selling tons at Chelsea market. We were selling quite a lot at Wakefield market, but we still had a lot more food. So we decided to start up a week to week food box, which definitely isn't a CSA, but it worked for us to give the community a trial of what our food box would be like, what our veggies are like, you know, what it's like to receive an assortment of veggies every week. (Joint-operator, female)

Three of the farms sell some of their produce directly to local restaurants that are interested in supporting small-scale farmers and willing to pay a premium for high-quality, seasonal, organic produce. The growers who market their produce in ways other than just the CSA, made it clear that they always put their members first:

I told my shareholdcrs - you guys are paying for your shares ahead of time, so you'll be getting a better deal than the people at the market because I'll have the money when I need it. I'm actually not making as much off the shareholders as I will be at the market, but the shareholders get their food first because they paid first. I'll need the market to make up the difference and to be able to have an outlet [for the surplus vegetables], because you don't know how much stuff you're going to get and I don't want to overwhelm them. If it's a good year you're going to get bigger shares than you would if it's a bad year, but I don't want to give you so much that you don't know what to do with it all. (Sole-operator, female)

The diversification of their markets is also an economic move on the part of the growers, as the CSAs in the Ottawa area, perhaps due to their small scale or the fact that most have only been in business for a few years, are not very lucrative or financially stable. Almost all of the growers rely on non-farm income, either from their spouses or their own off-farm work in the off-season. 
Throughout this thesis, further details of the backgrounds, experiences and practices of the CSA growers in this study will be given. In the following chapter, I turn to a discussion of the historical and philosophical underpinnings of the CSA movement and how this is manifested in various models of CSA in the Ottawa area. 


\section{Chapter 4: The Historical and Philosophical Roots of the CSA Movement and its Manifestation in the Ottawa Area}

In this chapter I will set the context for the development of CSA in the Ottawa area through a discussion of the growing interest of North American producers and consumers in a variety of alternative agrifood initiatives and the current issues shaping the movement. I will then outline the history of CSA in the United States and Canada and provide a brief discussion of how the Teikei movement in Japan and the biodynamic movement in Europe have shaped the evolution of the CSA movement in North America. A discussion of the various models of CSA will follow, with insights from the growers who participated in this study, including an introduction to the 'shared' or 'supported' debate that is taking place in Canada.

\section{The Rise of the Alternative Agrifood Movement}

The past 20 years have brought dramatic changes to the North American agricultural sector. Policy shifts, driven by a neoliberal model of agriculture aimed

primarily at sustaining economic growth through an emphasis on market globalization, have led to the removal of production subsidies and barriers to trade and an increased promotion of agricultural exports. The push for greater market responsiveness and competitiveness through cheaper and more efficient production resulted in fewer, but larger farms and an increased market presence of agribusinesses and transnational corporations (Friedmann 1993). Through horizontal and vertical integration, these corporations have gained control of the manufacturing of inputs (i.e. machinery, agrichemicals, animal feed, seeds) and the processing, marketing, distribution and sales of agricultural outputs 
(Hendrickson and Heffernan 2002). The restructuring of national agrifood systems has had dire economic consequences for farmers and rural communities and resulted in growing public concerns surrounding the health and environmental effects of industrialized agriculture. As James McCarthy and Scott Prudham point out, "neoliberalism, environmental change, and environmental politics are deeply if not inextricably interwoven" and environmental concerns "represent the most powerful source of political opposition to neoliberalism" (2004: 275).

In recent years, a growing alternative agrifood movement has emerged in North America and Europe as producers and consumers organize themselves around finding solutions to the problems stemming from conventional agrifood systems and offering up alternative systems of food production, distribution and consumption. The growing consumer and producer anxicty caused by recent food scares, an increased concern for the environmental, health and animal welfare consequences of industrial agriculture and 'factory farming,' and a greater awareness of the working and living conditions of farm labourers (especially migrant labour) have resulted in a loss of public confidence in the globalized food supply. Many consumers are now demanding to know where their food comes from, what potentially harmful ingredients it contains, and how and by whom it is produced and distributed (Bell and Valentine 1997; Freidberg 2004).

This diverse movement has been conceptualized in a variety of ways in the agrifood literature. It has been discussed in terms of alternative agrifood networks and systems (Goodman 2004; Watts et al. 2005), civic agriculture (DeLind 2002), alternative agrifood initiatives (Allen et al. 2003), alternative or shortened food chains (Renting et al. 2003) and postproductivism (Whatmore et al. 2003). Allen (2004: 1) claims that this young 
movement is the result of both an "increased knowledge about the agrifood system and increased understanding that the system can be changed". The movement tends to position itself in opposition to the globalized agrifood system, with a shared understanding of the inherent problems with the current system and what an alternative system might look like. Wendell Berry, an American writer and farmer and a common voice in the altemative agrifood movement, explains how the global economy is organized around the following set of principles:

They believe that a farm or forest is or ought to be the same as a factory; that care is only minimally necessary in the use of the land; that affection is not necessary at all; that for all practical purposes a machine is as good as a human; that the industrial standards of production, efficiency, and profitability are the only standards that are necessary; that the topsoil is lifeless and inert; that soil biology is safely replaceable by soil chemistry; that the nature or ecology of any given place is irrelevant to the use of it; that there is no value in human community or neighborhood; and that technological innovation will produce only benign results (ibid. 1996: $78)$.

Berry's proposed solution is the preservation (or creation) of sustainable, local food economies built on connections between urban and rural communities and hamonization with local ecologies; this belief is shared by many others in the altemative agrifood movement (e.g. Kloppenberg et al. 1996; Norberg-Hodge et al. 2002; Pretty 1999).

There is a broad range of activities and initiatives that compose the broader alternative agrifood movement. Henk Renting, Terry Marsden and Jo Banks (2003) identify three broad categories of alternative or short food supply chains: organic farming, quality production and direct selling. Projects such as buy local campaigns and direct marketing schemes like CSA, food box programs, co-ops and farmers' markets are gaining in popularity in recent years, as are community food security projects (e.g. community gardens, food system education programs, food-based microenterprises). Certification 
bodies that guarantee ecologically or socially just agriculture (e.g. organic, biodynamic, fair trade) or the 'quality' of regional specialties (e.g. France's appellation d'origine controlée, EU's Protected Designation of Origin) are also enjoying increased consumer recognition.

While alternative agrifood initiatives, by their nature, "employ different social constructions and equations with ecology, locality, region, quality convention, and consumer cultures" (Renting et al. 2003: 394), the common thread that joins these initiatives is that they all "affirm a shared political agenda: to create food systems that are environmentally sustainable, economically viable, and socially just...[and] present both critique - opposition to the existing food system - and an altemative vision of socioecological relations embedded in food" (Allen et al. 2003: 61). These initiatives all work towards redistributing power in the agrifood chain away from globalized commodity production and international and national regulatory regimes by rebuilding the 'trust', or the connection, between food producers and consumers and articulating new forms of political alliances and market governance based on ecologically sustainable agriculture (Allen et al. 2003; Whatmore et al. 2003). They also represent a shift from a largely homogeneous agricultural commodity market to a more segmented and diverse market (Winter 2003a: 506).

\section{Situating CSA in the Alternative Agrifood Movement}

CSA is in many ways a hybrid of the various types of altemative agrifood initiatives. Drawing on Renting et al.'s work on the quality conventions of short food supply chains (2003), the CSA model offers an alternative to the conventional agrifood system by offering a quality product based on both regional and artisanal characteristics 
that link the food with its place of production and producer, and ecological or natural characteristics that link with bioprocesses and production methods.

CSA provides a direct partnership between a farmer and local members, or shareholders, where all agree to share the costs and products of the farm or garden. Prior to the growing season, each member purchases a share of the harvest for a set price. Members receive farm products throughout the season, usually on a weekly basis. If the season is good they may receive more than expected, if poor, they may have to go without a certain crop. This relationship allows producers and consumers to share the risks associated with small-scale food production. As Elizabeth Henderson, author of one of the movement's most influential books, Sharing the Harvest: A Guide to Community Supported Agriculture explains, "the essence of the relationship is mutual commitment: the farm feeds the people, the people support the farm and share the inherent risks and potential bounty" (ibid. 1999: 3). While neither the structure of CSA nor the CSA literature dictate that the food must be organically produced, the majority of CSAs are organic or biodynamic, most likely due to the commitment of both the growers and members to the consumption of fiesh, local produce that is free of synthetic chemicals (Henderson 1999:7).

In addition to promoting the health and taste benefits of locally produced organic food, the CSA model encourages consumers to understand their food choices in relation to the broader context of concerns such as ecological sustainability, biodiversity, energy conservation, worker safety, living wages, community-building and the preservation of small farms and a rural way of life (Sharp et al. 2002). In her book, Henderson summarizes what she sees as the key problems with the conventional agrifood system:

[Consumers] cannot touch the soil or talk to the farmer who tends it. Food comes from stores and restaurants and vending machines. It has been 
washed, processed, packaged, maybe even irradiated, and transported long distances. As trade becomes "free," the food travels even longer distances (1999: 3).

As I discuss further in Chapter 6, reconnecting people with the land in order to facilitate their understanding as to where and how their food is grown is one of the strongest objectives of the CSA movement. The majority of members not only purchase a CSA share to obtain high quality, locally produced food, but also to support a system of agriculture that produces food in what they believe to be a more environmentally and socially beneficial way (Hinrichs 2000: 300).

The CSA model finds its strength in its ability to present an alternative to conventional supply chains that emphasizes both the quality (based on place- and naturebased characteristics) of the foods produced and the networks through which they circulate. This lessens the chance of CSA being incorporated into conventional agrifood chains, as has been the case with the commercialization and industrialization of organic agriculture and food (c.f. Watts et al. 2005). By focusing on organic and biodynamic agriculture, reducing the distance traveled between production and consumption, facilitating direct relationships between producers and consumers, and creating local markets that allow farmers to earn more money for their produce, CSA thus provides growers and consumers alike with an environmental, spatial, social and economical alternative to the conventional agrifood system.

\section{The History of CSA in North America}

CSA first appeared in North America in the mid-1980s, in the North-Eastern United States. The first known CSAs were Indian Line Farm in Massachusetts and Temple-Wilton Community Farm in New Hampshire. Both farms completed their first year of operation in 
1986. Robyn Van En of Indian Line Farm and Trauger Groh of Temple-Wilton Community Farm are considered the 'founders' of the CSA movement in North America because their individual efforts have both shaped the conceptual framework of the movement and educated others about the practicalities of starting up a CSA (c.f. Groh and McFadden 1997; Van En 1995). The models used by the founding CSAs differed slightly, yet have both influenced the various manifestations of CSA that are operating today. While Indian Line Farm divided its produce so that every member received an equal share or half-share, Temple-Wilton allowed members to take what they needed regardless of how much they paid (Henderson 1999:7). While it has taken various forms, the different CSA models share the overall objective of providing an alternative to consumers and producers who believe that the conventional agrifood system, in which food is transported vast distances and the majority of what consumers pay for their food goes to companies who transport, process and market farm products, rather than to the farmers, is environmentally, socially and economically unjust.

Dan Wiens is often touted as spearheading CSA in Canada in the early 1990s with the creation of Wiens Shared Farm located south of Winnipeg. In 1992, a short article appeared in the Winnipeg Free Press advertising a new fam that would be "environmentally friendly and provide a meaningful way for city and country people to connect" (Dyck 1994: 47). The same day the article was published, 'Farmer Dan' was inundated with phone calls from people wanting to sign up with his 'community shared agriculture' project. Wiens was subsequently hired by Agriculture and Agrifood Canada's Prairie Farm Rehabilitation Administration to establish four CSA farms on the Prairies. By the end of 1993, more than twenty CSAs had been organized in the region (Samson 1994). 
Little is known about how long it took for CSA to catch on as a movement in the rest of Canada. In the Ottawa region, the longest running CSA started in 1997 and the grower was not aware of any other CSAs operating with membership in the Ottawa at that time. A few years later, in 2002, another grower started up and she believes that there was only one other CSA in operation at that time. Since that time, a few CSAs have started up every year and the growers are getting to know one another through workshops and events organized by local groups such as Just Food and local chapters of Canadian Organic Growers and Slow Food International.

Due to the nature and small size of CSAs it is difficult to estimate the number in operation. In 1996 the number of CSAs in the United States and Canada was around 600 (Henderson 1999). Ten years later, the Robyn Van En Centre estimated that the number had grown to 1200 . These numbers are likely low, as many CSAs rely on word of mouth and cannot be found in any listings and, as is evident in the case of the Ottawa area, new CSAs are starting up on a yearly basis. The most recent estimate puts the number in Canada somewhere around 500 (McAdam 2002).

\section{European and Japanese Roots}

While CSA is premised on supporting local food systems, its conceptual roots are more global, spreading as far as Japan and Western Europe. As the story goes, in 1985 Jan Vander Tuin returned to the United States from a trip to Switzerland, where he had spent time on several biodynamic farms, and introduced the idea of community supported agriculture to the founders of Indian Line Farm. The farmers at Temple-Wilton Community farm were similarly influenced by the biodynamic teachings of Rudolph 
Steiner. It was not until a few years later that the founders of what came to be called CSA learned that the origins of the concept can also be traced to Japan.

\section{The Japanese Teikei System}

Following the devastation of the Second World War, consumer activism in Japan increased as people began to notice an influx of imported foods, the loss of farmland to development, and the migration of farmers to the cities. Consumers also became more concerned with food safety and the health effects of the increased use of additives and chemical pesticides, herbicides and fertilizers in Japanese agriculture (Van En 1995; Hashimoto 2000). In the late 1960s, a group of women decided to ask a local farm if they would be willing to directly provide their families with fresh fruits and vegetables. The farmers agreed to provide produce if multiple families made a commitment to support the farm. From this the teikei, or partnership, concept was born, which loosely translated means "food with the farmer's face on it" (Van En 1995).

Since 1971, the Japan Organic Agriculture Association (JOAA) has been the organizing authority of the system and has made it a priority to establish teikei as an alternative distribution system, independent of the conventional market. In 2000 there were an estimated range of 500 to 1000 Teikei groups in Japan, with membership varying from less than 10 to more than 5000 members (Hashimoto 2000: 10). There are different forms of teikei, but they are all based on direct marketing between producers and consumers, in which both parties are expected to provide labor and capital to support the growing, processing, and delivery of the food. Teike $i$ is not only an alternative distribution system of organic products, but rather an "ecological production and consumption system that places the producers and consumers in a dynamic and creative relationship" and stresses an 
ecological way of life rather than the technical aspects of sustainable agriculture (Hashimoto 2000: 9).

According to the JOAA, the key principles of teikei are that: agriculture should be ecologically sound and ultimately self-sufficient in terms of inputs; consumers should help producers as part of the farming experience; less concern should be given to the appearance and packaging of food; there needs to be a direct distribution system between producers and consumers; consumers need to adjust to seasonal diets and find ways to use all of the produce that is provided to them ("from root to leaf") and; prices and crop choices are set through negotiations between producers and consumers (JOAA website). Similar to CSA, the Japanese system is premised on consumers and producers sharing the same objective of building a healthy, ecologically sound food production and distribution model that relies on the trust and accountability of its members.

\section{The European Influence: Biodynamics}

In the book, Farms of Tomorrow Revisited (1997) Trauger Groh, one of the founders of Temple-Wilton Community Farm, prcsents a utopian vision of the future of agriculture in which farmland is no longer privately owned and farming is no longer considered a business. His vision, defined by the biodynamic agriculture tradition, sees farms as individualized organisms attuned to the rhythms of the cosmos. These "farms of tomorrow" operate on the principle that each farm is a closed holistic system, producing and recycling its own fertilizers, integrating animals as well as plants and soil as part of the natural system, and relying on diversity for productivity.

Biodynamic agriculture comes from the teachings of Rudolph Steiner (1861-1925), an Austrian scientist and philosopher. At the end of the $19^{\text {th }}$ century, Steiner created a 
series of esoteric lectures based on his explorations of "spiritual worlds" (Courtney 2005:

1). His work is known as spiritual science, or Anthroposophy, and has inspired, among other things, the founding of the Waldorf School of education. Steiner's agriculture lectures were given in June of 1924 , less than a year before he died, at the request of farmers who were concerned about the introduction of chemical fertilizers. The lectures were based on his belief that a more spiritual agriculture is needed in order to restore the ecological balance:

While the Earth is a living being, it is in the process of dying and the forces of nature are withdrawing from their previous role. A spiritually awakened humanity must take up the tasks that were originally the responsibility of such nature forces. However, humanity is not able to grow spiritually because the food that nourishes the human being no longer carries the forces that will lead to the necessary spiritual development (Courtney 2005: 3).

In order to provide humanity with the means to heal the Earth, Steiner developed what are known as "biodynamic preparations", designed to restore the Earth's life forces. The nine preparations are made from herbal and mineral substances. They include two field preparations - horn manure (cow manure packed into a cow horn and buried over the winter), horn silica (ground silica packed into a cow horn and buried over the summer) and various compost preparations (yarrow, stinging nettle, oak bark, dandelion, valerian and horsetail), a few of which are produced by burying the herbs in an animal membrane or skull. Biodynamic farmers claim that the use of these preparations can have multiple benefits, such as better soil quality through increased organic matter and microbial activity, heavier dews and, in viticulture, increased sugar content in the grapes (Courtney 2005: 7).

In addition to the use of these special preparations, biodynamic agriculture differs from conventional and organic agriculture in other ways. Biodynamic farmers view the Earth as a living being and the farm as a living organism. The farmers rely on a 
biodynamic planting calendar in order to relate their agricultural efforts to the movements of the sun, moon and other planets (Courtney 2005: 4). While both organic and biodynamic farmers avoid the use of chemicals, this practice is what defines organic agriculture, whereas biodynamic farmers go beyond the material and incorporate a spiritual element into their agricultural practices. Unlike conventional or organic agriculture, biodynamic agriculture is "an ongoing path of knowledge rather than an assemblage of methods and techniques" (Biodynamic Farming and Gardening Association). The majority of the CSAs in this study are biodynamic; five of the eight are biodynamic or are transitioning to biodynamic from organic.

\section{Models of CSA}

CSA is a growing movement; however, not all CSAs follow the same model. There is a diverse range of CSAs, with the more philosophical and community-oriented farms at one end and the more commercially driven subscription farms that use CSA more as a marketing tool at the other. Many CSAs are faithful to the original philosophy that the membership should provide whole-farm and whole-budget support - meaning that the members do not pay for a certain amount of produce, but instead agree to support the entire budgct of the farm and receive weekly the produce that is in season. In some cases these CSAs are actually managed by a group of people with access to land who hire a farmer to grow food for them. Other CSAs are farmer-run, but rely on a core group of shareholders to recruit new members, write newsletters, help with budgeting and administrative duties, coordinate distribution and organize events such as harvest parties. In this model, the members are often required to contribute a certain number of hours of labour on the farm. While this type of CSA promotes direct relationships and teamwork between the 
membership and the farmers, the commitment levels are often too onerous for the majority of consumers, who have their own jobs and families to manage. For this reason, many CSAs are farmer-run and the members are encouraged, but not required to contribute labour and participate in the day to day activities on the farm. The majority of CSAs in the Ottawa area operate with this moderate philosophy.

Many of the growers in this study have differing opinions as to whether CSA should be treated as a business or a lifestyle choice. One grower, a retired environmental scientist operating a CSA with his wife, believes that CSAs can be financially viable, but only with plenty of work and commitment:

It is possible to make a living with a CSA kind of model, but you have to go at it at a scale that allows you to make an income. Realistically you're talking about bringing in 50 to 60 thousand dollars per year. I personally think the customer base is there, but you've got to grow a lot more than we do and you've got to market yourself a lot harder than we do. I think you can do it. It's a challenge for people starting because I don't think you're going to get at that $\$ 50$ to 60 thousand level, and that's kind of the minimum, in year one or year two. I think there are steps you have to take to get to that stage. Now we're at a stage in our life where I don't think we will ever do that, simply because we don't have to and because we're not physically able to - you've got be a lot younger.

Another grower, a young woman who has been running her CSA since 2002 without additional off-farm income, explains that, while stressful at times, a CSA can be successful, depending on your expectations:

I don't have RRSPs. I don't have any money in the bank [laughs]. Truthfully, this time of year [January] is when it gets really thin. That's the one thing about a CSA - it requires a huge amount of discipline to manage when you get paid twice a year. You get a tonne of money twice a year and you have to make it coast. You have to be really disciplined and I' $m$ not that disciplined. By December I'm usually biting my knuckles quite a bit, but it's doable. When I'm giving workshops to people and they own a house and they have stuff and they have animals or children or something, a whole other, much more responsible world than mine going on, I always say, 'Hey I'm single - or I was - and I don't own a house. I don't own a farm'...but 
it's a good money maker as part of the bigger picture. You start with figuring out how much you want the CSA to make and then you work backwards from there, it can do anything for you. If you want it to be your sole income it might mean that you have to sell 300 shares, but it can do anything for you. It's guaranteed as long as you find that membership. I don't think that it's a huge wacky thing to be making money solely from a farm.

Another young woman, who had recently started a CSA with her husband, described the shock that they felt when they were actually starting up a business together:

Ignorance is bliss in a way. We really jumped in. I mean we knew how to grow food and we had worked with farmers, but I don't think we knew that we were really entering a business. It was like our dream to grow food and to provide food for the community. It was a rude awakening. In our planning stage we were like, okay we're now business owners and we need to make money and get to work if we want to keep doing this and go on with our dream. That was a big shift in our reality.

Still others viewed their CSA as a lifestyle choice and wcre more concerned with the philosophy behind the movement than the profitability of their gardens. One woman, who was preparing for her first CSA season at the time of the interview, secmed to have already accepted that the CSA would not provide her and her family with much financial support:

With this I'm making practically no money - and loving it! And I feel like I'm doing such good things. Yet, at the end of the year it's all been either composted or eaten and I have to start over. You know, what do you have to show for it? But the fulfilment is there, the education. I feel like that's what I'm getting in my first year - an education.

The same woman unfortunately had a tough first season and found that the labour burden and travel time to the land she was using was not allowing her to spend enough time with her family. She has decided to discontinue the CSA for now. Another young couple has a broader vision for their farm that involved securing their own self-sufficiency:

Our goal, like [his partner] says, is not to become millionaires. Our goal is to create a farm organism that not only sustains our livelihood - that fecds us and lessens our need to access the supermarket during the off seasonbut also allows us to generate money so that we have those things. I mean 
we don't make clothes, we don't make a lot of the things that we certainly need. Certainly we do understand that money has its role, but it's not our driving force. (Joint-operator, male)

One CSA that was started up by a group of Anthroposophists fully embraces the biodynamic vision of a farm, especially the concept of whole farm/whole budget support.

As the woman who was once the head gardener of the CSA explained:

The right price is enough for the person to be able to live the life they like until they choose another one. With the farmer it basically means a price that can carry them from season to season. It's not about carrot to carrot; it's about season to season. Right price becomes - here's the budget of the farm, here is what the farm produces and it can support this community and the community can support the farm. It becomes a system. So the farmer has enough money to live their life and the people get the food, and it is good food.

The experiences and goals of the growers in this study demonstrate that the decision to start

a CSA is definitely a lifestyle choice; however a certain amount of business sense is needed

to successfully plan the harvests, recruit and retain membership, secure access to or purchase land and buy inputs such as seeds and tools. Some of the issues around the various models of CSA will be further covered in the following chapters.

\section{Shared or Supported?}

An interesting debate in the CSA movement revolves around its name. In the United States, CSA refers to community supported agriculture, however in Canada; it is often referred to as community shared agriculture. I was interested in probing in my interviews to see whether this is a highly politicized issue, or if it merely comes down to a preference in wording. In the end, I could not come to a definite conclusion: some of the growers are quite heated over the issues, while others use both supported and shared interchangeably. The following comments from the growers who participated in this study 
provide a glimpse at the diverse and often conflicting opinions on the matter. A few of the growers felt very strongly that 'shared' insinuates that the membership, or the community, is more connected to and involved with the farm, whereas 'supported' implies that the community is providing only financial support to the growers:

For us it's shared because we want a really big community role in our community shared agriculture. We don't just want to drop off to people at their doorstep and never see them and have this anonymous thing and they're only supporting through money. We want to really share the whole project with them. We want them to buy into the idea with more than just their money - through volunteering, through a work share, through supporting other community members, through coming to the farm, through just sharing recipes. Whatever it is, we want them to be a bigger part of our project than just being the recipients of food. So for us it's shared.

(Joint-operator, female)

Regarding the two different words, the supported or shared, I think the community shared is more indicative of where the members in the community actually come out and actually have a hands-on feeling of where the food is coming from. Rather than just the supported - that's just food box delivery. It's saving the trip to the supermarket but keeping the food dollar and the activity in the community. (Joint-operator, male)

I try to stick to community shared because that tends to be the more Canadian version and American sites that I've surfed usually say supported. But I've goofed and written supported in some of my literature sometimes by accident. I can't always keep it straight. I don't know which one is better but $I$ know that shared is probably going to go over much better with Canadians because it's a more socialistic society. That's just the way it is. Americans are very free enterprise, focused on business and profit. They get the whole business thing whereas in Canada, people, and I shouldn't say all people, because we're getting better, but there is a bit of a mindset towards the community...everybody working together...one big happy family. So I like the shared because it tends to tap into that part of the psyche.

(Sole-operator, female)

Conversely, others believed that community supported agriculture remains truer to the original philosophy of the movement. A few of them, however, explained that the 
movement has strayed from that philosophy, making shared a better descriptor for the

model that is common today:

I don't understand community shared as well as I understand community supported. Like community shared - so this community is sharing the agriculture? The community is sharing the risk? Well they're buying a share into the farm like you'd buy a share into a business. In community supported, the community is supporting the farm. There's a great quote from the Robyn Van En Centre "ultimately what you want is an agriculture supported community." (Sole-operator, female)

I think the original understanding of it was community supported. It has become community shared because I don't think what is happening right now is community supported. People have taken CSA and wrenched it around to really mean a co-op garden. Community shared agriculture is actually more accurate for most of the models that are happening.

(Ex sole-operator, female)

I think we're all straying from the notion of community supported agriculture. In that sense I think it would be a little hypocritical for us to say, well we're a CSA, but you're not. We're all doing food boxes. Whether we're actually doing community supported agriculture... I'm not saying no, but if our farm is sustainable and it's sustainable because the community is supporting us and paying a truly fair price for the vegetables - which is not going to happen - that would be community supported agriculture. If I have to keep a full-time job away from the farm because the community is supporting us, but not quite enough to make it worthwhile, is that community supported agriculture? It's like community partly supported agriculture - it's something - but we're not actually community supported agriculture. (Joint-operator, male)

It was also common that the growers found the use of the two terms confusing and did not

actually see a difference in the connotations:

I didn't know what to call it: shared or supported. I think it's the same idea but just different words. I thought they were interchangeable, depending on what appeals to people the most. Supported gives the idea that you're supporting the farmer. The farmer's working hard to support you to give you healthy, fresh organic food and you're supporting the farmer by paying up front and allowing the farmer to have capital to start the crops and not having to get loans and so on and supporting local farms which are becoming fewer and fewer. That support is kind of nice. Shared maybe gives the idea that...well we always thought when we started, you sharedyou shared in the work. That hasn't happened, last year they were trying to 
encourage people to come out to see and enjoy it. But nobody came, there's no transportation out there for one thing. Most people who do our thing don't have cars. So they're not sharing in the work or even sharing in the joys of seeing it grow because they haven't been out there.

(CSA founder and ex-gardener, female)

The diverse opinions expressed by the growers in this study reveal that the 'name debate' in CSA is not simple, nor is it apolitical. They also reveal the ways in which growers in the Ottawa area may be struggling in terms of operationalizing the ideals of the movement. There are differing opinions on what words should be used practically, as well as a variety of understandings of what CSA stands for philosophically. In the following chapter on the discourses of food system localization common to the CSA movement I delve more deeply into the conceptual underpinnings of the commitment to community-building as manifested by growers in the movement. 


\section{Chapter 5: From Seed to Plate - Growing a Local Agrifood System}

The intersection of the global and the local has become a common theme in agrifood system literature in the past few years. Interest in the local has been growing ever since the neoliberal political economic shift of the 1980s delivered an expanding, and increasingly corporate-controlled, global market. These changes led many people to tum to localization as a defensive position against what they considered the disempowering and homogenizing effects of globalization and neoliberalism. Agrifood scholars are engaging more and more in lively discussions of how the local, community and place are imagined, who exactly is included in these visions of the local, and whether the globalization of local food systems is necessarily an inevitable process. Many have moved past thinking that the local is powerless in the face of a globalized economy and argue instead that the global and the local are intrinsically connected - the global market depends on trade at the local level and that the (re)embedding of food systems at the local scale reinstates the role of social, and not just economic, transactions in the agrifood economy (Winter 2003a).

While some scholars have conducted in-depth case studies of alternative agrifood initiatives that suggest that the (re)localization of food systems can encourage communitybuilding and environmentally sustainable agriculture, as well as create space for resistance against the globalized food economy (DeLind 2002; Hendrickson and Heffernan 2002; Kloppenburg et al. 1996), others believe that the local is not always an innocent term in that it can provide the ideological foundations for reactionary politics and nativism (Allen et al. 2003; DuPuis et al. 2006; Hinrichs 2003). According to Clare Hinrichs (2003: 37), the dualistic thinking that localization is the antidote to globalization is problematic because it 
can lead to a 'defensive localism' which imposes rigid spatial boundaries in defining the local 'good' and is built around assumptions about the homogeneity and common interests of local places that need defending. This kind of unreflexive and essentialized definition of the local can lead to unintended consequences for social justice.

As this chapter reveals, the CSA movement constructs a particular discourse of the local that distinguishes and separates the food system that they are creating from the globalized conventional agrifood system. Similar to players in other alternative agrifood initiatives, CSA farmers and members often "frame their engagement as opposing the global by reconstructing the local" (Allen et al. 2003: 61) and by offering an alternative to the 'placeless foodscapes' dominated by homogenous corporate brand names that define the global food marketplace (Ilbery and Kneafsey 2000: 319). Yet, as discussed above, the 'local' is not a simple concept and can have multiple and conflicting meanings. An analysis of the underlying assumptions that inform the discourses of food system localization is needed to more fully understand the motivations and goals that drive the CSA movement as well as the potential obstacles that it may face. For example, the glorification of community, place, and the local is common in the altemative agrifood movement discourse, but these categories are often not treated as contingent social constructions and the movement rarely acknowledges how the spatial scales of the global and the local shape each other's existence (Allen 2004: 178). This chapter examines how CSA growers in the Ottawa area engage with place-based politics and conceptualize the (re)localization of the agrifood system. The possible effects that these definitions have on the CSA movement's goals of community-building, social justice and equitable food systems will also be explored. 


\section{Links and Sites: Different Conceptualizations of the 'Local'}

The increasing mobilization of discourses and strategies of agrifood system localization has both practical and political motivations. Local agrifood systems are practical in that they reduce food miles, or the energy costs needed for storing and transporting food; they are political in the sense that they focus on community-building, strengthening rural economies and deepening democratic principles and practices (Allen 2004: 165). The alternative agrifood movement, including CSA, constructs the local in different ways, giving it different meanings depending on the context and political motivations. Patricia Allen et al. (2003) demonstrate that these visions of the local can be understood as drawing on two main themes: links and sites.

The first conceptualization focuses on the community element of localization. By creating or supporting local agrifood systems, farmers and consumers give moral value to building accountable social relations and encouraging environmentally sustainable practices. In this context, the local "carries the multiple connotations of common interest, of the construction of community through the development of links within everyday life, and the incorporation of a moral economy of interaction between neighbours or allies mutually engaged in production and consumption" (Allen et al. 2003: 64; original emphasis). In this construction the local is assumed to enable relationships of trust between producers and consumers and encourage both parties to "internalize the externalities of conventional agriculture, paying the full costs of food production directly, rather than indirectly through displaced environmental and social harm" (Allen et al. 2003: 64). Direct marketing schemes such as farmers' markets, farm-gate stands and CSAs, are good examples of initiatives that engage with this particular vision of the local. 
The second definition of the local draws on particular sites that differentiate products. A site-based conceptualization of the local works in direct opposition to the globalization of agricultural commodities, which involves the linking of multiple sites from production to consumption. Examples are regional labels and regional specialty products that imply material quality as well as very specific environmental and/or social qualities. In Canada, 'local flavour' or buy local campaigns are commonly used by farmers' associations, non-governmental organizations and even the government (i.e. the Province of Ontario's "Pick Ontario Freshness/Foodland Ontario" campaign). Another familiar regional labeling campaign in Ontario is the Vintners Quality Alliance label for wines produced in the province. Guthman (2007) explains that while these commodities and labeling schemes are often considered an important form of resistance to the neoliberalization of agriculture in the sense that they protect land, other natural resources, and labour from the negative effects of the market, they still share with neoliberalism the fetishization of market mechanisms in that they are designed to create markets where none previously existed. This chapter reveals how the CSA growers in the Ottawa area draw upon these different conceptualizations of the local in their struggle to carve out a niche in the local agrifood economy.

\section{Building Local Agrifood Economies}

In recent years, alternative agrifood initiatives have gained power by focusing public attention on the contradictions and problems associated with the industriallymodeled and corporately-controlled globalized agrifood system, and presenting (re)localized agrifood systems as a potential solution. DeLind (2002) refers to these initiatives collectively as "civic agriculture." This model of agriculture is community- 
based, and allows for less standardized, more direct and self-reliant approaches to food production, distribution and consumption. Civic agriculture, such as CSA, "moves away from a strictly mechanistic focus on production and economic efficiency and toward food and farming systems responsive to particular ecological and socioeconomic contexts" (DeLind 2002: 217). Whether referred to as civic agriculture or the alternative agriculture movement, these initiatives work to shift power from the global scale to the local scale. Mary Hendrickson and William Heffernan (2002: 49) provide a clear example of how power is negotiated in the globalized agrifood system:

As people foster relationships with those who are no longer in their locale, distant others can structure the shape and use of the locale, a problem that is being explicitly rejected by those involved in local food system movements across the globe. This compression of space and the speed-up of time are key components of accumulation in the modern era. In the global food system, power rests with those who can structure this system by spanning distance and decreasing time between production and consumption. This reorganization of time and space indicates a great deal of power on the part of just a few actors that are able to benefit from the restructuring of the food system.

By supporting the (re)localization of food systems, producers and consumers regain power in controlling how, where and by whom food is grown. The notion of a 'foodshed' appears frequently in the discourses of the alternative agrifood movement and demonstrates a model in which this process can occur. Supporters of this concept believe that consumers who choose to eat food grown within their geographic region will gain a greater concern for the social, environmental and economic welfare of that particular region. For example, it is more likely that city dwellers will be concerned about the loss of farmland if that farmland is the main source of their food supply. Such a connection to place can avert the "ethical distancing" characteristic of the global food system, making collective 
responsibility for stewardship of both people and the land a necessity (Kloppenburg et al. 1996).

Arguments in favour of food-system localization include strengthening community markets for local farmers and food processors, reversing the decline in the number of family farms, creating local jobs, protecting farmland from urbanization and keeping the food dollar in the local economy. These opinions were shared by many of the CSA growers involved in this study, who believe, as one grower worded it, that CSA is "not just about the vegetables" (Sole-operator, female). The participants were asked what their key motivations were for becoming involved in the CSA movement:

Sustainability. I want to do agriculture because agriculture means giving people food. Not feeding cows; feeding people. CSA is one way that I think we can achieve that. I have hesitations about whether it fails or whether it truly is sustainable. My interest in CSA, however, is for the sake of keeping people in agriculture. (Joint-operator, male)

The belief that local economies can be revitalized, or strengthened, through the creation of local production-consumption networks runs strong in the CSA movement. Many growers in this study talked about the importance of being able to ask the 'right price' - one that fairly compensates them for their labour, skills and consideration for the environment - for the food that they produce: "To be in a partnership with people so that we can be doing this and they actually recognize it sufficiently to be paying us to produce the vegetables. I think it's great. It's a respectful thing, CSA" (Joint-operator, female).

Due to its small-scale and reduced need for expensive inputs such as heavy machinery, CSA is also considered an ideal way for young people to get a start in agriculture. This is reflected in the age cohort of this study, with many of the CSAs in the Ottawa area being run by young people in their late 20 s and early 30 s. In this sense, it 
provides hope that a new generation of farmers will be around to replace the aging farm population in Canada and stimulate the revitalization of rural economies.

Other growers focused on the food security or food sovereignty aspects of food system localization. To them, being able to source local foods, or better yet, grow your own food, allows consumers and producers a certain level of self-reliance in opposition to complete dependence on the global food system. One CSA grower explained:

The economy has become so global that if something were to happen to the global economy the first thing that's going to go is trade. When trade goes, you no longer have importing and exporting. You don't have the ability to get things from other places. And if you can't grow it locally, you can't get it. It's an emergency-preparedness kind of thing too - a kind apocalyptical safety-net! (Sole-operator, female)

This sentiment was also echoed by another grower:

What doesn't make sense to me is that Canada's cash crop farmers grow unbelievable amounts of grains and export a lot of it. Because of the North American Free Trade Agreement, Canada imports the same thing that they're growing here so that they can manufacture chips and other products that may stay here in Canada, but then that product is exported. It just doesn't make sense to me. You're moving something four times so that you can make one product. You should be able to grow it here, process, manufacture, and sell it here. If you can't feed your own house how are you going to feed your neighbour? (Joint-operator, male)

While the growers in this study felt very strongly about supporting the local agricultural cconomy and encouraging young people to enter into farming, they also voiced concerns for farmers in other places, including the global south. Part of knowing where your food comes from is being able to see that it is being produced in an ethical way. One participant explained that she buys locally to "keep the money in the family" as opposed to "sending it over to where I don't know if the people who are growing it are being fairly treated or making a living or being treated like slaves" (Sole-operator, female). Another participant came to the realization of how deeply globalized the agrifood chain is while working at a 
major grocery store chain as a teenager: "I guess where it started for me was when I had all my food packed in these produce boxes from Loeb and none of the food was from Canada. You just have to think about what you're supporting or what you're not supporting... and I'm not supporting a bunch of exploitation" (Sole-operator, female). This awareness of the potential social and economic consequences of buying cheap, imported foods reveals how the CSA growers in this study strongly believe that they are supporting more equitable food systems by electing to avoid these foods. In this construction of the local, it is framed as "the space or context where ethical norms and values can flourish" (DuPuis and Goodman 2005: 359) and it is assumed that local food systems are inherently more just than the global alternatives. However, one participant brought up the employment of migrant labour by a local organic farm as an example of the complexities of defining local food systems. She asks: "How local can the food be if it is grown by migrant workers from Jamaica?" (Sole-operator, female). The question of whether or not impoverished farmers in the global south will necessarily find other sources of income if the export market were to collapse because of increased consumer demand for local foods in the global north was left unanswered by the growers in this study.

Also in line with the site-based conceptualization of the local is the ways in which many farmers construct value and meaning in food (Murdoch and Miele 1999). This is evident in this study, as the growers impart certain values to the food that they grow, as well as to local foods in general. One grower described his mistrust in the conventional agrifood system, where food no longer comes from a farm, but an agricultural industry: "The food comes a long way; there are a lot of modifications and transformations. Waxing is like the lightest problem - they're pumping radioactive stuff into the food - c'mon!" 
(Joint-operator, male). On the other hand, local foods and products are referred to as being higher in quality, better tasting, and more nutritious than imported foods found in the grocery stores. For example:

I'm definitely committed to buying locally - trying to keep a sustainable food industry within your community. With growing our own food and producing vegetables for twenty plus other families, the families are very appreciative of the nutrients and the freshness of the food. We lived in the city for many years and I bought from the grocery store for many years, but now, after living in the country and eating food from our garden, I feel much healthier. I think that the future for CSAs and for organic food will only grow because we're realizing that it is much healthier for you. Through the market we now buy organic meat. We get eggs from a farmer and the shells don't break when I'm cooking them. I just feel that the food that we're eating is much healthier and enjoyable and tastes better.

(Joint-operator, female)

The 'enjoyment' that this grower refers to alludes to not only the corporal pleasure of. consuming this food, but the less tangible social, or moral, value of supporting local farmers. Almost all of the CSA growers in this study talked about their personal choice to supplement their own produce by buying local foods whenever possible, often choosing local, non-organic, foods over organic. As evidenced in the following quotation, some growers believe in not only the economic and environmental benefits of local agriculture systems, but also the cultural and social qualities of local food consumption and rural revitalization:

To me it's a driving force. It's very, very, very important to support local. On our website we have a button called "local eats" and we will feature all of the producers who are in our foodshed to try and encourage our CSA members to also access people who are producing food in our foodshed. We do this for a lot of reasons - to reduce climate change and reduce your emissions kind of thing and food miles, but also to make the fabric in your community rich. We have people who are doing these regional specialities that taste like where you live. To me it's important to not go to big box stores that have no flavour of who you are and where you live and how you interact with others. (Joint-operator, female) 
This grower, instead of employing a defensive competitive stance against other farmers in her area, provides them with free advertising and encourages her CSA members to source other local specialities. To her, the mere act of eating locally produced foods is a way of identifying your cultural connection to a particular place and in her words, "make the fabric in your community rich".

\section{A Defensive Kind of Localism}

A few of the growers' comments discussed above suggest a vision of the local that draws on the powerful sociocultural and geographic associations of food that work to shape place-based identities. As such, alternative agrifood initiatives, such as CSA, run the risk of advocating a 'defensive localism' when they engage a politics that emphasizes the construction, relational positioning and protection of essential features of places or regions. According to Clare Hinrichs (2003: 37), this opposition to external forces can at limes coalesce around "assumptions about the homogeneity and common interests of local places and regions that need defending." Such discourses impose rigid spatial boundaries in defining the local "good" and equate the localization of food systems with resistance, which is then conflated to signifying social change and more equitable food chains (Hinrichs 2000; DuPuis et al. 2006).

In their case study of food system localization in Washington State, Joan Qazi and Theresa Selfa (2005) find that local food purchases acquire a 'totemic significance' in terms of supporting local farmers. The politics that emerge in their study are strongly defensive in nature, with the objective of protecting local farmers and the regional economy from competitive foreign threats and regulatory pressures (ibid. 2005: 49). This sentiment was not strongly expressed by the growers in this study, most likely because of their ability 
to market their produce directly to their members and thus avoid 'outside' competition and regulations. Most of the growers in this study did, however, emphasize the importance of supporting local or regional farmers rather than national or international agribusiness. For example, one grower called for a shift in the focus of the Canadian agrifood policy agenda to one that prioritizes:

Feeding your home, feeding your neighbourhood, feeding the people that are you before worrying about driving someone's economy, worrying about whether someone's stock goes up or that truck drivers and freight ships are able to move millions of tonnes of food over there so that they can make something with it and ship it back over here so that person who's driving the ship has a job. (Joint-operator, male)

Others voiced discontent with the fact that the majority of the stalls in the main farmers' markets in downtown Ottawa are rented to wholesalers selling bananas from Costa Rica and tomatoes from the United States, rather than to local farmers. ${ }^{7}$

The creation of rigid definitions of who and what constitutes the local can work against the CSA movement's goals of social justice by ignoring or excluding variations from the norm. Hinrichs suggests that although acknowledging the internal diversity of places can seem at odds with food system localization, it allows for the recognition of the richness of difference and works to deconstruct the assumed homogeneity and common interests of spatial locales (ibid. 2003: 37). The foodshed literature also calls attention to the fact that local food systems display multiple and overlapping features such as plant and wildlife communities, soil types, ethnicities, cultural traditions, and culinary patterns (Kloppenburg et al.. 1996). Supporters of this model urge against drawing sharply defined boundaries and identify proximity, rather than locality or regionality, as the fundamental principle of the foodshed (ibid. 1996).

\footnotetext{
"For more information on this issue see "The Byward Market Secret" in The Ottawa Citizen, June 18, 2005, p. El.
} 


\section{Toward a Community Supported Agriculture}

Community-building is one of the fundamental goals of the CSA movement. The original farms that shaped the movement were based more on a philosophy of commensality and sharing the risks and labour of agriculture than a marketing strategy aimed at providing organic vegetables to disceming consumers concerned with their health and that of the environment. Food is not a regular commodity, but an "intimate commodity" connected to social reproduction and everyday life that finds its place not only in the global market, but also in the home (Winson 1993). Food, therefore, has special potential to be used as a tool to build community-based alliances and networks between farmers and consumers. Food system (re)localization efforts, especially direct marketing schemes, bring food production and consumption "back to the heart of an authentic personal relationship" by (re)embedding them within a community and causing eaters to respect the entire food chain process as much as they desire the food that they eat (Hendrickson and Heffernan 2002: 364). CSA represents an element in the local food system spectrum where notions of community and place are positioned in close proximity (Feagan 2007). With food as a focal point, CSA brings people into a closer relationship with place, farming, nature and each other. This element of CSA fits nicely with the above mentioned conceptualization of local food systems as creating links.

CSA growers in the Ottawa area use a varicty of means and activities to bring their members together in a social atmosphere and increase their engagement with the CSA. A few of the growers organize potlucks, harvest parties, work days and other events. Requiring that members pick up their shares at the farm or at a central drop-off is another 
way in which the farmers and members can meet and associate with one another. One participant explained:

We think it's important to bring people together to a central drop-off. It was neat to see what happened last year. People would stay for a while, hang out, they'd talk, they'd laugh, they'd share recipes and talk about vegetables. At the final one we baked pumpkin cookies and made mulled wine and people would come and hang out. At the beginning people were just coming and getting [the vegetables] and by the end people were milling about and talking to each other. So it does create a sense of community.

(Joint-operator, female)

For some, the community aspect of CSA is key:

We want a really big community role in our community shared agriculture. We don't just want to drop-off [the shares] to people at their doorstep and never see them and have this anonymous thing where they're only supporting [the CSA] through money. We want to really share the whole project with them. We want them to buy into the idea with more than just their money. Whether that be through volunteering, through a work share, through supporting other community members, through coming to the farm, through just sharing recipes. Whatever it is, we want them to be a bigger part of our project than just being the recipients of food.

(Joint-operator, female)

In terms of visions I would like to see this farm as a hub of activity on a community level - both locally and regionally. I would like, and this is huge, but just to get the people around us, our neighbours, just curious about what we're doing. That would be fantastic. (Joint-operator, male)

In this sense, community-building comes through membership involvement in the CSA.

However, other CSA growers consider it a challenge to get their members more involved in farm activities.

Our ideal for our CSA is that we would like the members who receive our produce or our services to be part of what we do, or at least to come out and visit. Last year we invited all of our members to come out to the farm, we were going to give them a tour through the gardens and discuss what we do and maybe let them grab some extra stuff if they wanted to take it home for free. Just to get them connected - rather than it just being like a membership service, like a book of the month club where you pay some money and magically a nice tidy box or bag of veggies that have been labelled and cello wrapped and made all pretty shows up and it just saves you a trip from 
going to the supermarket kind of experience. In an ideal situation that's how we would perceive or wish for the true CSA model to work.

(Joint-operator, male)

It's too complicated, especially in the summer, people are just so involved with what they're doing and their social activities and weddings and holidays and stuff. Even when people say that they would like to come out and help, I say oh that's great - you're most welcome to come out and help at anytime, but not many people show up. (Joint-operator, female)

As a result of it being considered an inconvenience, none of the CSAs in this study require that their members spend any time helping out on the farm, although all of the CSAs would welcome more member involvement and invite members to at least visit the farm to sce how their food is being grown. Only one CSA in the Ottawa area has the beginnings of a 'core group' of members who help with event planning, putting together the newsletter and member recruitment. This is apparently rare for most CSAs currently in operation; according to one participant, about 75 percent of CSAs are basically "subscription programs" - more of a marketing scheme than CSA in the original sense of the concept. He explained that:

A lot of [CSAs] don't actually have people out very much to the farm. It's a lot of work to have untrained people there and people who aren't necessarily interested in working...I really admire the farmers who are able to have a lot of unskilled input because it's a real skill being able to turn a blind eye and be tolerant. (Joint-operator, male)

Because of this, he believes that it is more useful to get members involved with the administrative and recruitment duties involved with a CSA rather than the farming. Finding the time to organize social events and convincing their membership to help out or even visit the farm is an obstacle for growers in the Ottawa area that jeopardizes their ability to fulfil the community-building goals of CSA. While some of the growers believe that it is unfair to expect their membership to have the time to participate more fully, others 
are obviously frustrated with the lack of engagement demonstrated by their members. One grower in particular, who at the time of writing had just completed her first season and decided not to continue the CSA next year, voiced her frustrations on her website about halfway through the season. She informed her membership that in the next CSA she would be requiring either a minimum number of work hours, or an increased share cost, from them. The fact that the majority of the CSAs in this study have only been in operation for one to three seasons most likely plays a large part in the reduced involvement of their membership. The one CSA that does have a core group has been in operation since 2002 and has very low member turnover, suggesting that the members have become more committed to the success of the CSA over time.

An especially controversial issue in the CSA movement is the increase in the subscription-style CSAs, also known as food box schemes, which have less focus on community-building, risk-sharing and membership involvement in the farm, and more emphasis on the members getting 'value' for their money. In this model, the members often pay on a weekly basis and may be able to pick and choose what vegetables they receive, the shares are often delivered to the members' doors, and farmers may supplement their shares with produce from other farms if they do not have enough of a certain product. In some cases, the members may never meet the farmer, or other CSA members, face to face. In my interviews, one grower was particularly upset about these sorts of programs being mistakenly grouped as part of the CSA movement and talked about a local farmer who started up a CSA but was nervous about committing to her membership:

She likes to resell - she grows some stuff but she supplements with a wholesaler. She drives to people's homes and delivers their food and they can pick and choose every week what they want. Well, this is not a CSA this is a convenience. A CSA is about mutual commitment and support, it's 
about, in a sense, taking what you get and being thankful. And what that is doing is taking some of the risk away from the grower. In the meantime hopefully what's happening is a community is forming where people are getting to know each other and they're becoming attached, there is a relationship building that is personal. That is what it is; it is not a marketing scheme whereby people can pick and choose, you will deliver to their home because it's a marketing push, you have an advantage over someone else who is making them leave their house and go out of their way. That's capitalist marketing. Not to say there's no room, there's room for it all. But it's just that people need to be clear and honest with what their intentions are and what they're doing. I get really defensive about that because what I have is a CSA and I'm really trying to foster something deeper than a box program. It's not a judgment on box programs, but there's a community essence that I'm really trying to foster. (Sole-operator, female)

As this grower describes, this agrifood model, while still supporting local farmers, greatly reduces the emphasis on sharing the risk as well as the harvest and restricts personal contact between members and the farmers, thus detracting from the "community essence" of CSA.

\section{Trust in your Farmer and your Food}

Another community-building aspect of CSA is the relationship of trust and commitment between the food grower and the food eater. Direct agricultural markets allow consumers to regain control over the source and quality of their food and (re)connect to the local agrifood system. According to Hinrichs (2000: 295) agrifood initiativcs that create face-to-face links between producers and consumers "present an apparent counterpoint to large scale, more industrialized systems of food production and distribution, now under the growing control of a few seemingly unpeopled, yet powerful transnational corporations." While within the globalized agrifood system relations between producers and consumers are "distant and anonymous," in local, direct markets, they are "immediate, personal and 
enacted in shared space" (ibid. 2000: 295). The focus on community, reciprocity and education in CSA makes it a highly embedded direct agricultural market.

The literature produced by the CSA movement tends to refer to CSA growers as being 'personal family farmers' because of the intimate relationship between them and the members. Being able to know the person who is growing your food and see the production methods that they are using allows consumers to regain power and control over the quality and safety of their food. One grower emphasized how important this power shift is: "If you don't control your own food you have nothing really. You're leaving your basic health in someone else's hand and it's a little scary" (Joint-operator, female). Another grower contrasted the grocery store shopping experience with that of buying from local farmers:

Really knowing how and where and who is producing your food in a local food system is important. Whereas, in the real world, most of the food that you find in the store comes from who knows where. You don't even know where the factory is. The Pop Tarts that your kids want for breakfast may have had been run through a processing plant that had dog food run through it during the previous shift. (Joint-operator, male)

While yet another talked about how much he likes the fact that the CSA model allows him to move away from financial transactions to more personal interactions with his members:

CSA is interesting because we're stepping away from a very financial transaction. Like here are your vegetables, now give me $\$ 5$. I really like that we can give people stuff - I mean they've paid already - but we can give people stuff and it becomes an interaction that's not based on money, it's based on food. (Joint-operator, male)

Many of the growers in this study also discussed being able to forgo the expensive organic or biodynamic certification process by being completely transparent about their production methods with their members:

I'd rather people had a relationship based on trust and if they want to know if we use fish emulsions or whether we use super phosphates, well they can come see. We can show them, we can show them pictures, we can do a 
video if they want. I'd rather the relationship be based on a certain amount of trust and understanding rather than on a word that is probably misinterpreted a lot. That's a big challenge because the more that organics gets popular the less interested I am. And we are for all intents and purposes organic - we have been for years. But do we really need to call ourselves organic? (Joint-operator, male)

If you're the type of person who sources or who wants to source out local foods, the thing is to know who's doing the growing. Don't just call up and say do you deliver your stuff - go out and meet them. See who they are, see what they're growing. Build that confidence in the people that provide your food. If you don't care about yourself fine, but if you have family and you're responsible for someone else's health based on what you put on their plate, know at least where it's coming from. (Joint-operator, male)

I think certification is really really important when you are selling products through a distributor - a third person kind of thing. Certification is important because you don't have direct contact with the consumer; whereas with the CSA people can come and see what wc're doing, anytime. You want to see how we're gardening here, come have a look. It's a direct link between the grower and the consumer. I don't know whether certification is necessary as long as we're in CSA. (Joint-operator, female)

Another grower has recently become certified organic, in transition to biodynamic, and although he has not felt any pressure from his CSA members to be certified, he believes that increasing government regulations of organic agriculture leave him no choice:

In terms of being certified it's a relatively new notion for us farming. It would be a slight exaggeration but as recently as maybe three years ago someone possibly could have described me as being hostile to certification. We basically sell to people who can look me in the eyes and the money so to speak gets handed over person to person. So there's the possibility of having a personal relationship and a trust factor. But because it's all direct marketing I didn't see a real need for it. (Joint-operator, male)

On the other hand, a few of the growers felt that certification increases the trust between them and the people eating their food:

We debate about this a lot. It's not that we're gung ho on certification. We're certifying because we're new farmers and we want to have some credentials to say that we're organic. Also there's a lot of people, not a lot of people, but there are farmers in our region that we know aren't organic that claim to be pretty much organic. And it's really tricky because they're 
not; they do certain things that aren't necessarily organic. I don't think it's fair for the consumer because they can't go and visit every farm and they don't have the knowledge or the skills to know what's organic and what isn't organic. In a way I think certification is really good for the consumer to trust that the food you're eating has been farmed in a way that you want to support.

(Joint-operator, female)

This transparency and willingness to have members experience first hand the on-farm operations become convoluted when farmers decide to supplement their shares from outside sources. Many growers in this study believe that this practice goes against the CSA philosophy:

If I'm explaining CSA I say it's a partnership between a grower and the people that eat the produce in the sense that the risk is shared. We do our very best to produce good food and they're committed to buying the share for the season. They've committed their money, we've committed our time. I know that a lot of growers don't agree with the formula because they prefer the box system where people only pay as they go for what they get per week. To me that goes against the whole value of the partnership between growers and eaters. I once heard an interview with a CSA grower on French radio, a grower from Quebec, who said - the interviewer asked the question well what do you do if there's a crop failure and the grower said, well we'll buy something to replace it. And I thought, No! That's not it! No, you have to do your very best you can as a person, or as a farm, to grow the best food you can. That's what you're there to do, that's what you have to do. If there's something that happens and we can't deliver that, then really the consumers are there to share that risk. (Joint-operator, female)

In the box program kind of model, there are opportunities for people to buy something from someone else to supplement what they haven't done themselves. I suppose that works for them. But philosophically for me, it doesn't encourage what I think is most important, and that is to encourage the producer, so we tend to stay away from that. We personally believe that whatever it is that we give to our customers is something that we produce ourselves and we haven't had to change that. (Joint-operator, male) 
The trust-based partnership between food producers and consumers that comes with the CSA model works to strengthen ties not only between the CSA members and the farmer, but also to the place where their food is grown.

CSA farmers offer another benefit to their membership - an opportunity to learn about the importance of local food systems, the role of agriculture and food in defining place-based cultures and how the food that they eat is grown. Their responsibilities as educators were expressed by numerous growers in this study:

We're more than just growers. We like to help people learn or to understand what it is that we do and why we're doing it; about the things that we do. If we can make a difference for even one person in the season that really is a benefit for us because we've helped another person make that transition in thinking. (Joint-operator, male)

I like the certain level anonymity that we have too, being a CSA project. Whereas you don't have a thousand people coming around and asking you a thousand questions - you have one person coming and you become more intimate with that person. And that also comes back to when we were talking about education. If you're communicating on an intimate level with a smaller group, chances are they're going to retain more information.

(Joint-operator, female)

Not having a member base in tune with the philosophy behind CSA can have devastating impacts. In her interview, one farmer explained how she could not find time to educate her members on top of her gardening dutics and how this contributed to her decision not to continue with the CSA:

We did not first of all pay me adequately and secondly we did not look at the budget of the farm as a whole unit. It was more like what do you think we can get for a share. We tried, but the people who were involved in it with me didn't really understand that if you want to build this you have to educate people because it's a problem of language - like biodynamics what's that? Education was the key and we didn't put enough into it. My time was all taken up with gardening and the winters were for recovering there was no one to cover the education end of it. (Ex sole-operator. female) 
While CSA has the potential to encourage community-building and social embeddedness, the movement faces many challenges in this regard. Forging strong relationships based on trust, commitment and participation is a long and complex process that requires effort and investment from both the farmers and the members. As many of the CSAs in the Ottawa area are still very young, it is still too early to say if they are achieving these goals.

\section{Who benefits from Local Food Systems? Issues of Power and Privilege}

As discussed above, discourses of the $\operatorname{CS} \Lambda$ movement tend to construct the local as being more authentic and more socially just than the global. A more critical look at the CSA movement reveals that issues of power and privilege cannot be avoided in this seemingly benign agrifood model. In his work, David Goodman (2004: 13) looks at the class composition of producers and consumers in the alternative food movement in general and determines that "alternative quality food production seems destined to retain its status as a narrow "class diet' of privileged income groups" and that those unable to access safe, nutritious food through this type of system are the "missing guests at the table set by this model." Along the same line, Hendrickson and Heffernan (2002) call for a more in-depth examination of power and where it is situated in the food system as a tool for acting strategically in developing food systems that benefit a broad range of people.

Much of the alternative agrifood movement literature describes the strength of local food systems as coming from their capacity to increase community embeddedness in local norms. A normative vision of the local, however, is often based on uncontested local values and rests on the premise that the local is a "more authentic arena of public life" than the global, or even the national arenas (Allen 2004: 179). Yet Allen contends that community "has no practical meaning independent of the real people who construct it and 
act in it. It is defined differently by different people as mediated by income, wcalth, property ownership, occupation, gender, ethnicity, age and many other personal characteristics" (179). The creation of strict definitions and boundaries of the local mediates who is 'in' and who is 'out,' thereby risking an exclusionary politics.

Melanie DuPuis and David Goodman (2005: 362) envision a more reflexive local politics of food that takes into account how different discourses of 'right eating' are intertwined with investments in the different axes of social differentiation. Such a politics would "actively seek to expose and undermine the tendency of specific groups to work from this "politics of perfection," which univcrsalizes and elevates particular ways of eating as ideal when, in fact, all eating - like all human action - is imperfect and contradictory" (ibid. 2005: 362). In their study of the Kansas City Food Circle, Hendrickson and Heffernan find that the privileged position of the group is on the most part unacknowledged by its members. They decide that the conventional agrifood system can only be rejected by those in the position to do so. Locally-based agrifood initiatives still require money (and in the case of organic and biodynamic, more money than conventional) as a medium of exchange, so low-income groups have fewer resources with which to participate in the alternative (ibid. 2002: 365).

In this study, the CSA growers were well aware of the privileged composition of their membership. While this research did not entail any interviews with CSA members, many of the growers noted that the majority of their members were white, urban, middle to upper class, and university educated. Empirical studies have also shown that the majority of, and most active, CSA members are women (Cone and Myhre 2000; DeLind and Ferguson 1999; Wells and Gradwell 2001). Interestingly enough, the socio-cultural make- 
up of growers who were interviewed for this study tended to mirror that of their members (with income arguably being the only difference).

Women tend to take on the responsibilities of organizing the membership requirements of CSA. They are often the ones who initiate membership, pick up and process the shares and participate in on-farm activities. Allen (2004) points out that because they cannot get all of their food from a CSA, consumers are therefore burdened with an additional shopping trip. The tasks of processing, preserving, and packaging the food do not disappear, "they are simply displaced to a differcnt time, space, and labour relation. Somebody still has to do the work - it is simply reembedded in the home, the domain of women's labour, particularly in regard to food" (ibid. 2004: 113). The tendency for women to be members of CSAs was also observed by some of the growers:

Most of my customers, my members, were women. It was the women bringing the family forward. Possibly for traditional gendered reasons in terms of - I need to make sure my family's fed - I do the grocery shopping - this is part of grocery shopping. They also seemed to get it more. They understood the value of healthy food; they understood the value of supporting the farmer through the season instead of just purchasing and ending the relationship there. (Ex sole-operator, female)

The 'caring practices' of providing safe and nutritious food might also attract female growers to CSA. The tasks of educating themselves and others, and building relationships with other growers, their members and the land are appealing to many women in the movement (Wells and Gradwell 2001). A female grower in this study reflected on how women are noticeably drawn to CSA:

My impression is that it's like teaching, it's like nursing - it's nurturing. This is different than conventional agriculture - it's building community, it's taking care. There's a lot more of a personal touch to it. I think that it's just inherently more...well it attracts the feminine side more. That's my only explanation for that. Whereas traditional farming is more systematic, 
you know, pretty simple, you don't have to talk to anybody, there isn't any concern about presentation or diversity, details. (Sole-operator, female)

Betty Wells and Shelly Gradwell found in their study of gender and CSA in Iowa that "CSA provides a space in which traditional boundaries between male/female and farming/gardening are blurred and softened" (ibid. 2001: 111). Many of the women growers in this study talked about being attracted to the flexibility of being able to raise their families and work at the same time (this sentiment was also voiced by a couple of the men). While this functions well for those who operate a CSA on their own land, it can be a problem to those farmers who have to commute to their gardens, or who run the CSA by themselves. One such grower decided to discontinue her CSA after the first season when she came to this realization:

We looked as so many options, but what it all boils down to is that I could run a CSA, or I could have a life with my family. Every time I visited the garden I took an hour out of that day that was neither spent with my family, nor working in the garden. When I look at the countless hours I have spent driving to and from the farm, it didn't make sense. [From her website]

Other women in this study expressed motivations more related to working with nature and nurturing the land. This topic will be discussed further in the next chapter.

The CSA model can also be economically restrictive to prospective members. The requirement for paying a substantial lump sum up front makes it less accessible to lower income people. Some CSAs are trying to get around this by offering subsidized shares or payment in instalments. In the words of one grower "ideally, good food is available to everyone who wants to choose it, not just who can afford it" (Joint-operator, male). Another grower recounted how this has worked in her CSA:

We were concerned about certain people in our community who don't have a lot of money and who are on a limited income. So we did a 'share the 
food' share where community members can pay - buy a box or buy a full season for a family that's on a limited income. People come to us who have a limited income and tell us how much they can pay for a box and we're like, sure no problem, and we subsidize the rest. I think people really appreciate the fact that we offer that and that they have the opportunity to contribute. In the meeting last night everyone felt that it was a great idea. They were really happy with it. Someone came up to us who needed a limited income box and it was so nice for us to be able to say that we could subsidize her share. She had tears in her eyes, it was so touching; we had tears in our eyes. She said thank you and we said don't thank us, it's the community. To be able to say that is super cool. (Joint-operator, female)

In this case, around seven members have contributed toward a few food boxes for a local

family. Other growers commented that they would love to be able to offer a free or subsidized share; however their own tenuous financial situations complicate the issue:

It's really important to me that cost isn't a factor. Again, it's a balance issue that I've been dancing with, I had a thorn in my back for a long time just for the sake that I wanted to be affordable and what I'm realizing is that I'm not doing anyone a favour by barely being able to exist. So I need to take some too, it's just figuring out what works for everybody. (Sole-operator, female)

Last year we gave a share away. At the same time, we're not really in a position to do that... if only we had more money [laughs]... It's tricky, that question of how can it be affordable for lower income people. The thing is that the growers are the low-income people! You really want to be able to do that, but I mean you're cutting into what you've got from your season of work. If you're already working for $\$ 2$ per hour for the whole summer - so take a portion of that and give it away. Is it really the farmer that should be doing that? We should all be sharing more. Everybody needs to share more. That's a fact. (Joint-operator, female)

The above comments demonstrate how balancing the goals of social justice and community food security of the CSA movement with their personal need to earn a living is a difficult topic for many growers.

Another issue of power that arises in the movement is the level of participation required for members. According to Allen (2004: 120) farming "tends to be both romanticized and privileged over other forms of labour" in that members are expected to 
share in the labour of farming, yet farmers are not expected to reciprocate by helping the members perform their regular jobs. As she explains "most middle- and low-income people, already overwhelmed with the demands of productive and reproductive labour in their own jobs and households, have precious time for extra activities" (ibid.: 120). This is not a relevant issue to CSAs in the Ottawa area, as most of the farmers seem to be resigned to the fact that they cannot expect their members to volunteer their time and labour.

\section{A More Inclusive and Reflexive Vision of the Local}

The growers in this study tend to construct the local as an arena that, although affected by the negative impacts of globalization, has the potential of offering up spaces for alternative economic and social relationships that challenge and contest these effects. By rooting themselves in a particular place, the CSA growers in the Ottawa area seek to create an alternative agrifood system that is based on relationships of trust and commitment between themselves and the eaters of their food. These 'face to face' relationships encourage both the growers and members to (re)connect with and invest in the place and community where their food is grown. The growers, as well as the CSA members, gain a higher degree of control over the social, economic and environmental circumstances surrounding how and where their food is produced.

The CSA growers in this study do not defensively position themselves in direct opposition to the conventional agrifood system, but do prioritize local food systems and family farms over globalized agribusiness. Because they operate at such a small-scale and have neither the capital resources, nor the production to compete in the national or global marketplaces, to them the local food economy is the only space in which they have the power to influence change. The sort and amount of change that they can create however, is 
highly dependent on how deeply engaged their membership is in the community-building aspects of CSA. As I discuss in this chapter, CSAs in the Ottawa area place less focus on encouraging member involvement and responsibility in the activities of the farm and more on forging a space for new types of associative agrifood economies.

The CSA model works toward building interpersonal trust and a sense of community rooted in place. However, the discourses of the local demonstrated by the growers in this study are influenced by normative perspectives of what constitutes quality of life on a both a personal and societal level (DeLind and Ferguson 1999). DuPuis and Goodman (2003: 360) are cautious about such an 'emancipatory" food agenda that "relies primarily on the naming and following of a particular set of norms or imaginaries about place," as it can have unintended social justice consequences and deny the diverse politics of the local (ibid. 2003: 360). The growers in this study are aware of the exclusionary effects of CSA and its inability to attract a diverse membership; they are restricted by their own social and economic situations however, and find it challenging to finds ways to encourage diversity-receptive localization strategies.

Despite recent conceptualizations in the agrifood literature that posit that the global and the local cannot be conceptualized as distinct realms, that they are defined by what the other is not and participate in each other's existence, the growers in this study demonstrate that more binary definitions of the global and local are still in play at the grassroots level. Although the CSA movement is often defined by its opposition to the globalized agrifood economy, it is in no way restricted by the broader system. This is in line with J.K. GibsonGraham's suggestion that: "In the discursive context of globalization, attempts to restore identity and capacity to localities assume moral force and political priority. But such 
attempts cannot succeed if the local is necessarily confined and constrained by the global" (ibid. 2003: 50). In the context of local food economies, DuPuis and Goodman (2003: 369) also propose a more inclusive and reflexive politics of place that would help us to understand these systems:

...not as local "resistance" against a global capitalist "logic" but as a mutually constitutive, imperfect, political process in which the local and the global make each other on an everyday basis. In this more "realist" openended story, actors are allowed to be reflexive about both their own norms and about the structural economic logics of production.

The participants in this study find power and agency in the roles that they play in creating space for local agrifood economies. While they understand that they do not have the resources to operate in the same realm as the transnational corporations controlling the globalized agrifood economy, they believe that their own place-based resistance to this broader system can be effective at the local level. Their belief in this power, combined with their conviction that the globalized agrifood economy does indeed have its weaknesses, is what allows them to challenge its control and encourage others to do the same. 


\section{Chapter 6: Discourses of Nature in CSA}

Agriculture is an arena where humans intimately interact with nature and produce the necessities of everyday existence. Because of this, the overlapping arenas of society and nature are nowhere more evident than in the production and consumption of food (Vos 2000: 246). While all commodities begin and end in nature, this is particularly true in the case of food and other agricultural products. Agrifood systems cannot be abstracted from either the social or the natural domains - they are in play both "on the land, where agricultural nature and its harvest are co-produced and co-evolve with social labour, and at the table, where these co-productions are metabolized corporeally and symbolically as food" (Goodman 1999: 17; original italics). Farmers are highly dependent on natural resources and processes; soil, water, weather, plants, animals and the seasons are natural aids and constraints that affect agricultural production. Yet, these elements of the biosphere become "resources" only when people define, use, and exchange them as such (Allen 2004: 139).

The increased commodification of food, however, has led to most people lacking an understanding of where it comes from and how it is produced. The resources, both human and natural, required to produce food remain invisible to the average consumer, who on a routine trip to the grocery store can purchase foods that are cleaned, packaged, pre-cooked and ready to heat and serve. As Timothy Vos (2000: 246) explains, in the affluent societies, "food is taken for granted, and farming is an unknown, a form of lost knowledge, a gap in the collective memory signifying disassociation and alienation from nature, from the land." Organic and biodynamic agriculture, as practiced by the CSA growers in this 
study, are deemed more "natural" or environmentally-conscious alternatives to conventional agriculture by those who grow and consume its products.

In this chapter I reveal how CSA growers envision themselves as working in harmony with nature, not against it. As opposed to the environmentally destructive characteristics associated with conventional agriculture (soil erosion and degradation, intensified use of water, air and water pollution, negative health effects of chemical pesticides, 'factory farming' of livestock), organic and biodynamic farmers believe that they are not only preserving, but enhancing the ecosystems and natural resources that they are using. Once again, their self-described role as educators enables them to share with their members and surrounding communities the philosophy and practice of an environmentally sustainable agriculture and work toward reconnecting them with 'nature' and 'real' food. In this sense, their involvement with the CSA movement can be considered "a radical gesture of reconciliation with nature, an embodied attempt to change the way we actually live in the (social/natural) world" (Vos 2000: 246). That being said, this chapter will also discuss the tendency of the CSA movement to draw upon essentialized imaginaries of nature and sustainable agriculture and, in turn, how this may hinder or facilitate its success.

\section{An Agriculture in Harmony with Nature}

From the standpoint of the conventional agricultural system, the history of agriculture has triumphed in its ability to supply cheap food to the western world. Kevin Morgan et al. (2006: 2) discuss how in the discourses of conventional agriculture, where quantity is privileged over quality and a mass production system that is deeply embedded in corporate culture and designed to reap economies of scale for producers and low prices 
for consumers reigns: "the record looks like one success story after another, as food supply became progressively 'liberated' from the restrictions of nature and the seasons." This "liberation" from nature has allowed the globalized conventional agrifood system to overcome both spatial and temporal constraints. Food that cannot be produced in a certain climactic zone or during a certain season or that can be produced more cheaply elsewhere is simply imported from across the world to consumers who expect it to be affordable and available year-round.

In stark contrast, the CSA movement demonstrates a reverence for the power of nature and is built around a deep understanding of and respect for natural cycles and a diversity of ecosystems. Rather than isolating and concentrating on a farm's individual parts, organic and biodynamic production is dependent on close attention to the interrelation of those parts (fertility management, water management, pest control, etc.). In an ideal situation, the farm is recycling its outputs (e.g. compost, manure, waste water) and the farmer does not need to import expensive and often petroleum-based inputs from off the farm, but relies instead on the farm's own products and contributions from nature (e.g. rainwater, sunlight, beneficial plants and insects, organic fertilizers and pesticides). This humility towards nature and the acceptance that it, at times, can be unpredictable, was described by many of the growers in this study:

We're humble enough as growers to know that you can never really have it all figured out. We are part of, not separate from, the natural systems that typical agriculture tries to control or predict and nature is not predictable. You can do everything right by the books: when to seed, when to plant, what your fertility is, $\mathrm{pH}$, make sure you water correctly... and Mother Nature has a sense of humour sometimes that we don't understand. Check this out - throw in a bunch of bugs or some mould or a hurricane or a tornado or drought or whatever. (Joint-operator, male) 
You really have to nurture the living and the line you have to toe is nature's line. It's part of what I'm saying - observation, it doesn't matter what you think a plant ought to be doing, what they're doing is what's relevant and you need to be able to understand that. They're not going to lie to you; they're telling you if you can just see it. I mean farming is completely artificial, but it works best when it closely mimics nature.

(Joint-operator, male)

Common to both organic and biodynamic farmers is the belief that a diversity of crops and livestock is the linchpin of sustainable practice and integral to the "whole farm" approach. On the flipside, conventional agriculturalists tend to see specialization and monoculture as essential to efficiency and productivity. A handful of the CSAs in the Ottawa area raise poultry for eggs and meat; sheep, horses and cattle can also be found. An appealing aspect of having animals on the farm is being able to use their composted manure as fertilizer and to find a practical use for any vegetables that they cannot give to their members. One grower in this study uses heavy horses instead of machinery for cultivating the land and other cumbersome jobs. For the biodynamic growers, livestock are especially important: "Biodynamics is for the full farm organism and small farms do function very well with a diversity and variety of livestock. There really are multiple niches [on a farm] and different livestock fill niches very well" (Joint-operator, male). The same grower added that "creatures" should be kept as "naturally" and "dynamically" as possible, keeping in mind that they are domesticated animals. He prefers to have both male and female animals so that he does not have to rely on artificial insemination.

Crop diversity is a mainstay for the CSAs in this study, as they all operate as smallscale market gardens. Detailed harvest planning and crop rotations are key so that the growers can guarantee a variety of vegetables, berries and fruits to their members, attract beneficial birds and insects to their gardens, and lessen the chances of pest infestations. 
One grower explained his reasons for being drawn to market gardening: "I happen to like growing lots of different stuff. The idea of growing two or three crops, I can't imagine. It's hard to be ecologically sustainable doing that" (Joint-operator, male). He also notes that its scale makes it the easiest type of farming to do close to urban centres, so it makes sense to grow a variety of crops to suit the demands of local restaurants, farmers' markets and CSA members. Fresh, highly-perishable produce can be delivered the same day with no need for expensive refrigerated trucks and storage facilities.

In order to gain a better understanding of their motivations, values and ideals, the participants in this study were also asked why they chose organic or biodynamic agriculture for their CSAs. Interestingly, the majority of the growers expressed that it just makes sense, that they would never even consider doing conventional agriculture.

Organic? For us it's not really a question. We just don't want petrochemicals sprayed on our food or petrochemical fertilizers embedded in our food. We think it's a very unsustainable way to farm. We want our kids to be able to eat and all of the soil in the world to not be so depleted from all of the dangerous things that they're applying on them [sic]. I mean, also for us it's a manageable way to farm. We're not super mechanized people, we're pretty urban. A lot of that machinery stuff and sprays, I mean: A, we wouldn't do it; but B, I don't think we'd know how to do it anyway. We're just not into it at all. It just doesn't really fit with anything we believe in. (Joint-operator, female)

For another grower organic agriculture was the only way that she could be true to her desire to not only use the land in a sustainable manner, but to better it, because it was there before she arrived with her CSA and it will be there after she leaves:

I'm a farmer. I don't even say I'm an organic farmer because it's just like a non-thought; I mean why would you be anything else? [laughs] I mean, it comes back again to how I look at the land and I want to treat that piece of earth with the utmost integrity because it deserves it; it's been there for a long time. I'm using it and I want to make it better than it was before I got it. It's the same as if I were to stay at your place and it was a mess when I got there, but you let me stay for a week, so I'm going to tidy it up before I 
leave. It's the same sort of philosophy and all that comes back to you too; the reason why vegetables are so good for you is because they're sucking all this goodness out of the earth. It's not inexhaustible; you have to put it back. I find that it's part of my job to do that because otherwise I'm just stripping, I'm just land stripping really. The use of chemicals first of all it costs a lot of money, and it's just plain silly! Who thought of that in the first place? Organic for sure, it's just a non-thought. (Sole-operator, female)

While the previous grower feels that she has the ability, if not the responsibility, to ameliorate nature, the following grower has a 'nature knows best' attitude. She believes that she has only limited power to improve on nature and talked about her aversion to the harmfulness of chemicals and her mistrust in genetically modified plants:

I've never even considered any other method of growing food. I think that nature knows best. We have to work with nature. We have to be observant of nature to see what she's telling us. I don't think we can improve on it that much. We can improve on plants, I don't mind the idea of developing new plants, not genetically modified of course, but through a process that is a slow and careful process. But in the long-term cycle of things I don't think we can do any better than follow nature's lesson. And besides, it's too harmful, there's too much damage done with chemicals - to the environment, to ourselves, to life. It goes against the grain of life.

(Joint-operator, female)

Only one of the participants did not consider being organic as integral to CSA. Although

she does think organic agriculture is beneficial to both humans and the environment, her motivations appear to be driven more by consumer demand for organic produce:

I don't think it's as important to me as it is to some; partly because I don't really look at in the religious sense. I'm very practical. I have a religion. I'm happy with my religion. I don't need another religion. If something is totally attacking my vegetables and I need to do something drastic about it, I'm not going to let all of those vegetables die just because it's against my religion to help them. The thing is that the people who are buying the shares may feel stronger about it than I do. Even though it may not be as important to me, it's important to me to follow the standards - even if in my backyard I may not be as diligent. The vegetables that I'm growing for people and that I'm telling them are organic - there I'm going to be diligent. Not because it's my religion, but because of my commitment. (Sole-operator, female) 
This particular producer felt the need to distinguish herself from the "religion" that she believes defines the organic movement. Yet her understanding that organic agriculture and CSA go hand in hand is evident and while she has different standards for her personal garden, she remains true to the promise she has made to her members.

The biodynamic growers in this study expressed reasons similar to those of the organic farmers for choosing their particular production techniques. However, the biodynamic growers incorporate a more spiritual understanding of their relationship with nature, reflective of the philosophy guiding the movement. They believe that while agriculture transforms nature, humans have the role of developing nature in a way that mimics natural processes as accurately as possible. Similar to the organic growers, biodynamic farmers disagree with "mining" the Earth's natural resources and instead seek to contribute to its enhancement. Spiritually, biodynamic practitioners see the earth and their farms as living organisms. They consider the farm to be inseparable from the "living identity" of the earth as a whole; as such they use careful observation of nature and celestial activity as tools towards creating food with a "life force" and vitality:

Biodynamics puts right out there that the sorts of energies and harmonies that you're trying to establish on the farm are really important to the planet right now in terms of life forces continuing, because so much of how we live is annihilating them. The key is to not underestimate what your little farm might be doing. Biodynamics deals with homeopathic principles, where a microdose - if it's in the correct vibrational pattern - can actually have resonant effects throughout the larger whole. What you're able to achieve on your little farm might have consequences way beyond your farm. It's basically a vision of hope and a way of interacting in the world in a positive framework. (Joint-operator, male)

A previously organic grower described her motivations for embracing biodynamics: 
I've always sort of been into eco-psychology and eco-spirituality and deep ecology and how the cosmos affects your reality and how your spirit exists in the world and how what you do affects it and how intention affects it. For me, biodynamics makes [the farm] this little microcosm of intention and it's energetic and, I don't know, for me it's a little dose of healing for the planet to have a biodynamic farm. I think it's organic and all that and way more. To bring a spiritual element to your farm is very important. I think we have it anyway, but there're a lot of Rudolph Steiner's lessons that bring it together in a very practical way. Yes, you can intend for things to happen but you can also use practical tools and practical preparations to boost that good intention into an energetic reality in the soil and in the plants.

(Joint-operator, female)

The "good intentions" and spiritual and cosmic energies engaged by the biodynamic growers allow them to see everything that they do "from seed to fruit" as being based on potential. In the words of one participant "The seed is a potential plant. Our hard work is just energy becoming something at the end" (Joint-operator, female). The biodynamic growers see it as their responsibility to take over where nature left off after the abuse of humanity stripped the Earth of its "life forces".

Certification is a contentious issue for CSA farmers in the Ottawa area. Only three of the nine CSAs are certified organic - two of which are in transition to Demeter (biodynamic), and one is Dcmeter certified. Of the remaining, non-certified CSAs, four are organic (one with interest in biodynamics) and one is biodynamic. One of the certified organic CSAs is certified by default because the grower is using the land donated to her by organic beef farmers. In her interview she admitted that she would probably not be certified if her situation was different. As discussed in the previous chapter on food system localization, many of the growers do not feel the need to certify because of the direct relationships based on trust that they have with their members. To them, certification is an unnecessary and costly expense. Others prefer to remain "under the radar" and clear of the 
regulatory regimes of the government. They believe that it is unfair that small-scale farmers face the same rules and regulations as large-scale, industrialized farms:

The other thing that really bothers me is that organic farmers are paying so much to do good things for the planet, good things for the soil. They're small; they're not necessarily making a lot of money. It costs a lot of money to get certified. Meanwhile these super agri-businesses are destroying the soil and they don't have to pay. Why are we the ones who are paying? We should be regulating against agriculture that's detrimental to the planet. These people are penalized for doing agriculture that's bad for the soil and bad for your food and bad for the planet. It's such a weird system.

(Joint-operator, female)

In addition, all of the participants demonstrated resistance towards the recent turn to the commercialization and industrialization of organic agriculture and their fear of being associated with the new "big organics" industry. Many of the growers expressed disgust with the organic megafarms, located for the most part in California, such as Muir Glen (famous for canned tomato products) and Earthbound Farms (famous for their salad mixes and notorious for the $2006 \mathrm{E}$. coli outbreak linked to their fresh spinach). One grower summed up the general opinion of these farms: "How can you be bettering the land on that scale? Even if you're not using chemicals, you're still exhausting the land" (Sole-operator, female). The comments below further illustrate the concerns that the CSA growers voiced around the issues of certification and the organic industry:

I don't jive with corporate organic at all. I don't think it is [organic]. Again, it's your relationship with the planet; it's not a marketing scheme. Well, I. mean it's good - I mean there are hundreds of thousands of acres of earth that aren't being sprayed or that many acres of plants being grown without GMOs. That's all good, but the motivation is still to make money. I don't find that sustainable - you're still using the same amount of fuel to process it and ship it. It's still being packaged in the same amount of packaging. It's still exploiting people. The only thing is you're not poisoning the ground. Like I was saying before - are you actually improving it, are you putting back what you're taking out? There're a lot of synthetic organically 
certifiable fertilizers and pesticides out there - that's not organic to me. (Sole-operator, female)

I think in a way organic certification is heading in the wrong direction and it bugs me a lot. I don't like that there are organic greens at Loblaws from California that are mass produced on a super humungous farm with machines. I think the integrity of organic is being a bit watered down. I'm curious to see where it goes. I don't think that we'll always be certified. I think we might be certified for three years and then have that credibility and then just kind of lose our certification. Demeter certification on the other hand, I actually think is quite valuable. I'd like to one day become Demeter certified. I think it protects you because you're a specialized farm once you're certified with a biodynamic label, or even with an organic label, but it protects you in a way, in what you're doing and how you want to farm. (Joint-operator, female)

To the growers in this study, the commercialization of organic food goes against the founding philosophies of the organic, biodynamic and most relevant to this analysis, CSA movements. By disregarding the holistic and grassroots approach intended in these alternative agrifood movements, the 'big organics' industry has caused many farmers to doubt the organic movement as a whole.

Another element that is very important to the CSA movement is the idea of seasonality. Many consumers in Canada have come to expect that they can buy tomatoes and strawberries year round and overlook the fact that most fruits and vegetables are imported from more southern climes during the winter months. CSAs operate with a concept of time that is based on the seasons, weather patterns and the sunrise and sunset. While a few of the farms in this study have greenhouses in order to extend their growing season into the spring and fall, others are completely dependent on the changing and unpredictable whims of nature. This does not always translate well to their members, some of whom expect to have sweet corn and tomatoes in their June boxes. This requires an element of education on the part of the growers: 
I think that consumers are interested in nutrition and fresh food that's locally grown, but we also have to do a bit of education too. One of our customers asked - why can't I get asparagus in August? So consumers do have to realize that when you're buying locally there's a season for each item and you maximize the use of it during that season - or you freeze it or can it or whatever. You can't always get what you want.

(Joint-operator, female)

Eating with the seasons requires a certain level of skill and knowledge of food processing and preservation that many consumers no longer have. Commitment to a seasonal diet is also more time intensive, especially in Canada, where vast quantities of food need to be "put up" for the long winter. One of the growers shared this story of her and her husband's experience with the inconvenience of food preservation:

We joke when it's like one in the morning and we're making pesto - not because we want to but because we have to. Because we have committed to this 'making sure we have food for the winter thing' and that's the only time we have. I'm like 'oh isn't this romantic - we're making pesto at one $o$ 'clock in the morning - I'm so tired'. At the same time there is a romance to it because we're doing what we always wanted to do.

(.Joint-operator, female)

The "reskilling" of consumers is a task taken up by many CS $\Lambda$ growers, who believe that it leads to greater individual and community control over the production and consumption of food.

\section{Caretakers of the Earth}

Control over the production process is another way in which the growers in this study demonstrate power and resistance to the conventional system. This control is achieved through the management of small-scale operations that rely on manual, rather than mechanized labour and close observation of the farm's ecosystems. CSA growers consider themselves as 'caretakers of the Earth' and condemn agricultural practices that

\footnotetext{
${ }^{8}$ See Jaffe and Gertler 2006 for a more in-depth discussion of this process.
} 
contribute to soil erosion, groundwater depletion and contamination from chamical pesticides and fertilizers. While many conventional agriculturalists believe that "only by harnessing resources with advanced technology will we be able to feed the world and enjoy the affluence achieved through increased agricultural production" (Allen 2004: 37), the growers in this study believe that these unsustainable practices are merely borrowing from the future.

Many of the growers consider themselves to be highly-skilled artisans, operating outside of the realm of mass market commodification. CSA is often characterized as a noble and "life-giving" profession. One grower described her "passion" for the land:

I care very passionately about the land, very passionately and very deeply about the land itself, the planet. I would like to orient my life around a sustainable...well I would rather align my life to life than to death. In choosing to align myself to life, what am I going to do about that? I've got these capacities - I can produce food, I know I can, not only can I produce food I can raise lambs [laughs]. How am I going to contribute to it? I would say that that CSA was my commitment to producing a change in my world, my family's world, and my immediate, my small community world.

(Ex sole-operator, female)

A common metaphor expressed in the movement is that CSA farming is a puzzle-solving process that requires an intimate and intuitive connection with the land and a skillful decoding of the language of plants, animals and soils. One grower referred to this as a "plant positive philosophy":

We've never used chemical sprays on the land...we've never used any of that stuff because in the plant positive philosophy if you have a plant disease or insect problem it's because of your cultural practices, it's not because of an insect or disease. If you have vibrantly healthy soil and vibrantly healthy plants they're virtually pest and disease free.

(Joint-operator, male) 
The importance of "knowing the land" also surfaced when growers were reflecting on bad seasons or poor yields. A good example of this came from a grower who is no longer operating a CSA:

I would do a CSA again, but I would never bind myself into being required to produce without knowing my land first. I should have had at least two years of just market gardening - selling what I have as opposed to making a commitment. The stress was phenomenal. (Ex sole-operator, female)

Another couple, who relocated their CSA to new land this past season, was incredibly disappointed by their yields and frustrated by bad luck with the weather. They have since decided to try and find a different site for a future CSA and in this excerpt from a letter to their members they refer to this summer as their "season of learning":

Looking back over the last six months, we have come to realize that we were blessed with a great season - even though the gardens produced far less than we had hoped for. It's funny that given our rocky, less than perfect beginning, we had actually predicted this kind of end to our season either an earlier than normal frost or a tornado. Well, out here in Orleans, we got both, lots of frost and a small tomado touched ground last Friday night off Innes Road. All in all, the season was an experience we will not soon forget. We learned a great deal about soil quality and what to look for in future endeavors and land purchase.

While they accept that they have no power over the weather, they do admit to not having a good enough understanding of soil quality to know that they were going to face difficulties with vegetable production.

The growers' perception of themselves as caretakers or protectors of the land is also evident in their beliefs about land ownership. About half of the CSA growers in the Ottawa area do not own the land that they garden, but rather rent it, or are lucky enough to have access granted to them in return for a share. Many of these growers do comment that one day they would like to own their own land; however others consider land a "gift from the universe" (Joint-operator, male) that should not be paid for. As one participant explained 
"I've never been a huge one about ownership of land. I think people are a bit crazy about it. I just don't think land is there to be owned. I think it's there to be used and appreciated and respected and all these other things" (Sole-operator, female). Not having stable access to land can work at cross purposes for the CSA growers who value a deep understanding of the land. An in-depth knowledge of site-specific ecological characteristics is a long-term process and if the growers are required to find new land for their CSA every few years, such knowledge would be hard to attain.

The CSA movement frequently draws upon a negative picture of the beliefs and practices of conventional farmers in order to contrast their agricultural methods with their own. Some of the growers in this study demonstrated such an 'us versus them mentality':

I don't want to sound too drastic but an older generation of farmers is a little bit naïve about the entire environment and the idea of soil health, which is a completely foreign concept. "What do you mean soil health - the soil doesn't need to be healthy, what about your plants - are your plants dead or not?' You can drive down the highway and see these cornfields and they're not doing very well - and that's not sustainable. Even for their own sake, for the sake of them growing corn for the next 15 or 25 years. I think that what we're doing is moving towards an environmental sustainability so that not only is the ecosystem in good shape, but it's in better shape than where we came from. I think that's a very noble life goal. I could die happy with that - even on just our tiny 50 acres. (Joint operator, male)

[Conventional farmers] don't get it at all. They just don't get it at all. On one level I can totally understand why they don't get it - I mean they've been producing food for people all their lives, all their 60 or 70 years and they say 'what do you mean we've been doing it bad and hurting the earth and destroying the future for our children?' They can't go there, for their own lives, they can't go there. They don't get the CSA model, they think it's a big scam, or they can't be bothered with it. Why would I do that? I'm a cash cropper. I sell my crops, someone else distributes it [sic]. I don't care if it goes to cows or whatever. (Ex sole-operator, female)

The tendency to attribute these essentialized characteristics to conventional farmers is risky. Even if a farmer is not part of what is considered an alternative agriculture 
movement, they can still be good environmental stewards and take pride in their care of the land. If the movement is closed to 'outside' farmers it could possibly be excluding people who have interest in switching to the CSA model. By narrowly deciding who is 'in' and who is 'out', the movement risks going against its ideals of being inclusive and supporting democratic processes.

The CSA movement also defines itself as different by highlighting the fact that it attracts more women farmers than conventional agriculture (i.e. DeLind and Ferguson 1999; Trauger 2004; Wells and Gradwell 2001). The gendered element of CSA begs the question of whether the values and identities of women involved with CSA be understood as shaped by a "biologically given 'alliance' between women and nature" or as "constructed in a discursive practice" (Pederson and Kjærgård 2004: 374). The popular CSA literature has the tendency to fall into an essentialist trap and employ the symbolic metaphor of 'Mother Nature' and the stressing the 'natural' connection between women and the environment. In this study, gender was viewed as more of a non-issue by the growers. Many of the women interviewed did note that they liked the fact that CSA gardening was more hands-on and did not require heavy equipment or machinery, but both men and women commented on being able to work more closely with nature and spend more time with their partners and children. Only one grower referred to herself outright as an "Earth Mother" and that was more in reference to how her male CSA members treated her. More commonly, growers considered the 'nurturing' element to be the lure of CSA for women:

A lot of women are doing it for their values and principles and they're willing to sacrifice for what they believe in. I guess some men are too. It's so nurturing, it's such a nurturing thing to grow food to make people healthier and make the earth better. It's such a feminist thing to do [laughs]. 
It's compassionate and just and all those good things that appeal to people who want to make the world a better place.

(CSA founder and ex-gardener, female)

It's part of the mothering instinct to want to have all these plants around; they're like children. My father in law is a farmer, or was a dairy farmer, and he has a lot of different business and farm experience. When he thinks about farming, he thinks fields. A field, or an acre of potatoes. A field of corn. They have a little garden in the back yard but he grows mostly corn, beans, squash, potatoes. He doesn't fiddle with the little vegetable, he's thinking big. Whereas I think the women are more willing to fiddle with the little vegetables... because we're the ones who cook with them. Guys just want their meat and potatoes. (Sole-operator, female)

Regardless of their perceptions of why and how women are involved in the CSA movement, both male and female growers take very seriously the task of reconnecting themselves and their members with nature.

\section{Reconnecting People with Nature}

Reestablishing the connection between humans and the land that sustains them is a common objective among CSA growers. Organic growers are often dedicated to encouraging a reconnection with natural processes and food production. Building on that, the biodynamic discourse espouses the belief that the land is the source of spiritual sustenance and that social problems are the result of the separation between humanity and its 'roots in nature' (Steiner 2005). The growers in this study are concerned not only with connecting their members to the land where their food is grown, but also with achieving a personal harmony with nature. The following narratives illustrate the variety of relationships that the growers enjoy with nature in their gardens:

I like to get my hands dirty. Being able to do something with my hands is really important; it's a really good balance with the computer stuff. What you're doing on a computer doesn't have texture; it's very flat and cold. I think that computers are a cold medium. To be out there growing, it's a 
balance thing; it's really good for your mental health. You're out there, you're on your knees in the dirt, it's real life, it's life that's out there.

(Joint-operator, female)

I really like growing things. I get into the plants. I get into talking to them and being with them. (Joint-operator, female)

Sometimes it's hard work. When you're in [nature] you don't realize it. But then you'll be walking down the field and you look up at the sky and it's blue and you realize that it smells like the trees and the earth and everything is so rich and you're living the life that you always wanted to. It's hard to appreciate every moment no matter where you are...And that's the richness. It's so rich on the farm when the abundance is in. And it's like we are the luckiest people in the world. (Joint-operator, male)

There's something really cool about putting something in the ground, seeing it grow, nurturing it. There's something about that process that's really cool. The seasonal changes are so highlighted. You really cherish the winter and you really feel the winter, like the relaxation and the downtime. You feel a lot more connected to the cycles because you live them everyday. It's an awakening to your senses. I think that part of farming is amazing. I just never felt that in the city. It's very different. (Joint-operator, female)

The growers are also very committed to educating their members about where their food comes from and the natural processes on the farm. By doing this, they believe that they are helping them to "grow and learn" and on a broader scale, "bringing out the culture in agriculture" (Ex sole-operator, female):

Agriculture is a forgotten dimension. I mean food just comes off the shelves from somewhere. It's a total convenience package. Most of the visions of living are erroneous. It's so taken for granted...In terms of civilization, agriculture is the one thing we can't do without. Virtually every other part of what composes our civilization is negotiable, but agriculture is not. Agriculture is what enables civilization. (Joint-operator, male)

A few of the growers also offer apprenticeships for people wanting to get hands-on market gardening and CSA experience. In addition, almost all of the growers in this study talked about how important it is to educate children, including their own, about agriculture and food production. The growers with children involve them as much as possible in the farm, 
teaching them about how to care for plants and animals. Two of the CSAs include a structured educational component: one is technically composed of 'teaching gardens' at a spiritual-environmental retreat centre and the other hosts Waldorf students completing the agricultural component of their studies. Building connections between children and nature surfaced as a key goal in the interviews:

I get really scared that we're in a society where children don't really know how things grow and they don't really know what a carrot looks like with a head on it. Carrots just come from a grocery store! I think there are a lot of problems with children not knowing about food. They can't make smart choices if they don't know, and there's no connection to it and they don't care because mom and dad buy it and they bring it home.

\section{(Joint-operator, female)}

I'm teaching them what a farm can be. So that the symbol in their minds when they think farm is happy cows, happy sheep, organic, laid back, natural. They don't automatically think machines, tractors, fertilizers, measuring pesticides - 'don't let it touch your hands!' I feel like I'm building a symbol in their minds of what a farm is. And that's powerful; changing someone's symbol. When we had the kids from the gleaning project out and this little boy said to me 'That's mint? You mean it grows? No you're kidding!' And I said, 'Just put it in your mouth' - 'No no! Okay, I'll put in my mouth.' It's a mint leaf - he couldn't believe it. He didn't get it. He had no idea that mint was a plant and the flavour came from a plant. It's not like it's just like gum! It's like gum is like mint! This is where mint comes from. This is where milk comes from - see those teats under there and if I have a calf I'll say look the calf is drinking the milk. And I'll show them chickens - 'You know where the eggs come from, they come out of the bums of the chickens' [laughs]. It's a lot of fun.

(Ex-sole operator, female)

Many CSAs ask or try to give incentive for the members to come out and be physically involved in the farm or actually make it mandatory that the member come out for at least one day in the season and give a hand with weeding or harvesting or whatever. To help them actually connect. It's creating that connection with where the food is coming from. Certainly our children are educated but I think you can go to a large city and ask the average school kid where their food comes from and they'll say the supermarket. 'Did you know that an egg comes out of a chicken's ass?' 'What?!' [laughs] 'I thought it came on a muffin with some bacon on it from McDonalds!' (Joint-operator, male) 
To these growers, this model of agriculture is not just sustainable in the sense of being ecologically sound, but also in the sense that it gives people a deeper respect for and connection to nature and the processes that create their food.

\section{Providing People with 'Real' Food}

Another factor that motivates the growers to commit to organic and biodynamic agriculture is their sense of responsibility for providing their families and the members of their CSA with 'real' food. They believe that by growing crops and raising animals in a manner that mimics nature as closely as possible, they are producing food that is more "true to its essence" and therefore more nutritious, healing and better-tasting. Biodynamic farmers understand the food that they grow as having vitality or a spiritual life force that is healing to humans who have become disconnected from nature. The growers in this study have a deep-rooted belief that organic and biodynamic foods are inherently healthier than conventional foods, especially when they are grown and eaten locally:

I feel that our food system is in deep trouble. The food that we ate on a regular basis before we were farmers - we were forced to shop at big box grocery stores - was seriously deplctcd of nutrients and not grown with our health in mind; not grown with the planet in mind. That's not a good thing for our bodies - we're all starving for nutrients. So I wanted to do something to help repair the soil and land and eat food that is grown in soil and land that has been healed and nourished. (Joint-operator, female)

The next grower gives agency to the vegetables when she alludes that they should be free

to pick and choose the nutrients that they need:

I don't want empty vegetables; I want my vegetables to have what they're actually supposed to have in them. I actually have a problem even with greenhouse tomatoes for that reason. They're spoon-fed whatever the grower chooses to feed them. I mean they're all hydroponically grown in these things and the nutrients that they get are all what the grower chooses to give them. They don't really have the opportunity to go out into the soil and find what they really want. (Sole-operator, female) 
Another shared sentiment, especially among the biodynamic growers, was that their vegetables provide spiritual as well as nutritional nourishment:

I'm not political, environmental for sure, but for me it's more a question of enjoyment of food. I think that health falls into that, but really it has to with good food. Good food is fresh food and it should be as fresh as possible. It also has more vitamins when it's fresh but the main thing for me is that it tastes better. It's a nourishing thing that's nourishing on so many more levels. It's not just the biology of eating good food, or eating healthy foodit's part of the whole being of a person, the health thing is big picture health. But food for me is the most important ingredient of big picture health. (Joint-operator, female)

The first day that I went out there and I started picking and I knew people were going to be eating my vegetables I was thrilled, I was jumping all over the place, it was so exciting, it was great. Food is the basic ingredient of life and we're out there, we're growing this basic ingredient with what nature has to offer us and delivering it right to people so they can eat it fresh, healthy and it doesn't just feed the body, it feeds the soul too.

(Joint-operator, female)

Although many consumers seek out CSA because they are looking for sources of fresh and organic local vegetables, all of the growers mentioned the general disconnection that people have from their food. This grower talked about this separation in terms of consumers not understanding how conventional foods are grown:

You know what is a really big seller for organic vegetables? When you advertise as chemical-free. People go 'Well, what do you mean there are chemicals on my food, what are you talking about?' 'Oh, you didn't know that your cucumbers were dipped in food-grade petroleum wax?' That's where the education part comes in too... When you say chemical-free it sets off more bells and whistles than just organic. Which I kind of like.

(Joint-operator, female)

Another brought up the need to bring food "back to the dinner table" and to take the time to cook and enjoy it with your loved ones; linking food with the cultural and social aspects of cooking and eating: 
I think really the stumbling block may be that people don't cook enough. People don't know how to cook food. They go to the supermarket and eveything is done for them. It's so simple. You've done your day's work, you're tired, you've got to go and deal with the kids and take them to their evening activities. Dinner has to be fast. We've lost touch with that nourishing part - the importance of food as it fits in with family life except for with people who recognize now that there's something missing. (Sole-operator, female)

A few of the growers offer tools to 'reskill' their members such as information about the produce they receive, how it should be stored to maintain freshness and suggested recipes. Merely being a member of a CSA requires a certain level of commitment to investing more time and energy into food preparing or preserving the vegetables that are delivered; however the growers often go above and beyond what is expected of them in terms of educating their members about the food that they grow.

\section{Mobilizing Discourses of 'Nature'}

Fetishized discourses of the 'natural' are common to the CSA movement; however these constructions are complex, and vary from grower to grower. In regards to the sustainable agriculture movement as a whole, Allen (2004: 137) describes discourses of agriculture manifested as having the tendency of being "infused with environmentalist perspectives and approaches, particularly the privileging and essentializing of nature" (Allen 2004: 137). While some of the growers describe a reverence for the natural world that suggests that nature has inherent rights that are as, if not more, important than those of humans, others have a more holistic approach, in which they see themselves as part of the natural processes on the farm, protecting and enhancing the natural resources that they rely on for food production. These growers envision the nature on the farm as a "mediated" rather than "pristine" nature (Goodman 1999). A good example of this is the way in which 
one grower responds to vegetarian members who object to the fact that her CSA is located on a beef farm:

What, would you rather the compost to come from expensive pets? I mean it's gotta [sic] come from somewhere. You can't just have cows to scratch behind the ears, I mean they eat! It's just the world of farming; it's a circle, all of a sudden you'd have 300 head of cows. You have to maintain the population, we've domesticated them - so we're involved.

(Sole-operator, female)

The growers in this study understand livestock as being part of the farm ecosystem that they manage and distinguish domesticated animals (mediated nature) from wild animals (pristine nature). The same can be said for the vegetables and herbs that they cultivate, the majority of which are not native to the Ottawa area and have been selected and bred for specific characteristics.

This blurring of the boundaries between the natural and the social influences how the growers see their roles as caretakers of the land and their responsibility to facilitate the (re)connection between humans and nature. They draw on particular discourses of nature to further their own knowledge of ecological processes and to educate others about the CSA movement as a more ecological alternative to the conventional agrifood system. The nuanced ways in which they use 'nature' to define what is good about CSA and bad about the conventional agrifood system, suggests that they are well aware of their agency in 'constructing' nature. In particular, the CSA movement mobilizes discourses of the 'natural' in its project of decommodifying food:

These practices of decommodification imbue CSA food with romanticized meanings, transforming it into a symbol of natural splendor and ecological harmony. In the CSA context, however, practices of decommodification are also situated in a broader ideological agenda: defying the commodity fetishism that has become institutionalized in many quarters of agribusiness and fast food industries. (Thompson and Coskuner-Balli 2007: 144) 
Goodman (1999) refers to this as the "biopolitics" of food. He explains that alternative agrifood movements outside of the established conventional agrifood hegemony employ food as "a signifier for political, social, and ecological struggles that are otherwise easily ignored" and that such a vision of agriculture and food "directly subverts the modernist dichotomy of nature/society" (ibid. 1999: 32). In this sense, the CSA movement in the Ottawa area can be seen as working toward building a more moral community that bridges the division between nature and society through its emphasis on the connections between growing and eating food. 


\section{Chapter 7: Conclusion}

The CSA movement arose in North America in the 1980s out of a consumer and producer-driven demand for an alternative to an increasingly industrialized and globalized agrifood economy. The CSA model allows growers and eaters alike to contribute to and participate in a community-based, associative agrifood system based on ecologically and socially-just ideals and practices. This case study, based on in-depth interviews with 14 CSA growers in the Ottawa area, reveals how the motivations, beliefs and experiences of the growers shape how they envision a (re)localized agrifood economy. Through their goals of offering a more 'natural' choice for food consumers, educating their members about the environmental, health, cultural and social impacts of agriculture and food, and rebuilding the connection not only between farmers and consumers, but between individual community members and the places that bring them together, the growers are able to gain a sense of agency and control over shaping the future of the agrifood system in the region.

In this thesis, I have drawn on concepts from political ecology and social nature to examine how the CSA movement engages with discourses of 'nature' and the 'local' in its struggle to forge new spaces in the agrifood system and encourage new relationships between people, food and the land. I offer an in-depth examination of how, as a placebased social movement, CSA has the potential to influence change in the ways in which farmers and consumers interact in local agrifood systems and relate to local ecologies. In doing this, I explore the discourses shaping the practices and politics of CSA growers, as well as the material obstacles that they face, with the hope of illuminating ways in which the growers are fulfilling their objectives and where the movement may fail in understanding the actual extent of the change needed to realize its broader goals. 
The neoliberal restructuring of national agrifood systems and the increased dependence on corporate-controlled global markets has led the participants in this study to tum to localization as a means of creating spaces for new agrifood economies, offering up alternative networks and markets for farmers and consumers, and revitalizing rural communities. The resulting discourses of the local are both political and practical. While CSA is a way of strengthening local food systems and thus reduces the environmental and economic effects of food miles, it also encourages community-building and is premised on the creation of direct, trust-based relationships between growers and consumers. The growers give moral value to building an associative agrifood model and to encouraging and teaching people to regain power by controlling how, where, and by whom their food is produced. By (re)embedding food production and consumption in specific locales, the growers endeavour to bring their members into a closer relationship with the people around them and the place where their food is grown.

The participants in this study work toward creating local agrifood systems that challenge and contest the effects of neoliberalization and globalization. Yet, rather than acting defensively against the broader system, the growers recognize that they are not confined by it and believe that their resistance can be effective at the local level. Kevin Morgan et al. (2006:17) likewise caution that "we must balance any celebration of localized natures and cultures against a recognition that processes of industrialization and standardization continue to unfold." This does not mean, however, that the local cannot offer up spaces of resistance to these global processes for those affected by them, but rather that both the local and the global are mutually constituted by what the other is not and that one can never be completely subsumed by the other. 
This study also reveals how the participants construct specific discourses of nature that are based on a deep respect for and understanding of local ecosystems and natural processes. By practicing organic and biodynamic agriculture, the growers offer an alternative to what they believe to be the environmentally-destructive effects of the conventional industrialized agrifood system. To them, it is imperative to preserve, and ideally enhance, the natural resources that they are using to grow food, and seek to embrace, rather than overcome, the restrictions of nature and the seasons. The growers envision their farms and gardens as dynamic, living systems that require them, as caretakers of these systems, to be highly skilled, observant, and knowledgeable of specific ecosystems. In return for the care that they give the land, the growers, and their members, gain a way of reconnecting with nature and food production.

The nuanced ways in which they mobilize discourses of nature to both critique conventional agricultural practices and the commodification of food and support CSA as an alternative, suggests that the growers are aware of their agency in constructing 'nature'. By emphasizing the connection between growing and eating food, or putting the "culture" back into "agriculture", as one participant worded it, the growers in the Ottawa area are effectively bridging the nature-society dichotomy.

By creating new economic and social opportunities for themselves, as well as their members, the CSA growers in this case study are, in the words of Morgan et al. (2006), creating an "alternative geography of food". That being said, this research contributes to the broader field of agrifood studies and its recent turn to a more detailed exploration of alternative agrifood initiatives. Specifically, this thesis offers an analysis of the complex ways in which the CSA movement defines the natural and the social and the global and the 
local and how the mobilization of these discourses enables the movement to gain placebased power in the face of the larger globalized agrifood system. In addition, this research also adds to broader work in human geography and political ecology by providing an indepth case study of CSA with a Canadian, or, as McCarthy (2002) suggests, "first world" perspective of the philosophical and practical development of a social movement. By examining the diverse experiences that motivate the growers to embrace this alternative model of agriculture and exploring the multiple ways in which they engage with their surrounding ecologies, communities and each other, I hope to offer a "nuanced, richly textured empirical work... which matches the nuanced believes and practices of the world" (Peet and Watts 1996: 38).

The CSA movement in the Ottawa area is still early in its development, but it is growing quickly as more and more urban consumers seek out local sources of organic and biodynamic produce. As shown in this case study, a new generation of growers is increasingly drawn to this model of direct selling that makes a rural lifestyle and smallscale ecological market gardening an economically feasible option. Drawing on the experiences of the participants in this study, I believe that the future for CSA in the Ottawa area is optimistic. While a few of the CSAs are experiencing growing pains in terms of accessing land and making their operations financially viable, there is no lack of consumer, or grower, interest in this new agrifood model. I would, however, like to offer a fcw cautionary observations relating to the growers' success in putting into practice the movement's goals of strengthening community ties and connecting people to specific places and ecologies. 
Guthman (2003) and Renting et al. (2003) warn that food consumption is becoming increasingly intertwined with different lifestyles and that the detection and appreciation of 'quality' food is largely mediated by culture and class. In Guthman's exploration of the evolution of organic food she concludes that the success of the organic industry is "largely wrapped up with gentrification - and the class differentiation that necessarily entailed" (2003: 47). This is also suggested by the CSA growers in this study, who believe that the commercialization and industrialization that have resulted from the organic food "trend" represents a disconnection from the meanings that the organic farming movement originally embodied. The increasing demand and willingness to pay a premium for local foods that are organic, biodynamic, free-range and "natural" also affects the type of consumer who is drawn to CSA as an alternative way of sourcing these foods. This is manifested in the growers' difficulties in attracting members from a diverse range of cultural and socio-economic backgrounds. This is also related to the concern that a few of the growers share regarding the blurring of the distinction between subscription farming, or food box programs, and CSA, as consumers seek out convenience in accessing these foods rather than a reconnection with agriculture and community. An in-depth case study of CSA members in the Ottawa area would be needed to more fully understand any similarities and contradictions between the motivations and discourses of the growers and the members and how they affect the growth and success of the movement.

Interestingly enough, many of the participants also expressed that they felt quite isolated from other growers and that prior to this study were unaware of other CSAs operating in the area. Recently, efforts by Just Food, a local food security group, have brought together CSA growers and people interested in CSA in a series of workshops. 
They also work to connect interested consumers with CSAs seeking new members. For many, these activities and networking events were the first time that they met the other Ottawa growers. As these participants explained, building connections with other farmers is extremely important:

It's important for a CSA-type person to avail themselves to whatever is available to them. If I see someone that is growing something better than I am, I'll ask them how they've done that and most people are prepared to share their knowledge with you and that works really, really well. Learning is a never-ending thing. (Joint-operator, male)

People are very generous with their knowledge - everybody loves to give advice on gardening [laughs]. We had a farm tour here last summer and it was hard for me because here we had all these people coming to see the garden and I don't know much about gardening. I got a lot of compliments on some things but people weren't shy at all about telling me what I was doing wrong, which was great. (Joint-operator, female)

These growers understand the value of networking and sharing ideas, frustrations and experiences with others who work in similar climate and ecological zoncs, draw from the same membership population and face common everyday challenges. This engagement with other growers will hopefully provide the movement in the Ottawa area with the stability and resources that it needs to continue and develop.

The discourses and farming practices of the growers in this study present a vision of agriculture in which nature and society interact in mutually beneficial ways to reconnect people with the land and create nutritious, spiritually healing and culturally rich foods that, in the words of one grower, "taste like where you are from" (Joint-operator, female). However, some scholars warn that developing an alternative agrifood movement that works toward social, economic and environmental justice requires a coherent vision based on a nuanced understanding of the complexities and contradictions of the conventional system. Allen explains that: 
This requires an interrogation of the degree to which the contemporary food and agriculture problems can be solved without examining and changing some existing social and economic relations. Systemic problems require systemic solutions, a basic tenet of the heuristic approach of political ecology $(2004: 210)$.

For CSA to truly be a more equitable alternative to the conventional agrifood system, the movement needs to critically address questions of who is included and who is left out of its vision of community and the local and to consider appropriate solutions to issues of accessibility and social and economic exclusion. In order to "transcend particularities, and arrive at some conception of a universal alternative to that social system which is the source of their difficulties" (Harvey 2000, quoted in Allen 2004: 209), the CSA movement needs to effectively connect food and agricultural problems with social and environmental issues in ways that the average consumer can understand. While local agrifood initiatives such as CSA cannot be expected to replace the globalized agrifood system, they supplement and offer alternatives to conventional agrifood chains in important ways. By creating spaces in their own small plots and gardens where people can reconnect food to both the land where it was grown and the hands that tended to it, the CSA growers in the Ottawa area are building the beginnings of a new agrifood system based on an increased awareness and consciousness of the interconnectedness of nature and society and the global and the local. 


\section{Bibliography}

Abu-Lughod, Lila. 1993. Writing Women's Worlds: Bedouin Stories. Berkley and Los Angeles: University of California Press.

Allen, Patricia. 1999. Reweaving the food security safety net: Mediating entitlement and entrepreneurship. Agriculture and Human Values 16: 117-129.

Allen, Patricia. 2004. Together at the table: Sustainability and Sustenance in the American Agrifood System. University Park: Pennsylvania State University Press.

Allen, Patricia, Margaret FitzSimmons, Michael Goodman and Keith Warner. 2003. Shifting plates in the agrifood landscape: the tectonics of alternative agrifood initiatives in California. Journal of Rural Studies 19: 61-75.

Barron, Jennifer. 2000. In the name of solidarity: the politics of representation and articulation in support of the Labrador Innu. Capitalism, Nature, Socialism 11(3): $87-112$.

Bell, David and Gill Valentine. 1997. Consuming geographies: We are where we eat. London: Routledge.

Berry, Wendell. 1996. Conserving Communities. In: William Vitek and Wes Jackson (eds.) Rooted in the Land: Essays on community and place. New Haven and London: Yale University Press.

Biodynamic Farming and Gardening Association website: http://www.biodynamics.com/

Blaikie, Piers. 1985. The political economy of soil erosion. London: Longman.

Blaikie, Piers and Harold C. Brookfield (eds.). 1987. Land degradation and society. London: Methuen.

Braun, Bruce. 2005. Environmental issues: writing a more than human urban geography. Progress in Human Geography 29(5): 635-650.

Braun, Bruce and Noel Castree. 1998. Remaking reality: nature at the millennium. London and New York: Routledge. 
Bryant, Raymond L. 1998. Power, knowledge and political ecology in the third world: a review. Progress in Physical Geography 22(1): 79-94.

Bryant, Raymond L. 2001. Political Ecology: A Critical Agenda for Change? In: Noel Castree and Bruce Braun (eds.) Social Nature: Theory, Practice, and Politics. Malden, MA: Blackwell.

Bryant, Raymond, and L. Sinead Bailey. 1997. Third World Political Ecology. New York: Routledge Press.

Bryant, Raymond L. and David Goodman. 2004. Consuming narratives: The political ecology of 'alternative' consumption. Transactions of the Institute of British Geographers 29 (3): 344-366.

Butler, Judith. 1992. Contingent Foundations: Feminism and the Question of "Postmodernism." In: Judith Butler and Joan Scott (eds.), Feminists Theorize the Political. New York: Routledge.

Castree, Noel. 2001. Socializing Nature: Theory, Practice, and Politics. In: Noel Castree and Bruce Braun (eds.). Social Nature: Theory, Practice, and Politics. Malden, MA: Blackwell.

Castree, Noel. 2004. Differential geographies: place, indigenous rights and 'local' resources. Political Geography 23: 133-167.

Castree, Noel. 2005. The epistemology of particulars: Human geography, case studies and 'context'. Geoforum 36: 541-544.

Castree, Noel and Bruce Braun. 1998. The Construction of Nature and the Nature of Construction: Analytical and Political Tools for Building Survivable Futures. In: Bruce Braun and Noel Castree (eds.). Remaking Reality: Nature at the Millennium. New York and London: Routledge.

Castree, Noel and Bruce Braun (eds.). 2001. Social Nature: Theory, practice and politics. Malden, MA: Blackwell.

Cronon, William (ed.). 1995. Uncommon Ground: Remaking the Human Place in Nature. New York: Norton.

City of Ottawa. 2001. Food Security in Ottawa: A community profile. Report by People Services Department and the Ottawa Food Security Group. Available online at: http://www.perc.ca/library/resources/food/food-security/index.cn.html 
City of Ottawa Website - Quick Facts about Ottawa:

http://www.ottawa.ca/city_hall/glance/business_en.html (accessed September 2007).

City of Ottawa. 2003. Ottawa 20/20 Economic Strategy. Available online: http://ottawa.ca/city_services/planningzoning/2020/es/appen2_en.shtml

Cone, Cynthia A. and Ann Kakaliouras. 1995. Community Supported Agriculture: Building moral community or an alternative consumer choice? Culture and Agriculture 51/52: 28-31.

Cone, Cynthia A. and Andrea Myhre. 2000. Community-supported Agriculture: A sustainable alternative to industrial agriculture? Human Organization 59(2): 187-197.

Cooley, Jack P. and Daniel A. Lass. 1998. Consumer Benefits from Community Supported Agriculture Membership. Review of Agricultural Economics 20(1): 227-237.

Cotterill, Pamela. 1992. Interviewing Women: Issues of Friendship, Vulnerability and Power. Women's Studies International Forum 15(5/6): 593-606.

Courtney, Hugh. 2005. So that the Earth may be healed. In: Rudolph Steiner What is Biodynamics? A way to heal and revitalize the Earth. Great Barrington: Steiner Books.

Cronon, William (ed.). 1996. Uncommon Ground: Remaking the Human Place in Nature. New York: Norton.

DeLind, Laura B. 1999. Close encounters with a CSA: The reflections of a bruised and somewhat wiser anthropologist. Agriculture and Human Values 16: 3-9.

DeLind, Laura B. 2002. Place, work, and civic agriculture: Common fields for cultivation. Agriculture and Human Values 19: 217-224.

DeLind, Laura B. and Anne E. Ferguson. 1999. Is this a women's movement? The relationship of gender to community supported agriculture in Michigan. Human Organization 58(2): 190-199.

DuPuis, E. Melanie and David Goodman. 2005. Should we go "home" to eat?: Toward a reflexive politics of localism. Journal of Rural Studies 21:359-371. 
DuPuis, E. Melanie, David Goodman and Jill Harrison. 2006. Just values or just value? Remaking the local in agro-food studies. In: Terry Marsden and Jonathon Murdoch (eds.) Between the local and the global: Confronting complexity in the contemporary agri-food sector. Oxford: Elsevier.

Dwyer, Claire and Melanie Limb. 2001. Introduction: Doing qualitative research in geography. In: Melanie Limb and Claire Dwyer (eds.) Qualitative Methodologies for Geographers: Issues and Debates. London: Arnold.

Dyck, Bruno. 1994. Build in sustainable development and they will come: A vegetable field of dreams. Journal of Organizational Change 7(4): 47-63.

Escobar, Arturo. 1992. Culture, economics, and politics in Latin American social movements. In: Arturo Escobar and S.E. Alvarez (eds.) The making of social movements in Latin America. Boulder: Westview Press.

Escobar, Arturo. 1996. Constructing Nature: Elements for a Poststructuralist Political Ecology. In: Richard Peet and Michael Watts (eds.). Liberation Ecologies: Environment, Development, Social Movements. London and New York: Routledge.

Escobar, Arturo. 1999. After Nature: Steps to an Antiessentialist Political Ecology. Current Anthropology 40(1): 1-30.

Falconer Al-Hindi, Karen and Hope Kawabata. 2002. Toward a more reflexive feminist geography. In: Pamela Moss (ed.) Feminist Geography in Practice. Oxford: Blackwell Publishers Ltd.

Feagan, Robert. 2007. The Place of Food: Mapping out the 'local' in local food systems. Progress in Human Geography 31(1): 23-42.

Feenstra, Gail W. 1997. Local food systems and sustainable communities. American Journal of Alternative Agriculture 12(1): 28-36.

Fieldhouse, Paul. 1996. Community Shared Agriculture. Agriculture and Human Values 13(3): 43-47.

Flax, Jane. 1992. The end of innocence. In: Judith Butler and Joan Scott (eds.) Feminists theorize the political. New York: Routledge. 
Freidberg, Susanne. 2004. French beans and food scares: Culture and commerce in an anxious age. Oxford and New York: Oxford University Press.

Friedmann, Harriet. 1993. The political economy of food. New Left Review 197: 29 57.

Gibson-Graham, J.K. 1994. 'Stuffed if I know': Reflections on post-modern feminist social research. Gender, Place and Culture 1(2):205-224.

Gibson-Graham, J.K. 2003. An ethies of the local. Rethinking Marxism 15(1): 49-74.

Goodman, David. 1999. Agro-Food Studies in the 'Age of Ecology': Nature, Corporeality, Bio-Politics. Sociologica Ruralis 39(1): 17-38.

Goodman, David. 2004. Rural Europe Redux? Reflections on alternative agro-food networks and paradigm change. Sociologia Ruralis 44(1): 3-16.

Goodman, David and Michael Redclift. 1991. Refashioning Nature. London: Routledge.

Goodman, David and Michael Watts (eds.). 1997. Globalising Food: Agrarian questions and global restructuring. London and New York: Routledge.

Gregson, Nicky and Gillian Rose. 2000. Taking Butler elsewhere: Performativities, spatialities and subjectivities. Environment and Planning D: Society and Space 18: 433-452.

Groh, Trauger and Steven S.H. McFadden. 1997. Farms of Tomorrow Revisited. Kimberton PA: Biodynamic Farming and Gardening Association.

Guthman, Julie. 2003. Fast food/organic food: reflexive tastes and the making of 'yuppie chow'. Social and Cultural Geography 4 (1): 45-58.

Guthman, Julie. 2007. The Polanyian way? Voluntary food labels as neoliberal governance. Antipode 39(3): 456-478.

Haraway, Donna. 1991. Simians, cyborgs, and women: the reinvention of nature. New York: Routledge.

Hart, Gillian. 2004. Geography and development: critical ethnographies. Progress in Human Geography 28(1): 91-100. 
Harvey, David. 1996. Justice, nature and the geography of difference. Oxford: Blackwell.

Harvey, David. 2000. Spaces of Hope. Berkeley and Los Angeles: University of California Press.

Hashimoto, Shinji. 2000. Teikei system: An alternative marketing system in Japan. Ecology and Farming 23: 9-11.

Henderson, Elizabeth. 1999. Sharing the Harvest: A Guide to Community Supported Agriculture. Chelsea Green Publishing Company, White River Junction: Vermont.

Hendrickson, Mary K. and William D. Heffernan. 2002. Opening spaces through relocalization: Locating potential resistance in the weaknesses of the global food system. Sociologia Ruralis 42 (4): 347-369.

Hinrichs, C. Clare. 2000. Embeddedness and local food systems: Notes on two types of direct agricultural market. Journal of Rural Studies 16: 295-303.

Hinrichs, C. Clare. 2003. The practice and politics of food system localization. Journal of Rural Studies 19: 33-45.

Hoggart, Keith, Loretta Lees and Anna Davies. 2002. Researching Human Geography. New York: Oxford University Press.

Holloway, Lewis and Moya Kneafsey. 2000. Reading the Space of the Farmers' Market: A preliminary investigation from the UK. Sociologia Ruralis 40(3): 285-299.

Ilbery, Brian, and Moya Kneafsey. 2000. Registering regional specialty food and drink products in the UK: The case of PDOs and PGIs. Area 32(3): 317-325.

Imhoff, Daniel. 1996. Community Supported Agriculture: Farming with a face on it. In: Jerry Mander and Edward Goldsmith (eds.) The case against the global economy. San Francisco: Sierra Club Books.

Jaffe, JoAnn and Michael Gertler. 2006. Victual vicissitudes: Consumer deskilling and the (gendered) transformation of food systems. Agriculture and Human Values 23: 143-162. 
Japan Organic Agriculture Association website: www.joaa.net/English/teikei.htm (accessed 9/28/2007).

Jarosz, Lucy. 2000. Understanding agri-food networks as social relations. Agriculture and Human Values 17: 279-283.

Johnston, Josée and Lauren Baker. 2005. Eating outside the box: FoodShare's good food box and the challenge of scale. Agriculture and Human Values 22: 313 325.

Johnston, R.J., Derek Gregory, Geraldine Pratt and Michael Watts (eds.). 2000. The Dictionary of Human Geography, $t^{\text {th }}$ Edition. Malden and Oxford: Blackwell Publishing.

Kittredge, Jack. 1996. Community-supported agriculture: rediscovering community. In: William Vitek and Wes Jackson (eds.) Rooted in the Land: Essays on Community and Place. New Haven and London: Yale University Press.

Kloppenburg, Jack, John Hendrickson and G.W. Stevenson. 1996. Coming into the Foodshed. Agriculture and Human Values 13(3): 33-42.

Kneen, Brewster. 1995. CSA Roots in Japan. In Context, 42. Available online at: http://www.context.org/ICLIB/IC42/VanEn.htm

Kobayashi, Audrey. 2001. Negotiating the personal and the political in critical qualitative research. In: Melanie Limb and Claire Dwyer (eds.) Qualitative Methodologies for Geographers: Issues and Debates. London: Arnold.

Kolodinsky, Jane M. and Leslie L. Pelch. 1997. Factors influencing the decision to join a community supported agriculture (CSA) farm. Journal of Sustainable Agriculture 10(2/3): 129-141.

Lass, Daniel et al. 2003. CSA Across the Nation: Findings from the 1999 CSA Survey. Madison: Centre for Integrated Agricultural Systems.

Lea, Emma, Jodi Phillips, Madeleine Ward and Anthony Worsley. 2006. Farmers' and consumers' beliefs about community-supported agriculture in Australia: a qualitative study. Ecology of Food and Nutrition 45: 61-86.

Lefebvre, Henri. 1991. The Production of Space. Oxford: Blackwell. 
Mackenzie, A. Fiona D. 1998. Land, Ecology and Resistance in Kenya, 1880-1952. Edinburgh: Edinburgh University Press.

Marsden, Terry and Jonathon Murdoch (eds.). 2006. Between the local and the global: Confronting complexity in the contemporary agri-food sector. Oxford: Elsevier.

Massey, Doreen. 1992. Politics and Space/Time. New Left Review 1(196): 65-84.

Massey, Doreen. 2004. Geographies of Responsibility. Geografiska annaler 86B(1): $5-18$.

MacAdam, Murray. 2002. From the roots up. Sustainable Times Webzine available online: htp://www.sustainabletimes.ca/articles/CSAfarms.htm.

McCarthy, James. 2002. First World Political Ecology: Lessons from the Wise Use Movement. Environment and Planning A 34: 1281-1302.

McCarthy, James and Scott Prudham. 2004. Neoliberal nature and the nature of neoliberalism. Geoforum 35: 275-283.

McMichael, Philip. 2000. The power of food. Agriculture and Human Values 17: 21-33.

Mbilinyi, M. 1989. "I'd Have Been a Man": Politics and the Labor Process in Producing Personal Narratives. In: Personal Narratives Group (ed.) Interpreting Women's Lives. Bloomington: Indiana University Press.

Moekli, Jane and Bruce Braun. 2001. Gendered Natures. In: Noel Castree and Bruce Braun (eds.) Social Nature: theory, practice and politics. Oxford: Blackwell Publishers.

Morgan, Kevin, Terry Marsden, and Jonathan Murdoch. 2006. Worlds of Food: Place, Power, and Provenance in the Food Chain. Oxford Geographical and Environmental Studies: Oxford University Press.

Murdoch, Jonathan and Mara Miele. 1999. 'Back to nature': Changing 'worlds of production' in the food sector. Sociologia Ruralis 39(4): 465-483.

Murdoch, Jonathan, Terry Marsden and Jo Banks. 2000. Quality, Nature, and Embeddedness: Some Theoretical Considerations in the Context of the Food Sector. Economic Geography 76 (2): 107-125. 
Neumann, Roderick. 1998. Imposing Wilderness: Struggles over Livelihood and nature Preservation in Africa. Berkeley: University of California Press.

Norberg-Hodge, Helena, Todd Merrifield and Steve Gorelick. 2002. Bringing the Food Economy Home: Local Alternatives to Global Agribusinesses. London: Zed Books.

O'Hara, Sabine U. and Sigrid Stagl. 2001.Global Food Markets and their Local Alternatives: A Socio-Ecological Economic Perspective. Population and Environment 22 (6): 533-554.

Paulson, Susan, Lisa L. Gezon, and Michael Watts. 2003. Locating the Political in Political Ecology: An Introduction. Human Organization 62(3): 205-217.

Peet, Richard and Michael Watts. 1996. Liberation Ecology: Development, Sustainability, and Environment in an Age of Market Triumphalism. In: Richard Peet and Michael Watts (eds.). Liberation Ecologies: Environment, Development, Social Movements. London and New York: Routledge.

Peet, Richard and Michael Watts (eds.). 2004. Liberation Ecologies: Environment, development, social movements, $2^{\text {nd }}$ Edition. London and New York: Routledge.

Pretty, Jules. 1999. The living land: agriculture, food and community regeneration in the $21^{\text {st }}$ century. London: Earthscan.

Qazi, Joan A. and Theresa, L. Selfa. 2005. The Politics of Building Allernative AgroFood Networks in the Belly of Agro-industry. Food. Culture \& Society 8 (1): 45-72.

Renting, Henk, Terry K. Marsden and Jo Banks. 2003. Understanding alternative food networks: exploring the role of short food supply chains in rural development. Environment and Planning A, 35: 393-411.

Robbins, Paul. 2004. Political Ecology: A Critical Introduction. New York: Routledge.

Robyn Van En Centre website: www.csacentre.org 
Rocheleau, Dianne, Barbara Thomas-Slayter, and Esther Wangari (eds.). 1996. Feminist Political Ecology: Global Issues and Local Experiences. London and New York: Routledge.

Rose, Gillian. 1997. Situating knowledges: positionality, reflexivities and other tactics. Progress in Human Geography 21(3): 305-320.

Rose, Gillian. 2001. Visual Methodologies. London: Sage.

Ross, Nancy J. 2006. How civic is it? Success stories in locally focused agriculture in Maine. Renewable Agriculture and Food Systems 21(2): 114-123.

Samson, Roger. 1994. Putting the culture back into agriculture. Sustainable Farming (Spring edition), available online: http://www.eap.mcgill.ca/MagRack/SF/Spring\%2094\%20E.htm .

Selfa, Theresa and Joan Qazi. 2005. Place, taste, or face-to-face? Understanding producer-consumer networks in "local" food systems in Washington State. Agriculture and Human Values 22: 451-464.

Schroeder, Richard A. 1996. "Gone to their Second Husbands": Marital Metaphors and Conjugal Contracts in The Gambia's Female Garden Sector. Canadian Journal of African Studies 30(1): 520-548.

Sharp, Jeff, Eric Imerman, and Greg Peters. 2002. Community Supported Agriculture (CSA): Building Community among Farmers and Non-farmers. Journal of Extension, 40 (June). Available online:litp://www.joe.org/joe/2002june/a3.html.

Smith, S. 2001. Doing qualitative research: from interpretation to action. In: Melanie Limb and Claire Dwyer (eds.) Qualitative Methodologies for Geographers: Issues and Debates. London: Arnold.

Steiner, Rudolph. 2005. What is Biodynamics? A way to heal and revilalize the Earth. Great Barrington: Steiner Books.

Swyngedouw, Erik. 1997. Neither Global nor Local: "Glocalization" and the politics of scale. In: Kevin R. Cox (ed.) Spaces of Globalization: Reasserting the power of the local. The Guilford Press.

Thompson, Craig J. and Gokcen Coskuner-Balli. 2007. Countervailing Market Responses to Corporate Co-optation and the Ideological Recruitment of Consumption Communities. Journal of Consumer Research 34: 135-152. 
Trauger, Amy. 2004. 'Because they can do the work': women farmers in sustainable agriculture in Pennsylvania, USA. Gender, Place and Culture 11(2): 289 307.

Valentine, G. 2001. At the drawing board: developing a research design. In: Melanie Limb and Claire Dwyer (eds.) Qualitative Methodologies for Geographers: Issues and Debates. London: Arnold.

Van En, Robyn. 1995. Eating for your Community. In Context 42. Available online: http://www.context.org/ICLIB/IC42/VanEn.htm

Vayda, Andrew P. and Bradley B. Walters. 1999. Against Political Ecology. Human Ecology 27(1): 167-179.

Venn, Laura, Moya Kneafsey, Lewis Holloway, Rosie Cox, Elizabeth Dowler and Helen Tuomainen. 2006. Researching European 'alternative' food networks: some methodological considerations. Area 38(3): 248-258.

Vos, Timothy. 2000. Visions of the middle landscape: Organic farming and the politics of nature. Agriculture and Human Values 17: 245-256.

Walker, Peter A. 2005. Political Ecology: Where is the Ecology? Progress in Human Geography 29(1): 73-82.

Watts, D. H. C, B. Ilbery and D. Maye. 2005. Making reconnections in agro-food geography: alternative systems of food provision. Progress in Human Geography, 29(1): 22-40.

Watts, Michael and Richard Peet. 2004. Liberating Political Ecology. In: Richard Peet and Michael Watts (eds.) Liberation Ecologies: Environment, development, social movements, $2^{\text {nd }}$ Edition. London \& New York: Routledge.

Wells, Betty, Shelly Gradwell and Rhonda Yoder. 1999. Growing food, growing community: Community supported agriculture in rural Iowa. Community Development Journal 34(1): 38-46.

Wells, Betty L. and Shelly Gradwell. 2001. Gender and resource management: Community supported agriculture as caring-practice. Agriculture and Human Values 18: 107-119. 
Whatmore, Sarah. 2002. Hybrid Geographies: natures, cultures, spaces. London: Sage Publications.

Whatmore, Sarah and Lorraine Thorne. 1997. Nourishing Networks: Alternative geographies of food. In: David Goodman and Michael Watts (eds.) Globalizing food: Agrarian questions and global restructuring. New York: Routledge.

Whatmore, Sarah, Pierre Stassart and Henk Renting. 2003. Guest Editorial. Environment and Planning A 35: 389-391.

Winson, Anthony. 1993. The Intimate Commodity. Toronto: Garamond Press.

Winter, Michael. 2003a. Embeddedness, the new food economy and defensive localism. Journal of Rural Studies 19: 23-32.

Winter, Michael. 2003b. Geographies of food: agro-food geographies- making reconnections. Progress in Human Geography 27(4): 505-513.

Winter, Michael. 2005. Geographies of food: agro-food geographies - food, nature, farmers and agency. Progress in Human Geography 29(5): 609-617.

Worden, Eva C. 2004. Grower Perspectives in Community Supported Agriculture. HorTechnology 14(3): 322-325. 


\begin{tabular}{|c|c|c|c|c|c|c|c|c|c|c|c|c|c|c|}
\hline 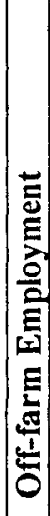 & 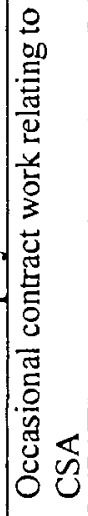 & 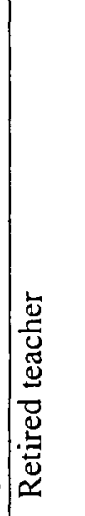 & 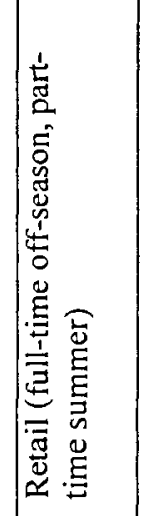 & 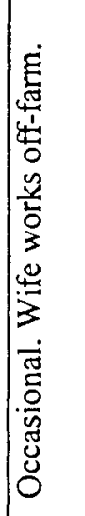 & 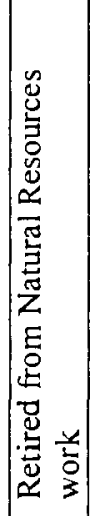 & 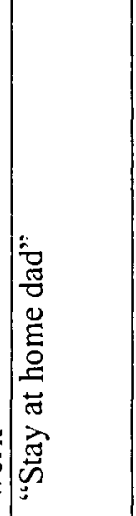 & 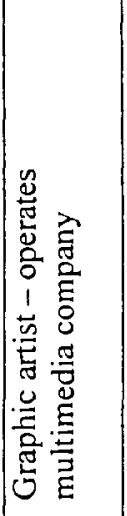 & $z$ & 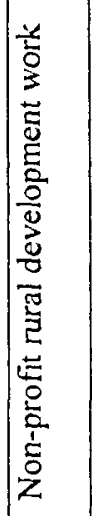 & 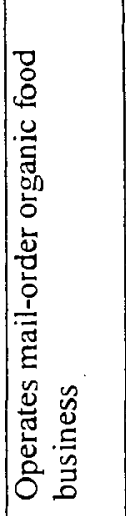 & 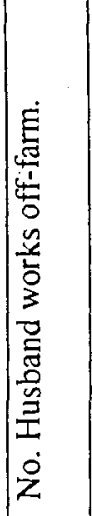 & 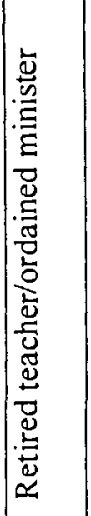 & 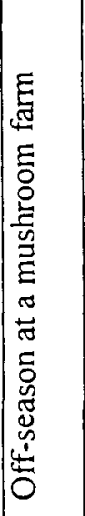 & 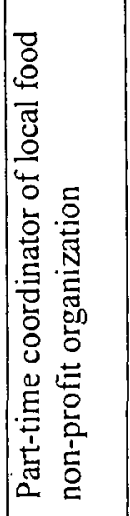 \\
\hline 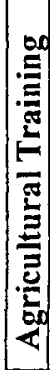 & 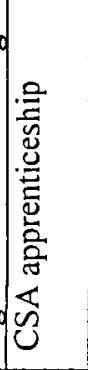 & z & 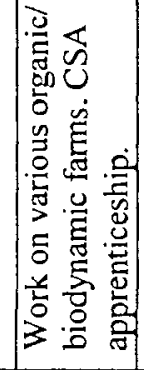 & & 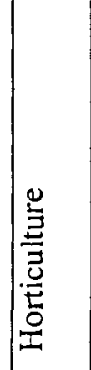 & 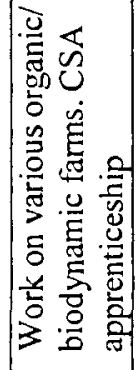 & 2웅 & 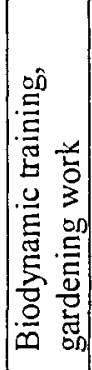 & 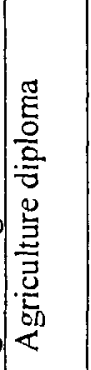 & $\not z$ & $\not 2$ & 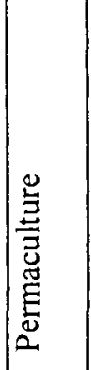 & 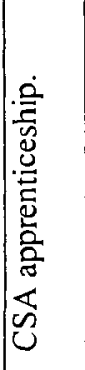 & 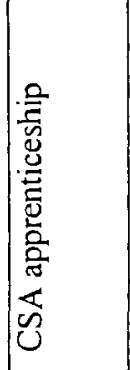 \\
\hline 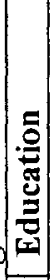 & 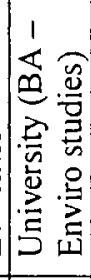 & 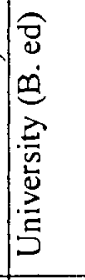 & \begin{tabular}{|l} 
\\
$\frac{5}{3}$ \\
0 \\
$\frac{5}{5}$ \\
5 \\
\end{tabular} & 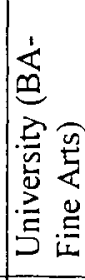 & 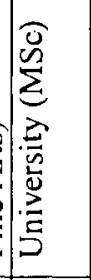 & $\begin{array}{l}5 \\
3 \\
0 \\
5 \\
5 \\
5 \\
\end{array}$ & 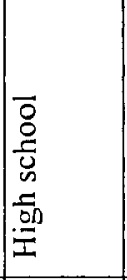 & 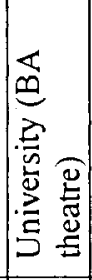 & 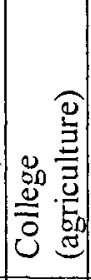 & 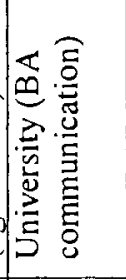 & 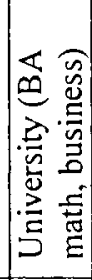 & $\begin{array}{l}5 \\
5 \\
0 \\
5 \\
5 \\
5 \\
5\end{array}$ & 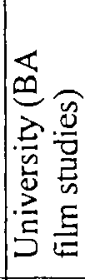 & 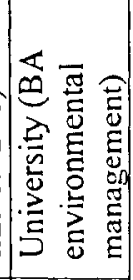 \\
\hline 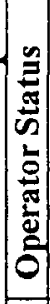 & 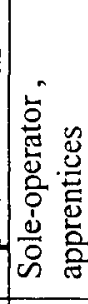 & 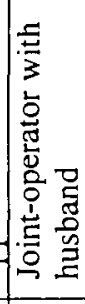 & 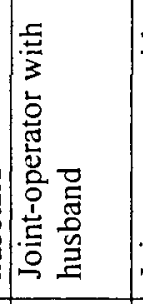 & 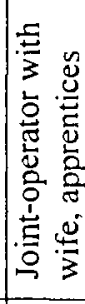 & 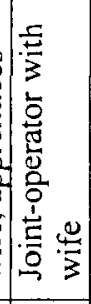 & 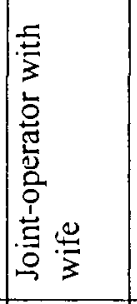 & 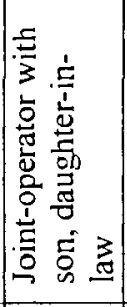 & 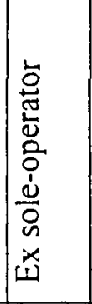 & 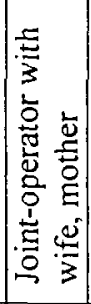 & 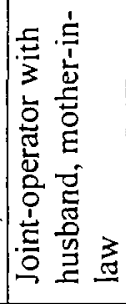 & 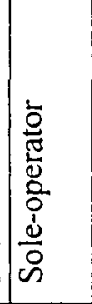 & 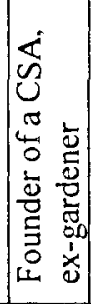 & 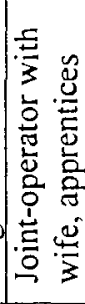 & 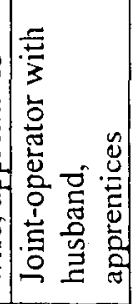 \\
\hline 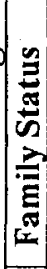 & 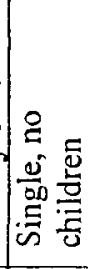 & 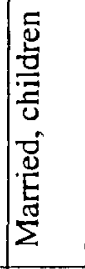 & 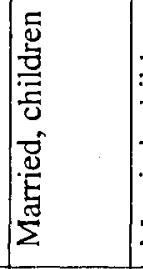 & 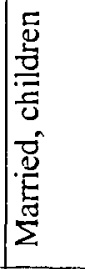 & 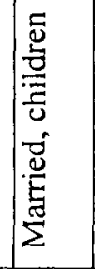 & 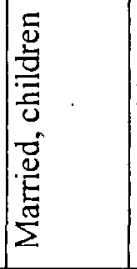 & 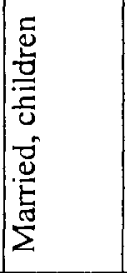 & 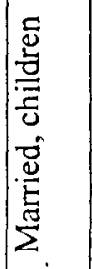 & 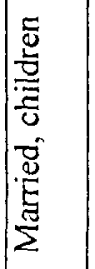 & 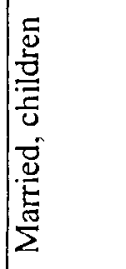 & 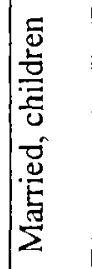 & 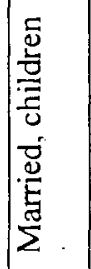 & 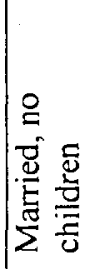 & 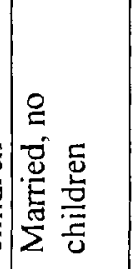 \\
\hline 8 & 售 & 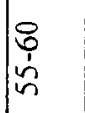 & $\hat{n}$ & 令 & $\begin{array}{l}80 \\
\vdots \\
\text { in } \\
\text { n. }\end{array}$ & 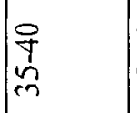 & $\begin{array}{l}\stackrel{5}{5} \\
\stackrel{2}{+}\end{array}$ & 䓟 & $\begin{array}{l}\stackrel{\Upsilon}{7} \\
\grave{n} \\
\end{array}$ & ڤิ & 吕 & 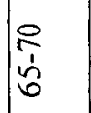 & $\hat{\tilde{s}}$ & 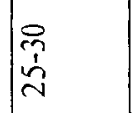 \\
\hline \% & 步 & 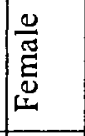 & 岂 & $\frac{2}{\pi}$ & $\sum^{\frac{0}{\pi}}$ & $\frac{0}{\pi}$ & 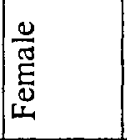 & $\frac{\mathscr{U}}{\tilde{\widetilde{E}}}$ & $\sum^{\frac{\omega}{2}}$ & $\frac{\omega}{\frac{\omega}{\tilde{N}}}$ & 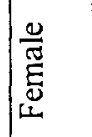 & 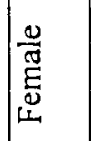 & $\frac{\pi}{\Sigma}$ & 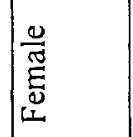 \\
\hline & 1 & $\mathrm{IN}$ & $\ln$ & $\nabla$ & in & 0 & r & $\infty$ & a & $=$ & 三 & 1 & 12 & \pm \\
\hline
\end{tabular}




\section{Appendix 2: Map of the Ottawa Area}

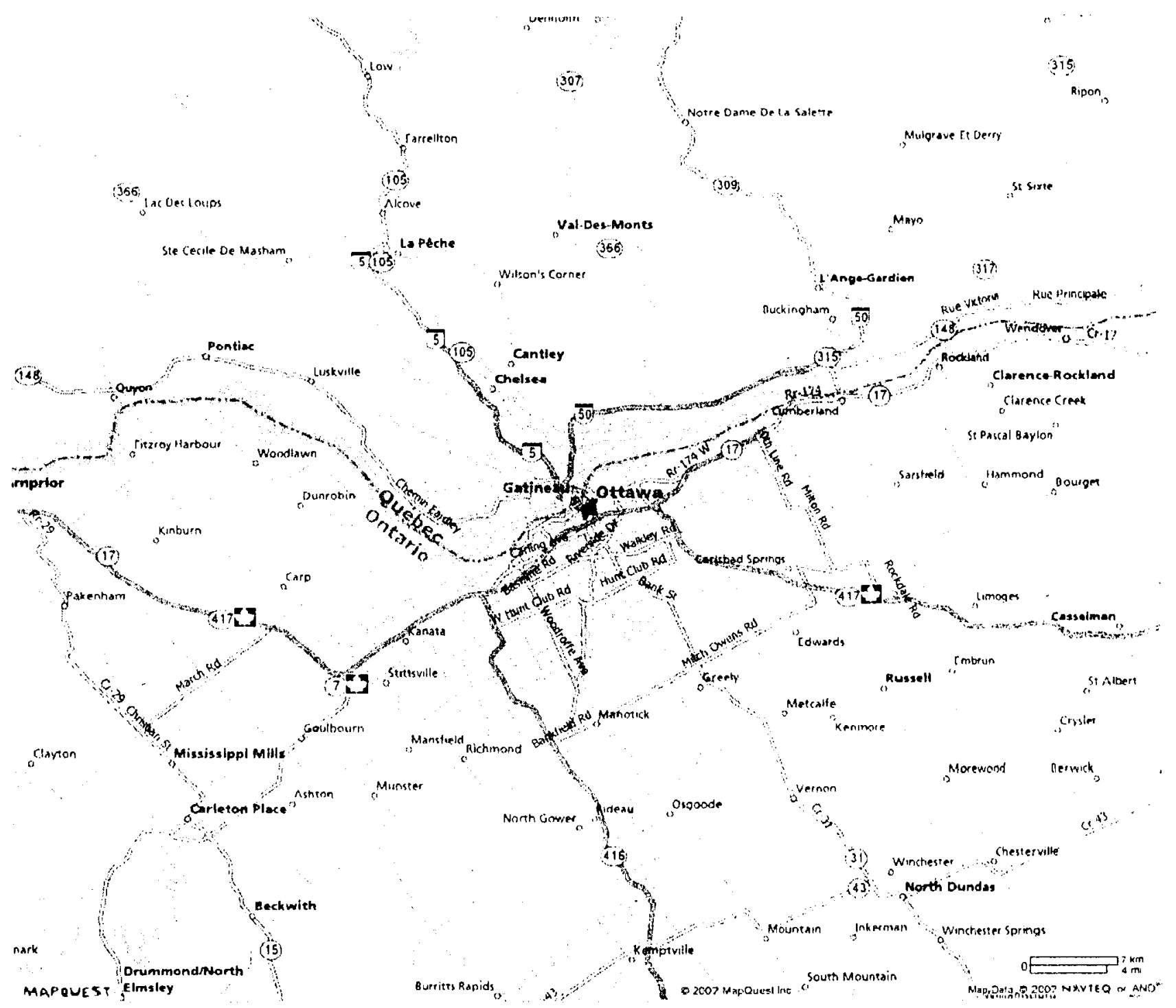

